Supporting Information

\title{
Development of Scalable Routes to 1-Bicyclo[1.1.1]pentylpyrazoles
}

Cayetana Zarate, ${ }^{\star \ddagger \dagger}$ Michael Ardolino, ${ }^{\ddagger \dagger}$ Gregori J. Morriello, ${ }^{\S}$ Kaitlyn M. Logan, ' William P. Kaplan,' Luis Torres, ${ }^{\S}$ Derun Li,' Meng Chen, ${ }^{\perp}$ Hongming Li, ${ }^{\dagger}$ Jing Su, ${ }^{\S}$ Peter Fuller,' Matthew L.

Maddess, ${ }^{\dagger}$ Zhiguo Jake Song"

Affiliations:

tDepartment of Process Research and Development, Merck \& Co., Inc., Boston, Massachusetts 02115, United States

§Department of Discovery Chemistry, Merck \& Co., Inc., Kenilworth, NJ 07033, United States

'Department of Discovery Chemistry, Merck \& Co., Inc., Boston, Massachusetts 02115, United States

$\llcorner$ WuXi AppTec (Tianjin), Chemistry Service Unit, Tianjin 300457, China

"Department of Process Research and Development, Merck \& Co., Inc., Rahway, NJ 07065, United States

\section{cayetana.zarate.saez@merck.com}

\section{Table of Contents}

I. General Considerations S3

I.A. Materials $\quad$ S3

I.B. Methods $\quad$ S3

I.C. Instrumentation and Software $\quad$ S4

II. Preparation of C3-methyl ester BCPP

II.A. Synthesis via decarboxylative $\mathrm{C} 1-\mathrm{N}$ coupling $\quad$ S5

II.B. Synthesis of $\mathbf{3}$ via Chan-Lam C1-N coupling S6

$\begin{array}{ll}\text { III. } & \text { Preparation of } 4 \\ \end{array}$

$\begin{array}{ll}\text { IV. Preparation of } 6 & \text { S12 }\end{array}$

V. Preparation of $\mathbf{1 1} \quad \mathrm{S16}$

$\begin{array}{ll}\text { V.A. Decarboxylative hydrazination } & \text { S16 }\end{array}$

$\begin{array}{lr}\text { V.B. N-amination of BCP amine } & \text { S17 }\end{array}$ 
$\begin{array}{ll}\text { VI. Preparation of } \mathbf{1 4} & \text { S22 }\end{array}$

VII. Preparation of $16 \quad$ S24

VII.A. Preparation of 16 from $15 \quad$ S24

$\begin{array}{lr}\text { VII.B. Preparation of } 16 \text { from [1.1.1]propellane } & \text { S27 }\end{array}$

VIII. Unsuccessful synthetic approaches $\quad$ S28

VIII.A. Decarboxylative C1-N coupling attempts $\quad$ S28

VIII.B. Chan-Lam C1-N coupling attempts $\quad$ S30

VIII.C. C3-Functionalization attempts $\quad$ S31

VIII.D. Attempted synthesis of BCP pyrazole intermediates S36

IX. NMR Spectra $\quad$ S39

X. References $\quad$ S62 


\section{General Considerations}

\section{I.A. Materials}

$\mathbf{1}^{1}$ and $\mathbf{9}^{2}$ were prepared according to literature procedures. Anhydrous solvents were purchased from Sigma-Aldrich in Sure-Seal ${ }^{\mathrm{TM}}$ bottles and used as received. Deuterated solvents were purchased from Cambridge Isotope Laboratories, Inc. and used as received. All other substrates were purchased from commercial sources and used as received.

\section{I.B. Methods}

Reactions were performed in round-bottomed flasks or scintillation vials with Teflon septa. Reactions were monitored by liquid chromatography/mass spectrometry (LC/MS), ${ }^{1} \mathrm{H}$ NMR or gas chromatography/mass spectrometry (GC/MS) analysis. Thin-layer chromatography (TLC) was carried out on silica gel60 F254 plates (EMD) and visualized with UV light $(254 \mathrm{~nm})$ and/or a ninhydrin in EtOH stain solution. Air- and moisture-sensitive manipulations were carried out using a high vacuum Schlenk line. Flash column chromatographic purification was performed using prepacked RediSep gold Rf silica gel columns on a Teledyne Isco CombiFlash Rf automated chromatography system. Volatiles were concentrated under reduced pressure on a Buchi rotary evaporator.

HTE Experiments (Scheme 4) were conducted in an MBraun glove-box (oxygen typically <5 ppm), and the reactions carried out in microvials in a 96-well plate aluminum reactor block. Liquid chemicals were dosed using an Eppendorf pipetter. The stirring was accomplished with parylene stir bars and a tumble stirring mechanism with a heating block to insure uniform stirring throughout the 96 -well plate. The bases $(30 \mu \mathrm{mol})$ were dosed into the $1 \mathrm{~mL}$ shell vials as slurry, and the solvent removed by evacuation on a Genovac. The reactions were sealed in the 96-well plate during reaction. Below each reactor vial in the aluminum 96-well plate was a $0.062 \mathrm{~mm}$ thick 
silicon-rubber gasket. Directly above the glass vial reactor tops was a $(0.002 \mathrm{~mm})$ Teflon PFA (perfluoroalkoxy copolymer resin) sealing gasket and above that, two more $0.062 \mathrm{~mm}$ thick silicon-rubber gaskets. The entire assembly was compressed between an aluminum top and the reactor base with 9 evenly-placed screws.

\section{I.C. Instrumentation and Software}

${ }^{1} \mathrm{H}$, proton-decoupled ${ }^{13} \mathrm{C}\left\{{ }^{1} \mathrm{H}\right\}$ and ${ }^{19} \mathrm{~F}$ NMR spectra were recorded at $23^{\circ} \mathrm{C}$ on 400 or $600 \mathrm{MHz}$ NMR spectrometers. All ${ }^{1} \mathrm{H}$ and ${ }^{13} \mathrm{C}$ NMR chemical shifts $(\delta)$ are reported in part per million (ppm) using the ${ }^{1} \mathrm{H}\left(\mathrm{CDCl}_{3}: 7.26 \mathrm{ppm}\right.$; dimethyl sulfoxide- $\left.d_{6}: 2.50 \mathrm{ppm}\right)$ and ${ }^{13} \mathrm{C}\left\{{ }^{1} \mathrm{H}\right\}\left(\mathrm{CDCl}_{3}: 77.16 \mathrm{ppm}\right.$; dimethyl sulfoxide- $d_{6}: 39.51 \mathrm{ppm}$ ) chemical shifts of the solvent as a standard. NMR data is reported as follows: chemical shift (multiplicity, coupling constants $\mathrm{J}$ in $\mathrm{Hz}$, integration) where $\mathrm{s}=$ singlet, $d=$ doublet, $t=$ triplet, $q=$ quartet, $p=$ pentet, and $m=$ multiplet). NMR spectra were processed using the MestReNova software suite. ${ }^{3}$

Reaction monitoring was carried out by: (a) LC/MS analysis using an Agilent 1100 or 1200 instrument with an Inductively Coupled Plasma (IPC), (b) GC/MS analysis using a GCMS-004 GCMS-005 (Shimadzu GC2030) instrument with an AB-5 (30 m-0.32 mm-0.25 $\mu \mathrm{m}$ ) or HP-5MS column and an FID detector, or (c) Agilent 1290 UPLC instrument. High-resolution mass spectrometry (HRMS) data was recorded on a Waters Acquity UPLC with Synapt G1 Q-ToF MS instrument in ESI+ (electrospray) ionization mode with an Acquity UPLC BEH C18 $1.7 \mu \mathrm{m}$ column.

$\mathrm{J}-\mathrm{Kem}{ }^{\circledR}$ temperature controller was employed to monitor the temperature during selected reactions.

Photochemical transformations were carried out in an integrated Merck photoreactor. ${ }^{4}$ 


\section{Preparation of C3-methyl ester BCPP}

\section{II.A. Synthesis via decarboxylative $\mathbf{C} 1-\mathrm{N}$ coupling ${ }^{5}$}
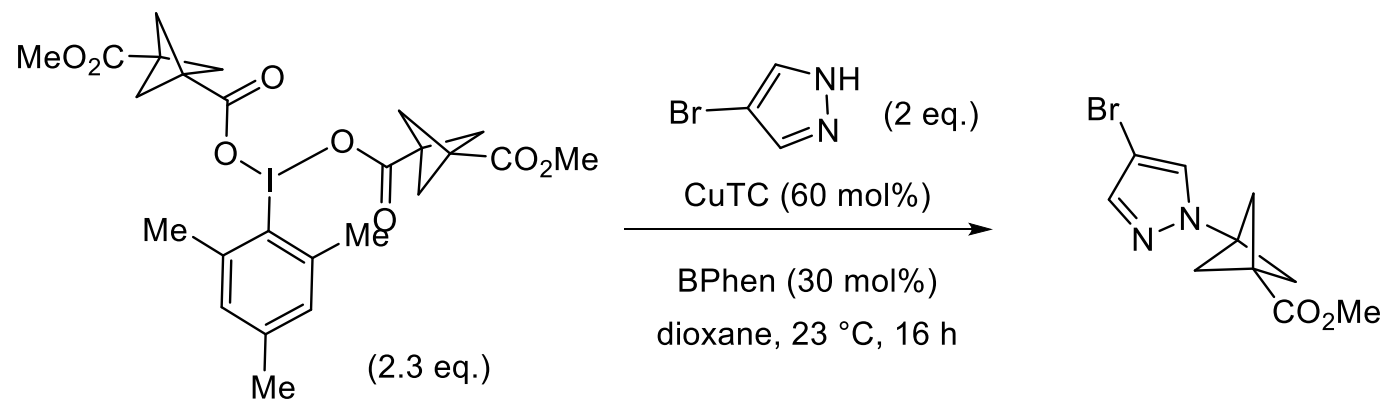

A flask was charged with 4-bromo-1H-pyrazole (72.4 g, 493 mmol, 2.0 eq.), O'1,O1-(mesityl-I3iodanediyl) 3,3'-dimethyl bis(bicyclo[1.1.1]pentane-1,3-dicarboxylate) ${ }^{5}$ (331 g, 567 mmol, 2.3 eq.), bathophenanthroline (BPhen, $24.6 \mathrm{~g}, 73.9 \mathrm{mmol}, 30 \mathrm{~mol} \%$ ), thiophene-2-carbonyloxycopper (CuTc, $28.2 \mathrm{~g}, 148 \mathrm{mmol}, 60 \mathrm{~mol} \%$ ) and dioxane (2.0 L). The solution was degassed by sparging with $\mathrm{N}_{2}$ for $5 \mathrm{~min}$ and then sonicated for $1 \mathrm{~min}$. The resulting reaction mixture was stirred at $25^{\circ} \mathrm{C}$ for $16 \mathrm{~h}$. TLC analysis showed that starting material was consumed. The reaction was then filtered and concentrated under vacuum to give the crude product. Purification of the crude reaction mixture by silica gel chromatography with $0-50 \%$ EtOAc in petroleum ether as eluent afforded methyl 3-(4-bromo-1H-pyrazol-1-yl)bicyclo[1.1.1]pentane-1-carboxylate (25.6 g, $93.7 \mathrm{mmol}, 38 \%$

yield) as a white solid. ${ }^{1} \mathrm{H}$ NMR (600 MHz, $\left.\mathbf{C D C l}_{3}\right)$ : $\delta 7.49(\mathrm{~s}, 1 \mathrm{H}), 7.45(\mathrm{~s}, 1 \mathrm{H}), 3.74(\mathrm{~s}, 3 \mathrm{H}), 2.55$ (s, 6H). ${ }^{13} \mathrm{C}\left\{{ }^{1} \mathrm{H}\right\}$ NMR (151 MHz, $\left.\mathrm{CDCl}_{3}\right):$ 169.4, 141.0, 127.9, 93.9, 54.5, 52.3, 51.2, 34.0. HRMS $[\mathrm{M}+\mathrm{H}]^{+}$: calculated 271.0082, found 271.0085 . 


\section{II.B. Synthesis of 3 via Chan-Lam C1-N coupling}

\section{Ligand screening for Chan-Lam C1-N coupling}

Table S1. Ligand screening for Chan-Lam $\mathrm{C} 1-\mathrm{N}_{\text {pyrazole }}$ bond coupling.
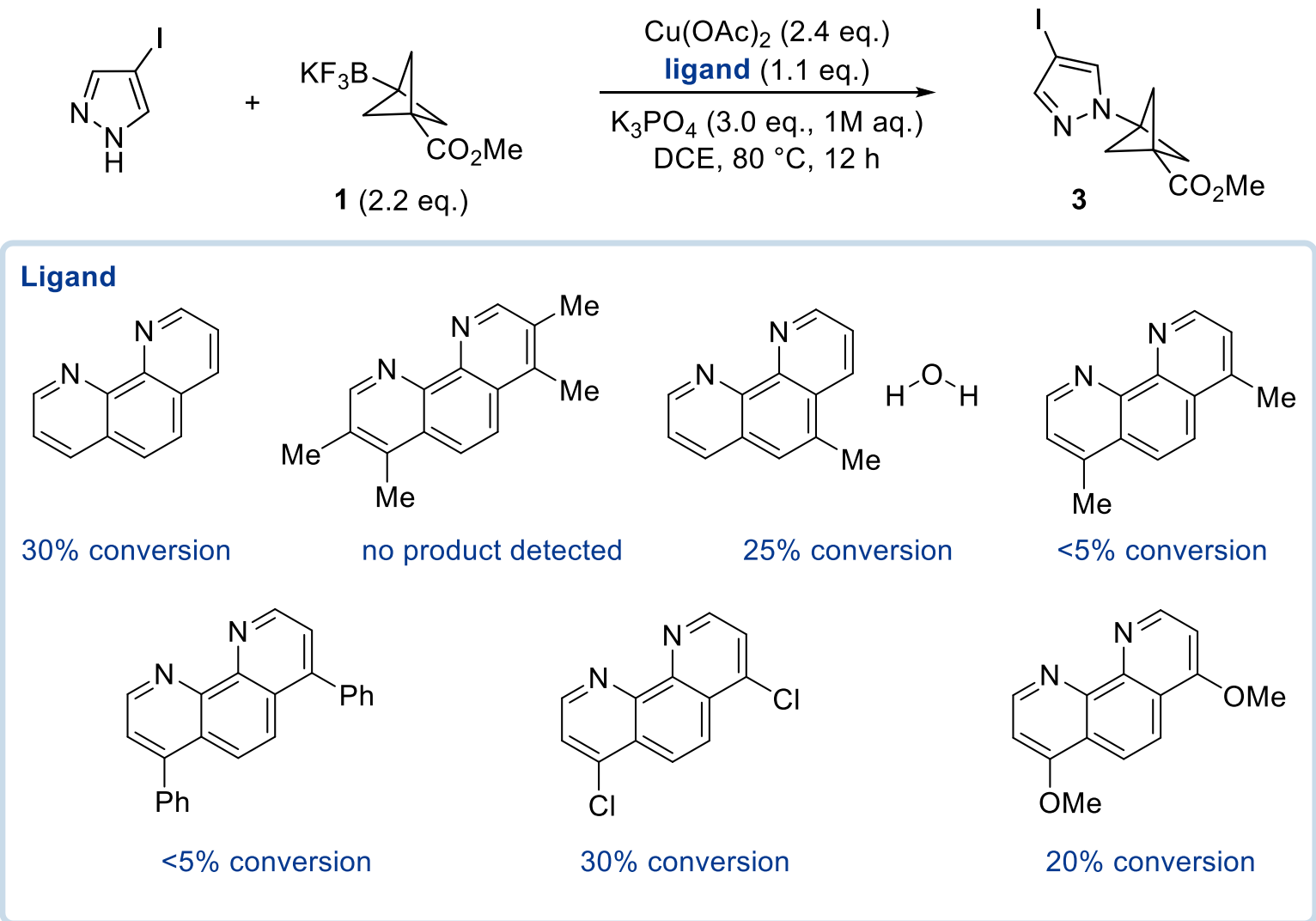

General procedure. To a scintillation vial with a stir bar was added 4-iodo-1H-pyrazole $(5 \mathrm{mg}$, $0.03 \mathrm{mmol}, 1.0$ eq.), 1 (16 mg, $0.07 \mathrm{mmol}, 2.2$ eq.), ${ }^{1} \mathrm{Cu}(\mathrm{OAc})_{2}(13 \mathrm{mg}, 0.07 \mathrm{mmol}, 2.4$ eq.) and ligand $(0.03 \mathrm{mmol}, 1.1$ eq.). The vial was capped with a Teflon septum and submitted to three vacuum $/ \mathrm{N}_{2}$ refill cycles. DCE $(25 \mathrm{~V})$ and $\mathrm{K}_{3} \mathrm{PO}_{4}(1 \mathrm{M}$ aq., $90 \mu \mathrm{L}, 0.09 \mathrm{mmol}, 3.0$ eq.) were then added under a positive pressure of $\mathrm{N}_{2}$. The resulting suspension was stirred at $80^{\circ} \mathrm{C}$ for $12 \mathrm{~h}$ and the mixture was then analyzed by LC/MS. Tabulated LC/MS conversions (uncorrected) correspond to the ratio of absorbances of $\mathbf{3} /$ biphenyl (IS). 


\section{Synthesis of 2}

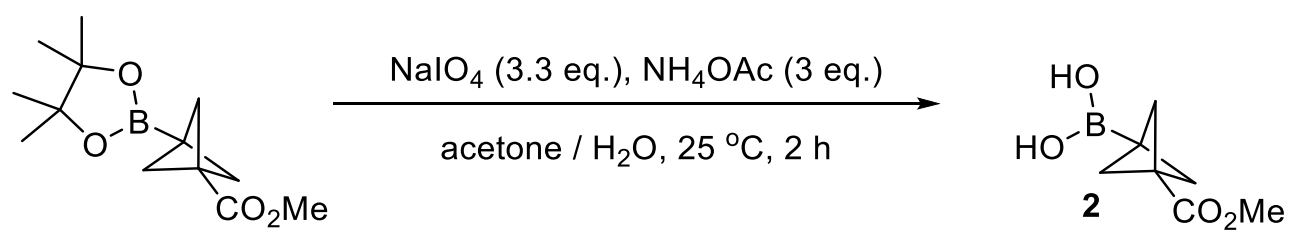

Three reactions were carried out in parallel. To a suspension of methyl 3-(4,4,5,5-tetramethyl1,3,2-dioxaborolan-2-yl)bicyclo[1.1.1]pentane-1-carboxylate $(50.0 \mathrm{~g}, 198 \mathrm{mmol}, 1.0 \mathrm{eq} .)^{1}$ in acetone $(500 \mathrm{~mL})$ and $\mathrm{H}_{2} \mathrm{O}(250 \mathrm{~mL})$ was added $\mathrm{NH}_{4} \mathrm{OAc}\left(45.9 \mathrm{~g}, 595 \mathrm{mmol}, 3.0\right.$ eq.) and $\mathrm{NalO}_{4}$ (140 g, $654 \mathrm{mmol}, 36.3 \mathrm{~mL}, 3.3 \mathrm{eq}$ ) ) in one portion. The resulting mixture was stirred at $25^{\circ} \mathrm{C}$ and after $1 \mathrm{~h}$, TLC analysis showed that starting material was consumed. The three reaction mixtures were combined and the resulting suspension was filtered through a fritted glass. The filter cake was washed with acetone $(200 \mathrm{~mL} \times 4)$ and the filtrate was concentrated under vacuum. The resulting residue was extracted with EtOAc $(300 \mathrm{~mL} \times 3)$ and the combined organic phases were concentrated under vacuum to give the crude product as a brown solid. The crude product was triturated with petroleum ether $(500 \mathrm{~mL})$ for $10 \mathrm{~min}$ and the resulting suspension was filtered. The filter cake was collected and dried under vacuum to give (3(methoxycarbonyl)bicyclo[1.1.1]pentan-1-yl)boronic acid (2, $85.0 \mathrm{~g}, 500 \mathrm{mmol}, 84 \%$ yield) as a white solid. ${ }^{1} \mathrm{H}$ NMR (600 MHz, DMSO- $\left.d_{6}\right): \delta 7.66(\mathrm{~s}, 2 \mathrm{H}), 3.55(\mathrm{~s}, 3 \mathrm{H}), 1.95(\mathrm{~s}, 6 \mathrm{H}) .{ }^{13} \mathrm{C}\left\{{ }^{1} \mathrm{H}\right\} \mathrm{NMR}$ (151 MHz, DMSO- $\left.\boldsymbol{d}_{6}\right)$ : 169.5, 51.6, 51.1, 41.5. HRMS [M+H]+: not found, poor/weak ionization. 


\section{Chan-Lam C1-N coupling with BCP trifluoroborate salt 1}
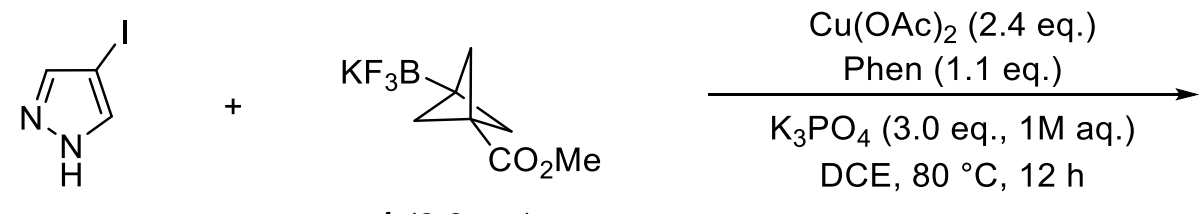

1 (2.2 eq.)

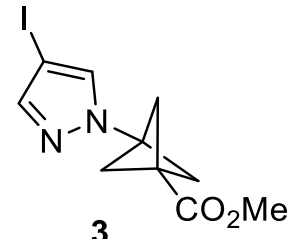

To a $25 \mathrm{~mL}$ round-bottomed flask with a stir bar was added 4-iodo-1H-pyrazole (200 mg, 1.03 mmol, 1.0 eq.), 1 (526 mg, 2.27 mmol, 2.2 eq.), $\mathrm{Cu}(\mathrm{OAc})_{2}$ (449 mg, $2.47 \mathrm{mmol}, 2.4$ eq.) and 1,10phenanthroline (204 mg, $1.13 \mathrm{mmol}, 1.1$ eq.). The vial was capped with a Teflon septum and submitted to three vacuum $/ \mathrm{N}_{2}$ refill cycles. DCE (25 V) and $\mathrm{K}_{3} \mathrm{PO}_{4}(1 \mathrm{M}$ aq., $3.1 \mathrm{~mL}, 3.09 \mathrm{mmol}$, 3.0 eq.) were then added under a positive pressure of $\mathrm{N}_{2}$. The resulting suspension was stirred at $80{ }^{\circ} \mathrm{C}$ for $12 \mathrm{~h}$. The reaction mixture was then diluted with $\mathrm{H}_{2} \mathrm{O}(10 \mathrm{~mL})$ and the organic phase was extracted with EtOAc $(20 \mathrm{~mL} \times 3)$, washed with brine $(20 \mathrm{~mL})$, dried over $\mathrm{Na}_{2} \mathrm{SO}_{4}$, filtered and concentrated under vacuum. Purification of the resulting crude by silica gel chromatography with $0-45 \%$ EtOAc in hexanes as eluent afforded methyl 3-(4-iodo-1H-pyrazol-1yl)bicyclo[1.1.1]pentane-1-carboxylate $\left(3,105 \mathrm{mg}, 0.330 \mathrm{mmol}, 32 \%\right.$ yield) as a white solid. ${ }^{1} \mathbf{H}$ NMR (600 MHz, CDCl $): \delta 7.53(\mathrm{~s}, 1 \mathrm{H}), 7.47(\mathrm{~s}, 1 \mathrm{H}), 3.73(\mathrm{~s}, 3 \mathrm{H}), 2.55(\mathrm{~s}, 6 \mathrm{H}) .{ }^{13} \mathrm{C}\left\{{ }^{1} \mathrm{H}\right\}$ NMR (151 MHz, $\mathbf{C D C l}_{3}$ ): 169.3, 145.4, 132.2, 56.8, 54.6, 52.2, 51.0, 34.0. HRMS [M+H]+: calculated 318.9943, found 318.9951. Note: low conversion ( $5 \%)$ was obtained during the scale-up reaction (119 mmol 4-iodopyrazole) with 1 under the same reaction conditions. Scale-up was successful with boronic acid 2 (vide infra). 


\section{Chan-Lam C1-N coupling with BCP boronic acid 2}

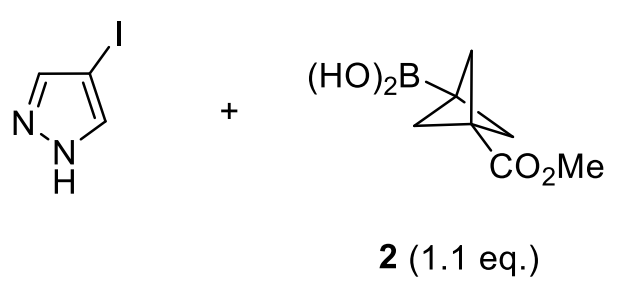

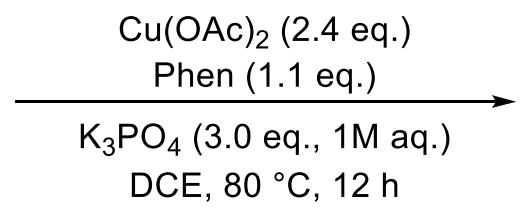

DCE, $80^{\circ} \mathrm{C}, 12 \mathrm{~h}$

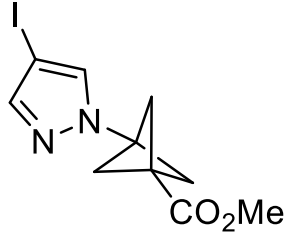

3

To a $500 \mathrm{~mL}$ two-necked round-bottomed flask with a stir bar was added 4-iodo-1H-pyrazole (3.0 g, 15.5 mmol, 1.0 eq.), 2 (2.9 g, 17.1 mmol, 1.1 eq.), $\mathrm{Cu}(\mathrm{OAc})_{2}(6.8 \mathrm{~g}, 37.2 \mathrm{mmol}, 2.4$ eq.) and 1,10- phenanthroline $(3.1 \mathrm{~g}, 17.1 \mathrm{mmol}, 1.1 \mathrm{eq}$.$) . A reflux condenser was attached to one of the$ necks of the flask and the other neck was capped with a Teflon septum. The flask was submitted to three vacuum $/ \mathrm{N}_{2}$ refill cycles. $\mathrm{DCE}(30 \mathrm{~V})$ and $\mathrm{K}_{3} \mathrm{PO}_{4}(1 \mathrm{M}$ aq., $46.5 \mathrm{~mL}, 46.5 \mathrm{mmol}, 3.0$ eq.) were then added via syringe under a positive pressure of $\mathrm{N}_{2}$. The resulting suspension was stirred at $80^{\circ} \mathrm{C}$ for $12 \mathrm{~h}$. The reaction mixture was then diluted with $\mathrm{H}_{2} \mathrm{O}(100 \mathrm{~mL})$ and the organic phase was extracted with EtOAc (100 mL x 3), washed with brine $(100 \mathrm{~mL})$, dried over $\mathrm{Na}_{2} \mathrm{SO}_{4}$, filtered and concentrated under vacuum. Purification of the resulting crude by silica gel chromatography with $0-45 \%$ EtOAc in hexanes as eluent afforded $3(2.1 \mathrm{~g}, 6.7 \mathrm{mmol}, 43 \%$ yield $)$ as a white solid. Spectroscopic data match those reported above.

\section{Scale-up synthesis of 3}
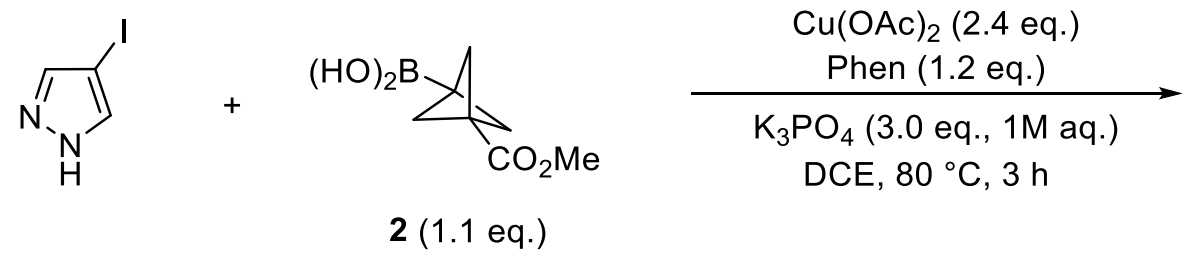

2 (1.1 eq.)

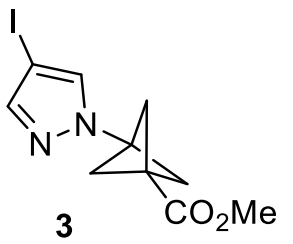

Three reactions were carried out in parallel. 4-lodopyrazole (20.8 g, 107 mmol, 1.0 eq.), 2 (20 g, $118 \mathrm{mmol}, 1.1$ eq.), $\mathrm{Cu}(\mathrm{OAc})_{2}(23.3 \mathrm{~g}, 128 \mathrm{mmol}, 1.2$ eq.) and 1,10- phenanthroline (21.2 g, 118 mmol, 1.1 eq.) were added to a $2 \mathrm{~L}$ two-necked round-bottomed flask containing a stir bar. A reflux condenser was attached to one of the necks of the flask and the other neck was capped 
with a Teflon septum. DCE (600 mL) and $\mathrm{K}_{3} \mathrm{PO}_{4}(1 \mathrm{M}$ aq., $321 \mathrm{~mL}, 321 \mathrm{mmol}, 3$ eq.) were then added via syringe under a positive pressure of $\mathrm{N}_{2}$. The resulting suspension was stirred at $80^{\circ} \mathrm{C}$ for $3 \mathrm{~h}$. After this time, TLC analysis showed full consumption of 4-iodopyrazole. The three reaction mixtures were combined and the resulting suspension was filtered through a plug of Celite. The filter cake was washed with DCM $(500 \mathrm{~mL} \times 3)$ and the organic phase of the filtrate was extracted. The aqueous phase was washed with $\mathrm{DCM}(300 \mathrm{~mL} \times 2)$ and the combined organic phases were concentrated under vacuum. The resulting residue was extracted with EtOAc (300 $\mathrm{mL} \times 3$ ) and the combined organic phases were concentrated under vacuum to give a black oil residue. The residue was dissolved with $\mathrm{DCM} /$ petroleum ether $(2: 1,600 \mathrm{~mL})$ and the resulting solution was passed through a pad of silica gel, washing the pad with additional DCM/petroleum ether $(2: 1,200 \mathrm{~mL})$. The solution was concentrated under vacuum to give the crude product as an off-white solid, which was triturated with petroleum ether $(300 \mathrm{~mL})$ for $30 \mathrm{~min}$. The resulting suspension was filtered through a fritted glass filter and the filter cake was dried under vacuum providing 3 (46 g, $145 \mathrm{mmol}, 45 \%$ yield) as a white solid. Note: isolated yield was calculated as the media of the three reactions run in parallel. Spectroscopic data match those reported above. 


\section{Preparation of 4}

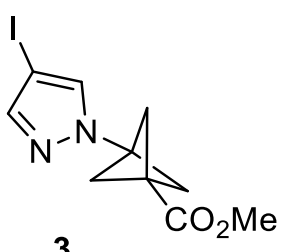

3
1. $\mathrm{LiBH}_{4}$ (1.5 eq.)

$\underset{\mathrm{THF}, 0 \rightarrow 23^{\circ} \mathrm{C}, 18 \mathrm{~h}}{\longrightarrow}$

2. $\mathrm{NaH}$ (1.6 eq.), Mel (2.3 eq.)

THF, $0 \rightarrow 23^{\circ} \mathrm{C}, 18 \mathrm{~h}$

A $1 \mathrm{~L}$ round-bottomed flask with a stir bar was charged with 3 (15.0 g, $47.2 \mathrm{mmol}, 1.0 \mathrm{eq}$.) and the flask was submitted to three vacuum $/ \mathrm{N}_{2}$ refill cycles. Then, anhydrous THF (240 ml) was added under a positive pressure of $\mathrm{N}_{2}$ and the mixture was cooled to $0{ }^{\circ} \mathrm{C}$ in an ice/water bath. Lithium tetrahydroborate (2 M in THF, $35 \mathrm{~mL}, 70.8 \mathrm{mmol}, 1.5$ eq.) was added dropwise under a $\mathrm{N}_{2}$ atmosphere and the reaction was stirred at $23^{\circ} \mathrm{C}$ for $24 \mathrm{~h}$ (reaction temperature monitored with J-Kem® temperature controller, no significant exothermicity observed). The reaction mixture was quenched with $\mathrm{MeOH}(130 \mathrm{~mL})$ at $0{ }^{\circ} \mathrm{C}$, warmed to $23^{\circ} \mathrm{C}$ and stirred at this temperature for 90 min. The resulting solution was concentrated under vacuum to give a sticky white foam. Upon addition of EtOAc $(130 \mathrm{~mL})$ a white precipitate was formed. The suspension was filtered through a fritted glass filter washing with EtOAc $(100 \mathrm{~mL} \times 2)$. The resulting clear filtrate was dried under vacuum and the crude product was transferred to a $500 \mathrm{~mL}$ round-bottomed flask with a stir bar. The flask was evacuated and refilled with $\mathrm{N}_{2}(\times 3)$. Then, anhydrous THF (100 mL) was added and the resulting solutions was stirred at $23^{\circ} \mathrm{C}$ for $15 \mathrm{~min}$. A $1 \mathrm{~L}$ three-necked round-bottomed flask with a stir bar was charged with $\mathrm{NaH}$ (60\% dispersion in mineral oil, $3.00 \mathrm{~g}, 75 \mathrm{mmol}, 1.6 \mathrm{eq}$ ). A $\mathrm{J}-\mathrm{Kem}{ }^{\circledR}$ temperature controller was connected to one of the flask necks. The second neck was connected to the $\mathrm{N}_{2}$ Schlenk line and the third neck was sealed with a Teflon septum. The flask was submitted to three vacuum/ $\mathrm{N}_{2}$ refill cycles and anhydrous THF (100 mL) was then added under a positive pressure of $\mathrm{N}_{2}$. The resulting suspension was cooled to $0{ }^{\circ} \mathrm{C}$ using an ice/water bath. To the cooled suspension was added dropwise the previously prepared reaction crude solution. The solid residue that remained in the flask was transferred with additional anhydrous 
THF (40 mL). The resulting mixture was stirred at $0{ }^{\circ} \mathrm{C}$ for $45 \mathrm{~min}$ under a positive pressure of $\mathrm{N}_{2}$. Then, methyl iodide $\left(6.74 \mathrm{ml}, 108 \mathrm{mmol}, 2.3\right.$ eq.) was added dropwise at $0^{\circ} \mathrm{C}$ and the resulting reaction mixture was stirred for $18 \mathrm{~h}$ at $23^{\circ} \mathrm{C}$. The reaction mixture was then cooled to $0{ }^{\circ} \mathrm{C}$ and quenched by slow addition of a saturated, aqueous solution of $\mathrm{NH}_{4} \mathrm{Cl}(150 \mathrm{~mL})$. The organic phase was extracted with EtOAc $(150 \mathrm{~mL} \times 3)$ and the organic layers were combined, washed with brine, dried over $\mathrm{Na}_{2} \mathrm{SO}_{4}$, filtered and concentrated under vacuum to give a yellow oil. Purification of the crude oil by silica gel chromatography with 0-70\% EtOAc in hexanes as eluent afforded 4-iodo-1(3-(methoxymethyl)bicyclo[1.1.1]pentan-1-yl)-1H-pyrazole (4, 8.2 g, $27.1 \mathrm{mmol}, 59 \%$ yield over two steps) as a white solid. ${ }^{1} \mathrm{H}$ NMR $\left(600 \mathbf{~ M H z}, \mathbf{C D C l}_{3}\right)$ : $\delta 7.49(\mathrm{~s}, 1 \mathrm{H}), 7.44(\mathrm{~s}, 1 \mathrm{H}), 3.54(\mathrm{~s}, 2 \mathrm{H})$, 3.35 (s, 3H), $2.19(\mathrm{~s}, 6 \mathrm{H}) .{ }^{13} \mathrm{C}\left\{{ }^{1} \mathrm{H}\right\}$ NMR (151 MHz, $\left.\mathbf{C D C l}_{3}\right):$ 144.9, 132.0, 71.1, 59.2, 56.3, 52.4, 51.6, 34.4. HRMS [M+H] ${ }^{+}$: calculated 305.0151, found 305.0162.

\section{Preparation of 6}

BCP Hydrazine 5 is commercially available in bulk quantities and can be synthesized through in situ generation of [1.1.1.]propellane, followed by Bunker hydrohydrazination ${ }^{6}$ as follows.

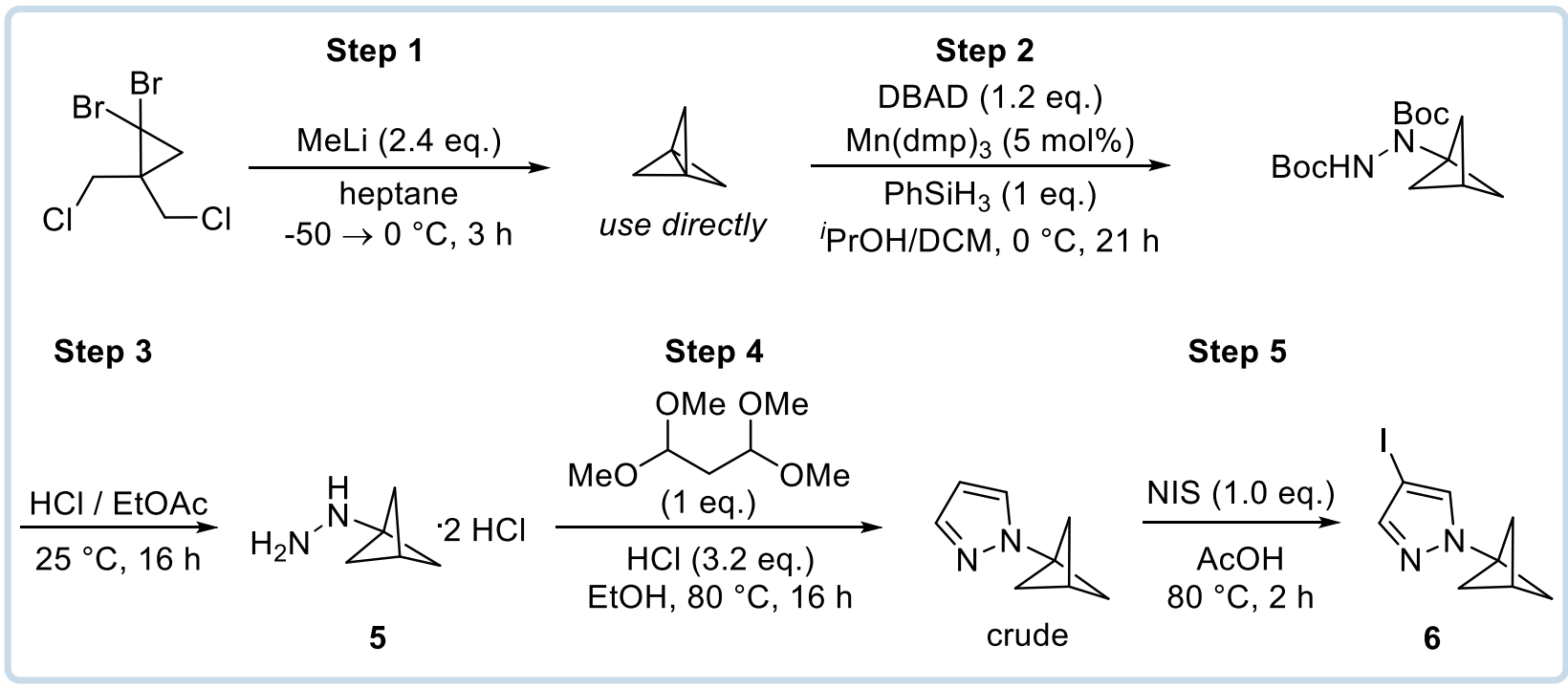

Step 1: [1.1.1]propellane. ${ }^{7}$ To a $5 \mathrm{~L}$ round-bottomed flask with a stir bar was added 1,1-dibromo2,2-bis(chloromethyl)cyclopropane (100 g, $337 \mathrm{mmol}, 1.0$ eq.) and pentane (200 mL) under a $\mathrm{N}_{2}$ 
atmosphere. Then, MeLi (1.6 M in Et $\mathrm{t}_{2} \mathrm{O}, 505 \mathrm{~mL}, 809 \mathrm{mmol}, 2.4$ eq.) was added dropwise at -50 ${ }^{\circ} \mathrm{C}$ for $2.5 \mathrm{~h}$. Upon MeLi addition, the resulting mixture was warmed to $0{ }^{\circ} \mathrm{C}$ and stirred at this temperature for $3 \mathrm{~h}$. GC/MS analysis showed full conversion of the starting material. The mixture was warmed to $23^{\circ} \mathrm{C}$ and distilled using a water pump at $23^{\circ} \mathrm{C}$ followed by distillation with an oil pump at $60^{\circ} \mathrm{C}$. The title compound $(22 \mathrm{~g}, 333 \mathrm{mmol})$ was obtained as solution in $\mathrm{Et}_{2} \mathrm{O} /$ pentane. The solution was used directly in the following step. Note: [1.1.1]propellane is highly volatile and the yield is lower and less reproducible at smaller reaction scales (i.e.10 g).

Step 2: di-tert-butyl 1-(bicyclo[1.1.1]pentan-1-yl)hydrazine-1,2-dicarboxylate. ${ }^{6}$ To a 5 L three-necked round-bottomed flask was added $\mathrm{Mn}(\mathrm{dpm})_{3}(10.1 \mathrm{~g}, 16.6 \mathrm{mmol}, 5 \mathrm{~mol} \%)$ and ${ }^{\mathrm{i}} \mathrm{PrOH}$ $(1650 \mathrm{~mL})$ at $23^{\circ} \mathrm{C}$ and the resulting mixture was cooled to $0^{\circ} \mathrm{C}$. Then, $\mathrm{PhSiH}_{3}(41 \mathrm{~mL}, 333 \mathrm{mmol}$, 1.0 eq.) and di-tert-butyl azodicarboxylate (DBAD, $115 \mathrm{~g}, 499 \mathrm{mmol})$ in anhydrous DCM (1650 $\mathrm{mL})$ were added at $0{ }^{\circ} \mathrm{C}$ during $15 \mathrm{~min}$. Next, the [1.1.1]propellane $(22 \mathrm{~g}, 333 \mathrm{mmol})$ solution in $\mathrm{Et}_{2} \mathrm{O} /$ pentane prepared in step 1 was added at $0{ }^{\circ} \mathrm{C}$. The mixture was stirred at $0{ }^{\circ} \mathrm{C}$ for $21 \mathrm{~h}$. GC/MS analysis showed full conversion of the starting material and formation of the desired product. The reaction mixture was quenched by adding a saturated, aqueous solution of brine $(500 \mathrm{~mL})$ and the organic layer was extracted with EtOAc $(500 \mathrm{~mL} \times 3)$. The organic layers were combined and concentrated under reduced pressure to give the crude product, which was purified by column chromatography on silica gel with $0-5 \%$ EtOAc in petroleum ether as eluent to give the title compound ( $35.6 \mathrm{~g}, 0.12 \mathrm{mmol}, 35 \%$ yield over two steps) as a white solid. Signal broadening and additional splitting was observed due to the presence of amide rotamers. ${ }^{1} \mathbf{H} \mathbf{~ N M R}(600 \mathrm{MHz}$, $\left.\mathrm{CDCl}_{3}\right)$ : $\delta: 6.29(\mathrm{~s}, 0.65 \mathrm{H}), 6.02(\mathrm{~s}, 0.35 \mathrm{H}), 2.38(\mathrm{~s}, 1 \mathrm{H}), 2.03(\mathrm{~s}, 6 \mathrm{H}), 1.46(\mathrm{~s}, 18 \mathrm{H}) .{ }^{13} \mathrm{C}\left\{{ }^{1} \mathrm{H}\right\}$ NMR (151 MHz, $\mathrm{CDCl}_{3}$ ): 81.1, 54.6, 52.6, 28.4, 28.3, 23.0 (carbonyl signal not detected). Spectroscopic data match those previously reported in the literature. Error! Bookmark not defined. 
Step 3: bicyclo[1.1.1]pentan-1-ylhydrazine, $\mathrm{HCl}$ salt (5). To a $500 \mathrm{~mL}$ round-bottomed flask with a stir bar was added di-tert-butyl 1-(bicyclo[1.1.1]pentan-1-yl)hydrazine-1,2-dicarboxylate (35.6 g, $119 \mathrm{mmol}, 1.0$ eq.) and the flask was evacuated/refilled with $\mathrm{N}_{2}$. Then, $\mathrm{HCl}$ (4M in EtOAc, $356 \mathrm{~mL}$ ) was added to the mixture at $25^{\circ} \mathrm{C}$ under $\mathrm{N}_{2}$. The resulting mixture was stirred at $25^{\circ} \mathrm{C}$ for $16 \mathrm{~h}$ and during this time a solid precipitate was formed. TLC analysis showed full conversion of the starting material. The suspension was filtered through a fritted glass filter and the filtered solid was washed with EtOAc $(50 \mathrm{~mL} \times 2)$ under $\mathrm{N}_{2}$ protection and dried under high vacuum at 40 ${ }^{\circ} \mathrm{C}$. The title product $\left(14 \mathrm{~g}, 82 \mathrm{mmol}, 69 \%\right.$ yield) was obtained as a white solid. ${ }^{1} \mathbf{H}$ NMR (600 $\mathbf{~ M H z}$, DMSO- $\left.d_{6}\right): \delta 2.44(s, 1 H), 1.82(s, 6 H) .{ }^{13} \mathrm{C}\left\{{ }^{1} \mathrm{H}\right\}$ NMR (101 MHz, DMSO-d $\left.d_{6}\right): 54.8,50.2,22.3$. Spectroscopic data match those previously reported in the literature. Error! Bookmark not defined. Note: filtration was carried out under $\mathrm{N}_{2}$ as the product is hygroscopic.

Step 4: 1-(bicyclo[1.1.1]pentan-1-yl)-1H-pyrazole. Four reactions were carried out in parallel. Bicyclo[1.1.1]pentan-1-ylhydrazine, $\quad \mathrm{HCl}$ salt $\quad(20 \mathrm{~g}, \quad 117 \mathrm{mmol}, 1.0$ eq. $)$, 1,1,3,3tetramethoxypropane (19 mL, $117 \mathrm{mmol}, 1.0$ eq.) and $\mathrm{EtOH}(140 \mathrm{~mL})$ were added to a $250 \mathrm{~mL}$ round-bottomed flask containing a stir bar. Then, concentrated $\mathrm{HCl}(37 \%$ wt., $36.9 \mathrm{~g}, 374 \mathrm{mmol}$, 3.2 eq.) was added to the suspension and a color change from white to yellow was immediately observed. A reflux condenser was attached to the flask and the reaction mixture was stirred at 80 ${ }^{\circ} \mathrm{C}$ for $16 \mathrm{~h}$. During this time the reaction mixture turned brown. GC/MS analysis showed full conversion of the starting material. The four reaction mixtures were combined and $\mathrm{H}_{2} \mathrm{O}(500 \mathrm{~mL})$ was added to the resulting mixture. The organic phase was extracted with DCM (200 mL x 5). The combined organic layers were dried over $\mathrm{Na}_{2} \mathrm{SO}_{4}$, filtered and concentrated under vacuum $\left(30 \mathrm{mmHg}, 30^{\circ} \mathrm{C}\right)$ providing a light yellow solid (crude, $60 \mathrm{~g}$ ) that was directly used in the next step. Note: 1-(bicyclo[1.1.1]pentan-1-yl)-1H-pyrazole is volatile and concentration should be carried out under specified pressure and temperature. 
Step 5: 1-(bicyclo[1.1.1]pentan-1-yl)-4-iodo-1H-pyrazole (6). Four reactions were carried out in parallel. In a $500 \mathrm{~mL}$ round-bottomed flask with a stir bar, 1-(bicyclo[1.1.1]pentan-1-yl)-1Hpyrazole (crude, $15.3 \mathrm{~g}, 114 \mathrm{mmol}, 1.0$ eq.) and NIS (25.6 g, $114 \mathrm{mmol}, 1.0$ eq.) were dissolved in acetic acid $(381 \mathrm{~mL})$. The reaction mixture was then stirred at $80{ }^{\circ} \mathrm{C}$ for $2 \mathrm{~h}$. During this time, the reaction mixture turned from a light yellow to a brown solution. LC/MS analysis showed that the reaction was completed. The four reaction mixtures were combined and concentrated under vacuum. The residue was diluted with $\mathrm{H}_{2} \mathrm{O}(300 \mathrm{~mL})$ and extracted with $\left.\mathrm{DCM} 300 \mathrm{~mL} \times 3\right)$. The combined organic layers were washed with aqueous $\mathrm{Na}_{2} \mathrm{~S}_{2} \mathrm{O}_{3}(300 \mathrm{~mL} \times 3)$, dried over $\mathrm{Na}_{2} \mathrm{SO}_{4}$, filtered and concentrated under vacuum. The resulting residue was purified by silica gel chromatography with 0-15\% EtOAc in petroleum ether as eluent providing 6 (105 g, $396 \mathrm{~mol}, 85 \%$ yield over two steps) as a light yellow solid. ${ }^{1} \mathbf{H}$ NMR (600 MHz, $\left.\mathbf{C D C l}_{3}\right): \delta 7.51$ (s, $\left.1 \mathrm{H}\right), 7.45$ (s, 1H), 2.60 (s, 1H), 2.27 (s, 6H). ${ }^{13} \mathrm{C}\left\{{ }^{1} \mathrm{H}\right\}$ NMR (101 MHz, DMSO-d6): 144.8, 131.9, 56.2, 53.7, 52.8, 22.8. HRMS [M+H] ${ }^{+}$: calculated 260.9888, found 260.9893. Note 1: isolated yield was calculated as the media of the four reactions run in parallel. Note 2: scale-up of steps 4 and 5 with commercial bicyclo[1.1.1]pentan-1-ylhydrazine (345 g, $2.02 \mathrm{~mol})$ afforded 6 (300 g, $1.12 \mathrm{~mol}$, $55 \%$ yield over two steps). 


\section{Preparation of 11}

\section{V.A. Decarboxylative hydrazination}

Table S2. Optimization of photodecarboxylative hydrazination (selected reactions). ${ }^{8}$

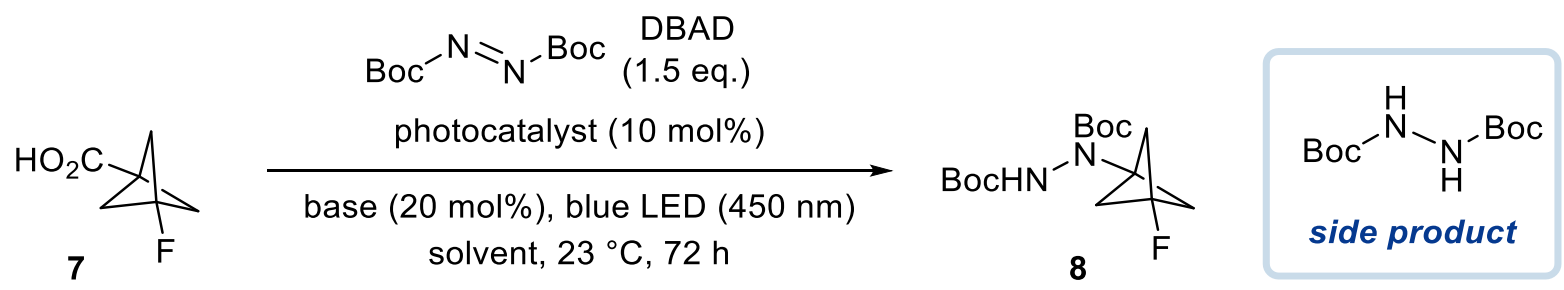

\begin{tabular}{|c|c|c|c|c|c|}
\hline Entry & mmol SM & Solvent & Photocatalyst & Base & GC 7/8 ratio ${ }^{a}$ \\
\hline 1 & 0.38 & $\operatorname{MeCN}(23 \mathrm{~V})$ & $\mathrm{CeCl}_{3} \cdot 7 \mathrm{H}_{2} \mathrm{O}$ & $\mathrm{Cs}_{2} \mathrm{CO}_{3}$ & AY: $5-30 B^{b, c}$ \\
\hline 2 & 0.38 & $\operatorname{MeCN}(23 \mathrm{~V})$ & $\mathrm{CeCl}_{3}$ & $\mathrm{Cs}_{2} \mathrm{CO}_{3}$ & $15: 2$ \\
\hline 3 & 0.38 & $\mathrm{MeCN}(23 \mathrm{~V})$ & $\mathrm{CeCl}_{3} \cdot 7 \mathrm{H}_{2} \mathrm{O}$ & DBU & $1: 1$ \\
\hline 4 & 0.38 & MeCN/DMA (11.5 V/11.5 V) & $\mathrm{CeCl}_{3} \cdot 7 \mathrm{H}_{2} \mathrm{O}$ & $\mathrm{Cs}_{2} \mathrm{CO}_{3}$ & $4: 1$ \\
\hline 5 & 0.38 & MeCN/DMSO (11.5 V/11.5 V) & $\mathrm{CeCl}_{3} \cdot 7 \mathrm{H}_{2} \mathrm{O}$ & $\mathrm{Cs}_{2} \mathrm{CO}_{3}$ & $1: 1$ \\
\hline 6 & 0.38 & MeCN/Dioxane (11.5 V/11.5 V) & $\mathrm{CeCl}_{3} \cdot 7 \mathrm{H}_{2} \mathrm{O}$ & $\mathrm{Cs}_{2} \mathrm{CO}_{3}$ & $12: 1$ \\
\hline 7 & 0.3 & $\operatorname{MeCN}(31.5 \mathrm{~V})$ & $\mathrm{CeCl}_{3} \cdot 7 \mathrm{H}_{2} \mathrm{O}$ & $\mathrm{Cs}_{2} \mathrm{CO}_{3}$ & $11: 5$ \\
\hline 8 & 0.3 & $\operatorname{MeCN}(31.5 \mathrm{~V})$ & $\mathrm{CeCl}_{3} \cdot 7 \mathrm{H}_{2} \mathrm{O}$ & BTMG & $20: 11 ; A Y: 11 \%^{b}$ \\
\hline 9 & 2 or 4 & $\operatorname{MeCN}(30 \mathrm{~V})$ & $\mathrm{CeCl}_{3} \cdot 7 \mathrm{H}_{2} \mathrm{O}$ & $\mathrm{Cs}_{2} \mathrm{CO}_{3}$ & AY: $10-40 \% \%^{b, c}$ \\
\hline 10 & 2 & $\operatorname{MeCN}(30 \mathrm{~V})$ & $\mathrm{CeCl}_{3} \cdot 7 \mathrm{H}_{2} \mathrm{O}$ & BTMG & $15: 1, A Y: 0.8 \%^{b}$ \\
\hline
\end{tabular}

${ }^{a}$ Normalized ratio of absorbances of 7 and $\mathbf{8} .{ }^{b}$ Assay yield calculated by GC analysis. ${ }^{c}$ Average of 5

independent reactions.

General procedure for decarboxylative hydrazination of 7 (entry 9 as reference). To a scintillation vial with a stir bar was added 7 (260 mg, 2 mmol, 1.0 eq.), di-tert-butyl azodicarboxylate (DBAD, $691 \mathrm{mg}, 3 \mathrm{mmol}, 1.5 \mathrm{eq}$.), $\mathrm{CeCl}_{3} \cdot 7 \mathrm{H}_{2} \mathrm{O}$ (grinded to a fine powder in a mortar, $75 \mathrm{mg}, 0.2 \mathrm{mmol}, 10 \mathrm{~mol} \%), \mathrm{Cs}_{2} \mathrm{CO}_{3}(130 \mathrm{mg}, 0.4 \mathrm{mmol}, 20 \mathrm{~mol} \%)$ and $\mathrm{MeCN}(30 \mathrm{~V})$. The vial was capped with a Teflon septum and $\mathrm{N}_{2}$ was bubbled through the resulting solution with a needle for $15 \mathrm{~min}$. Then, the mixture was stirred in an integrated Merck photoreactor (450 nm, 
100\% LED, stir: $2000 \mathrm{rpm}$, fan: $6800 \mathrm{rpm})^{4}$ for $72 \mathrm{~h}$. Ratios of absorbances of 7 and 8 and assay yields were determined by GC analysis of the reaction crude. The reaction crude was then quenched with a saturated solution of $\mathrm{NaHCO}_{3}(10 \mathrm{~mL})$ and the organic phase was extracted with EtOAc $(20 \mathrm{~mL} \times 3)$. The combined organic layers were dried over $\mathrm{Na}_{2} \mathrm{SO}_{4}$, filtered and concentrated under vacuum. Purification of the crude residue by silica gel chromatography with 0-50\% EtOAc in hexanes as eluent provided 8 (165 mg, $0.52 \mathrm{mmol}, 26 \%$ yield) as a white solid. Signal broadening and additional splitting was observed due to the presence of amide rotamers. ${ }^{1} \mathrm{H}$ NMR (600 MHz, $\left.\mathrm{CDCl}_{3}\right)$ : $\delta 6.70-6.06(\mathrm{~m}, 1 \mathrm{H}), 2.36(\mathrm{~s}, 6 \mathrm{H}), 1.46(\mathrm{~s}, 18 \mathrm{H})$. Note 1: running the reaction at the specified stir rate and fan speed was crucial for product formation. Note 2: batchto-batch inconsistencies were observed (entry 1 \& 9). Note 3: conditions shown in Table S2 were inspired by a literature report. ${ }^{8}$ Other conditions inspired by related photocatalyzed processes were also employed but only trace amounts of product 8 were detected. ${ }^{9}$

\section{V.B. $\mathrm{N}$-amination of BCP amine}

\section{Synthesis of $9^{10}$}

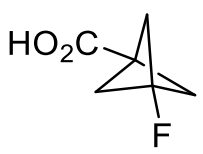

7

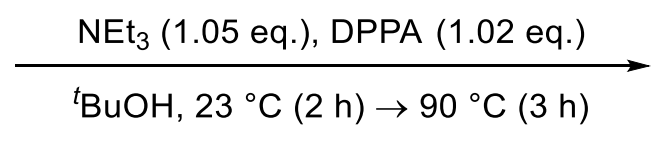

${ }^{t} \mathrm{BuOH}, 23^{\circ} \mathrm{C}(2 \mathrm{~h}) \rightarrow 90^{\circ} \mathrm{C}(3 \mathrm{~h})$

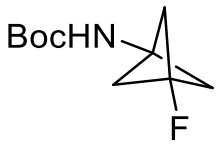

9

To a $100 \mathrm{~mL}$ round-bottomed flask with a stir bar was added $7(2.50 \mathrm{~g}, 19.2 \mathrm{mmol}, 1.0$ eq.). The flask was capped with a Teflon septum and submitted to three vacuum $/ \mathrm{N}_{2}$ refill cycles. Anhydrous ${ }^{t} \mathrm{BuOH}(25 \mathrm{~mL})$ and anhydrous triethylamine $(2.04 \mathrm{~g}, 20.0 \mathrm{mmol}, 1.05 \mathrm{eq}$.) were then added at 23 ${ }^{\circ} \mathrm{C}$ under a positive pressure of $\mathrm{N}_{2}$. Diphenyl phosphoryl azide (DPPA, $4.47 \mathrm{~mL}, 19.6 \mathrm{mmol}, 1.02$ eq.) was added dropwise to the mixture via syringe during $20 \mathrm{~min}$. The resulting reaction mixture was stirred at $23^{\circ} \mathrm{C}$ for $2 \mathrm{~h}$ and then at $90^{\circ} \mathrm{C}$ for $3 \mathrm{~h}$. GC/MS analysis showed full consumption of 7. The reaction mixture was concentrated under vacuum and the crude residue was diluted with 
MTBE $(25 \mathrm{~mL})$ and washed with a saturated aqueous solution of $\mathrm{NaHCO}_{3}(15 \mathrm{~mL} \times 3)$. The organic layer was dried over $\mathrm{Na}_{2} \mathrm{SO}_{4}$, filtered and concentrated under vacuum. Purification of the crude residue by silica gel chromatography with $0-5 \%$ EtOAc in petroleum ether as eluent provided 9 (3.2 g, $15.9 \mathrm{mmol}, 83 \%$ yield) as a white solid. Signal broadening and additional splitting was observed due to the presence of amide rotamers. ${ }^{1} \mathrm{H} \mathbf{N M R}\left(600 \mathbf{M H z} \mathbf{C D C l}_{3}\right): \delta$ 5.01 (s, 1H), $2.30(\mathrm{~s}, 6 \mathrm{H}), 1.43(\mathrm{~s}, 9 \mathrm{H}) .{ }^{13} \mathbf{C}$ NMR (151 MHz, $\left.\mathbf{C D C l}_{3}\right): \delta 154.9,77.8,75.8,55.3$ (d, $J=20.3 \mathrm{~Hz}$ ), $39.9(\mathrm{~d}, J=71.5 \mathrm{~Hz}), 28.5 .{ }^{19} \mathrm{~F}$ NMR (564 MHz, $\mathbf{C D C l}_{3}$ ): $\delta-169.1$. Spectroscopic data match those previously reported in the literature. ${ }^{10}$ Note: reaction run with $7(26 \mathrm{~g}, 196 \mathrm{mmol})$ under the same conditions afforded 9 (35 g, $174 \mathrm{mmol}, 89 \%$ yield).

\section{Optimization of $\mathrm{N}$-amination of 9}

Table S3. Optimization of $\mathrm{N}$-amination of $\mathbf{9}$ (selected reactions).
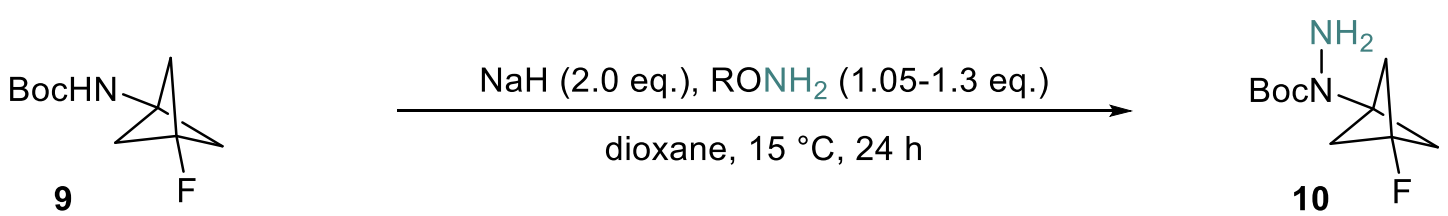

\begin{tabular}{|c|c|c|c|c|}
\hline Entry & $\mathrm{RONH}_{2}$ & $\mathrm{NaH}$ & Temp. $\left({ }^{\circ} \mathrm{C}\right)$ & ${ }^{1} \mathrm{H}$ NMR 9/10 ratio \\
\hline 1 & HOSA (1.05 eq.) & $1.1 \mathrm{eq}$. & 15 & $1: 0$ \\
\hline 2 & $\mathrm{NbzONH}_{2}(1.05$ eq. & $1.1 \mathrm{eq}$. & 15 & $1: 0$ \\
\hline 3 & DPPH (1.05 eq.) & $1.1 \mathrm{eq}$. & 15 & $3: 2$ \\
\hline 4 & DPPH (1.05 eq.) & 2.0 eq. & 40 & $\begin{array}{l}\text { full conversion, messy } \\
\text { mixture }\end{array}$ \\
\hline 5 & DPPH (1.05 eq.) & 2.0 eq. & 15 & $1: 11$ \\
\hline 6 & DPPH (1.3 eq.) & $2.0 \mathrm{eq}$. & 15 & $1: 95$ \\
\hline & & $\mathrm{O}$ & & O \\
\hline \multicolumn{2}{|c|}{ HOSA } & $\mathrm{zONH}_{2}$ & & DPPH \\
\hline
\end{tabular}


General procedure for $\mathrm{N}$-amination of 9 (entry 6 as reference). To a scintillation vial with a stir bar was added 9 (50 mg, $0.25 \mathrm{mmol}, 1.0$ eq.). The vial was capped with a Teflon septum and submitted to three vacuum $/ \mathrm{N}_{2}$ refill cycles. Anhydrous 1,4-dioxane $(20 \mathrm{~V})$ and $\mathrm{NaH}(60 \%$ dispersion in mineral oil, $20 \mathrm{mg}, 0.50 \mathrm{mmol}, 2.0$ eq.) were then added at $15^{\circ} \mathrm{C}$ under a positive pressure of $\mathrm{N}_{2}$. The mixture was stirred at $15{ }^{\circ} \mathrm{C}$ for 1 h. Then, O(Diphenylphosphinyl)hydroxylamine (DPPH, $76 \mathrm{mg}, 0.325 \mathrm{mmol}, 1.3 \mathrm{eq}$.) was added under a positive pressure of $\mathrm{N}_{2}$ and the resulting mixture was stirred at $15^{\circ} \mathrm{C}$ for $24 \mathrm{~h}$. Formation of 10 was confirmed by GC/MS analysis. 9/10 Ratio was determined by ${ }^{1} \mathrm{H}$ NMR analysis in DMSO- $d_{6}$ (see NMR characterization below).

\section{Scale-up synthesis of 11}

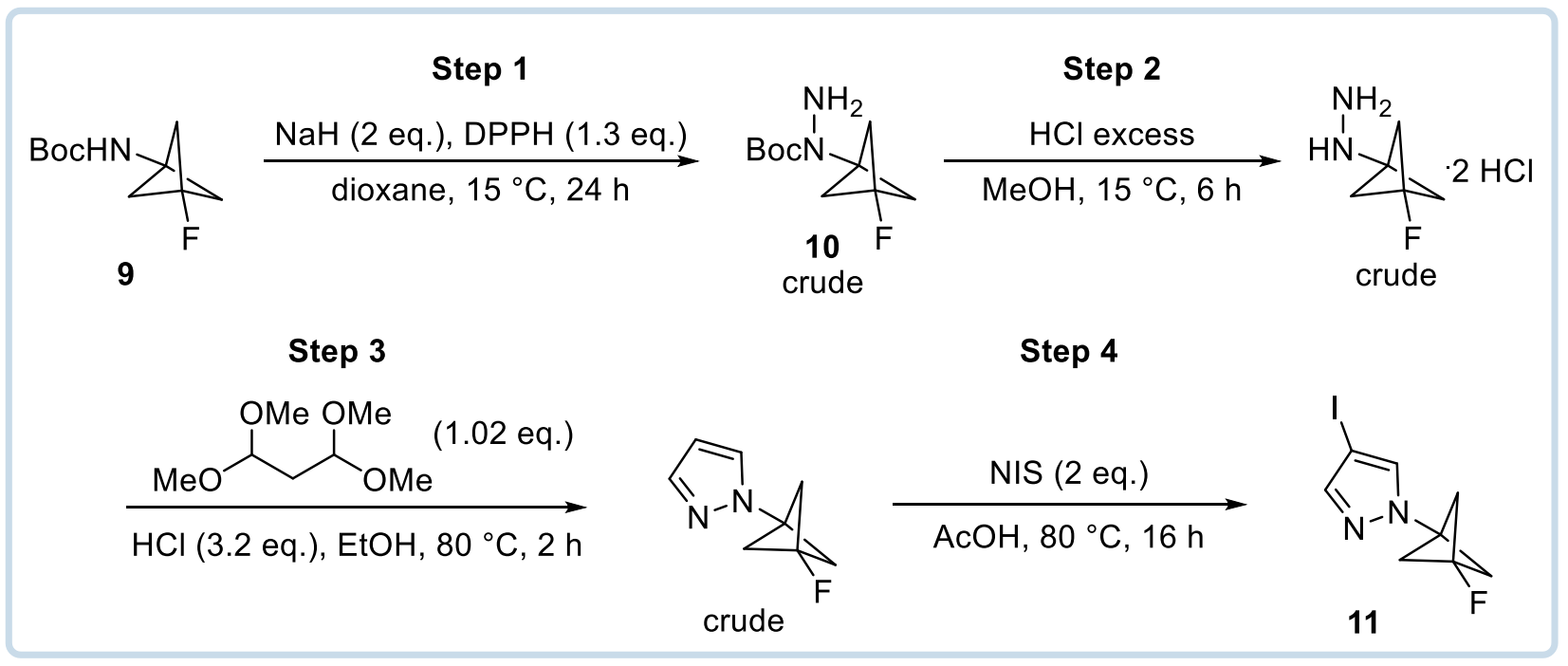

Step 1: tert-butyl 1-(3-fluorobicyclo[1.1.1]pentan-1-yl)hydrazine-1-carboxylate (10). A 100 $\mathrm{mL}$ round-bottomed with a stir bar and $9(1.00 \mathrm{~g}, 4.97 \mathrm{mmol}, 1.0$ eq.) was capped with a Teflon septum and submitted to three vacuum/ $\mathrm{N}_{2}$ refill cycles. Then, anhydrous 1,4-dioxane $(20 \mathrm{~mL})$ and $\mathrm{NaH}$ (60\% dispersion in mineral oil, $398 \mathrm{mg}, 9.94 \mathrm{mmol}, 2.0$ eq.) were added to the flask under a positive pressure of $\mathrm{N}_{2}$ at $15{ }^{\circ} \mathrm{C}$ and the resulting mixture was stirred for $3 \mathrm{~h}$. After addition of DPPH (1.51 g, $6.46 \mathrm{mmol}, 1.3 \mathrm{eq}$.) under a positive pressure of $\mathrm{N}_{2}$, the mixture was stirred at 
$15{ }^{\circ} \mathrm{C}$ for $21 \mathrm{~h}$. GC/MS analysis showed full consumption of 9 . The reaction mixture was then quenched with $\mathrm{H}_{2} \mathrm{O}(10 \mathrm{~mL})$ and the organic phase was extracted with EtOAc $(20 \mathrm{~mL} \times 3)$. The combined organic layers were washed with brine $(20 \mathrm{~mL})$, dried over $\mathrm{Na}_{2} \mathrm{SO}_{4}$, filtered and concentrated under vacuum $\left(30 \mathrm{mmHg}, 40{ }^{\circ} \mathrm{C}, 5 \mathrm{~h}\right.$ ). The crude was purified by silica gel chromatography with 0-15\% EtOAc in petroleum ether as eluent providing 10 (912 mg, $4.22 \mathrm{mmol}$, $85 \%$ yield) as a yellow solid. ${ }^{1} \mathrm{H}$ NMR (400 MHz, DMSO- $\left.d_{6}\right): \delta 4.50(\mathrm{~s}, 2 \mathrm{H}), 2.28(\mathrm{~d}, J=2.1 \mathrm{~Hz}$, 6H), $1.41(\mathrm{~s}, 9 \mathrm{H}) .{ }^{19} \mathrm{~F}$ NMR (376 MHz, DMSO-d $)$ : $\delta$-170.2. Note: reaction run with 9 (35 g, 174 $\mathrm{mmol}$ ) under the same conditions afforded 10 (crude directly carried out to step 2 without chromatographic purification, $21 \mathrm{~g}, 92.5 \mathrm{mmol}, 53 \%$ yield).

Step 2: (3-fluorobicyclo[1.1.1]pentan-1-yl)hydrazine, $\mathrm{HCl}$ salt. To a $50 \mathrm{~mL}$ round-bottomed flask was added 10 (720 mg, $3.33 \mathrm{mmol}, 1.0$ eq.) and $\mathrm{HCl}$ in $\mathrm{MeOH}$ (4 M, $14 \mathrm{~mL}, 56$ eq.). The reaction mixture was stirred at $15^{\circ} \mathrm{C}$ for $6 \mathrm{~h} .{ }^{1} \mathrm{H} \mathrm{NMR}$ in DMSO- $d_{6}$ showed full consumption of 10. The reaction mixture was concentrated under vacuum to give the title product (crude, $500 \mathrm{mg}$, $2.64 \mathrm{mmol}, 79 \%$ yield) as a yellow solid that was directly employed in the following step without further purification. ${ }^{1} \mathrm{H}$ NMR (400 MHz, DMSO- $\left.d_{6}\right): \delta 2.18(\mathrm{~d}, J=2.1 \mathrm{~Hz}, 6 \mathrm{H}) .{ }^{19} \mathrm{~F} \mathrm{NMR}(376 \mathrm{MHz}$, DMSO- $\left.\boldsymbol{d}_{6}\right): \delta-166.6$. Note: reaction run with $10(14 \mathrm{~g}, 64.8 \mathrm{mmol})$ under the same conditions afforded the title product (crude, $12 \mathrm{~g}, 63.5 \mathrm{mmol}, 98 \%$ yield).

Step 3: 1-(3-Fluorobicyclo[1.1.1]pentan-1-yl)-1H-pyrazole. (3-Fluorobicyclo[1.1.1]pentan-1yl)hydrazine, $\mathrm{HCl}$ salt (500 mg, $2.64 \mathrm{mmol} .1 .0$ eq.) and 1,1,3,3-tetramethoxypropane (448 $\mu \mathrm{L}$, $2.70 \mathrm{mmol}, 1.02$ eq.) were added to a two-necked $50 \mathrm{~mL}$ round-bottomed flask. Then, EtOH (5 $\mathrm{mL}$ ) and concentrated $\mathrm{HCl}(37 \%$ wt., $257 \mu \mathrm{L}, 8.45 \mathrm{mmol}$, 3.2 eq.) were added to the suspension and one neck of the flask was attached to a reflux condenser while the other neck was capped with a Teflon septum. The reaction mixture was then stirred at $80^{\circ} \mathrm{C}$ for $2 \mathrm{~h}$. LC/MS analysis showed product formation. To the reaction mixture was added $\mathrm{H}_{2} \mathrm{O}(5 \mathrm{~mL})$ and the organic phase 
was extracted with $\mathrm{DCM}(10 \mathrm{~mL} \times 5)$. The combined organic layers were dried over $\mathrm{Na}_{2} \mathrm{SO}_{4}$, filtered and concentrated under vacuum $\left(30 \mathrm{mmHg}, 30^{\circ} \mathrm{C}\right)$. The title product (crude, $400 \mathrm{mg}, 2.63$ mmol, 99\% yield) containing residual DCM and $\mathrm{EtOH}$ was obtained and used in the following step without further purification. ${ }^{1} \mathrm{H}$ NMR (400 MHz, DMSO- $\left.\boldsymbol{d}_{6}\right): 7.79(\mathrm{~d}, \mathrm{~J}=2.3 \mathrm{~Hz}, 1 \mathrm{H}), 7.52(\mathrm{~m}, 1 \mathrm{H})$, $6.31(\mathrm{t}, J=2.0 \mathrm{~Hz}, 1 \mathrm{H}), 2.61(\mathrm{~d}, J=2.1 \mathrm{~Hz}, 6 \mathrm{H}) .{ }^{19} \mathrm{~F}$ NMR (376 MHz, DMSO- $\left.d_{6}\right): \delta-171.0$. Note 1: (3-fluorobicyclo[1.1.1]pentan-1-yl)-1H-pyrazole is volatile and concentration should be carried out under specified pressure and temperature. Note 2: reaction run with (3fluorobicyclo[1.1.1]pentan-1-yl)hydrazine, $\mathrm{HCl}$ salt $(11 \mathrm{~g}, 90.4 \mathrm{mmol})$ under the same conditions afforded the title product (crude, $12 \mathrm{~g}, 78.9 \mathrm{mmol}, 87 \%$ yield).

Step 4: 1-(3-fluorobicyclo[1.1.1]pentan-1-yl)-4-iodo-1H-pyrazole (11). In a $50 \mathrm{~mL}$ roundbottomed flask with a stir bar, (3-fluorobicyclo[1.1.1]pentan-1-yl)-1H-pyrazole (400 mg, 8.87 mmol, 1.0 eq.) and NIS (2.00 g, $5.26 \mathrm{mmol}, 2.0$ eq.) were dissolved in acetic acid (10 mL). The reaction mixture was stirred at $80^{\circ} \mathrm{C}$ for $16 \mathrm{~h}$. During this time, the reaction mixture turned from a light yellow to a brown solution. LC/MS analysis showed that the reaction was completed. The solution was concentrated under vacuum and the resulting residue was purified by silica gel chromatography with $0-10 \%$ EtOAc in petroleum ether as eluent providing a crude yellow solid (580 mg). Then, the crude product was further purified by prep-TLC with 10:1 petroleum ether/EtOAc as eluent affording 11 (492 mg, $1.77 \mathrm{mmol}, 67 \%$ yield) as a yellow solid. ${ }^{\mathbf{1}} \mathbf{H}$ NMR $\left(600 \mathrm{MHz}, \mathrm{CDCl}_{3}\right): \delta 7.54(\mathrm{~s}, 1 \mathrm{H}), 7.43(\mathrm{~s}, 1 \mathrm{H}), 2.61(\mathrm{~d}, J=2.0 \mathrm{~Hz}, 6 \mathrm{H}) .{ }^{13} \mathrm{C}\left\{{ }^{1} \mathrm{H}\right\} \mathrm{NMR}(151 \mathrm{MHz}$, $\left.\mathrm{CDCl}_{3}\right): 145.1,133.3,77.3,75.1,57.0,56.2(\mathrm{~d}, \mathrm{~J}=21.1 \mathrm{~Hz}) .{ }^{19} \mathrm{~F}$ NMR (564 MHz, CDCl $):-173.5$ ppm. HRMS [M+H]+: calculated 278.9794, found 278.9800. Note: reaction run with (3fluorobicyclo[1.1.1]pentan-1-yl)-1H-pyrazole (10 g, $65.7 \mathrm{mmol})$ under the same conditions afforded 11 (12 g, $43.2 \mathrm{mmol}, 66 \%$ yield). 


\section{Preparation of 14}

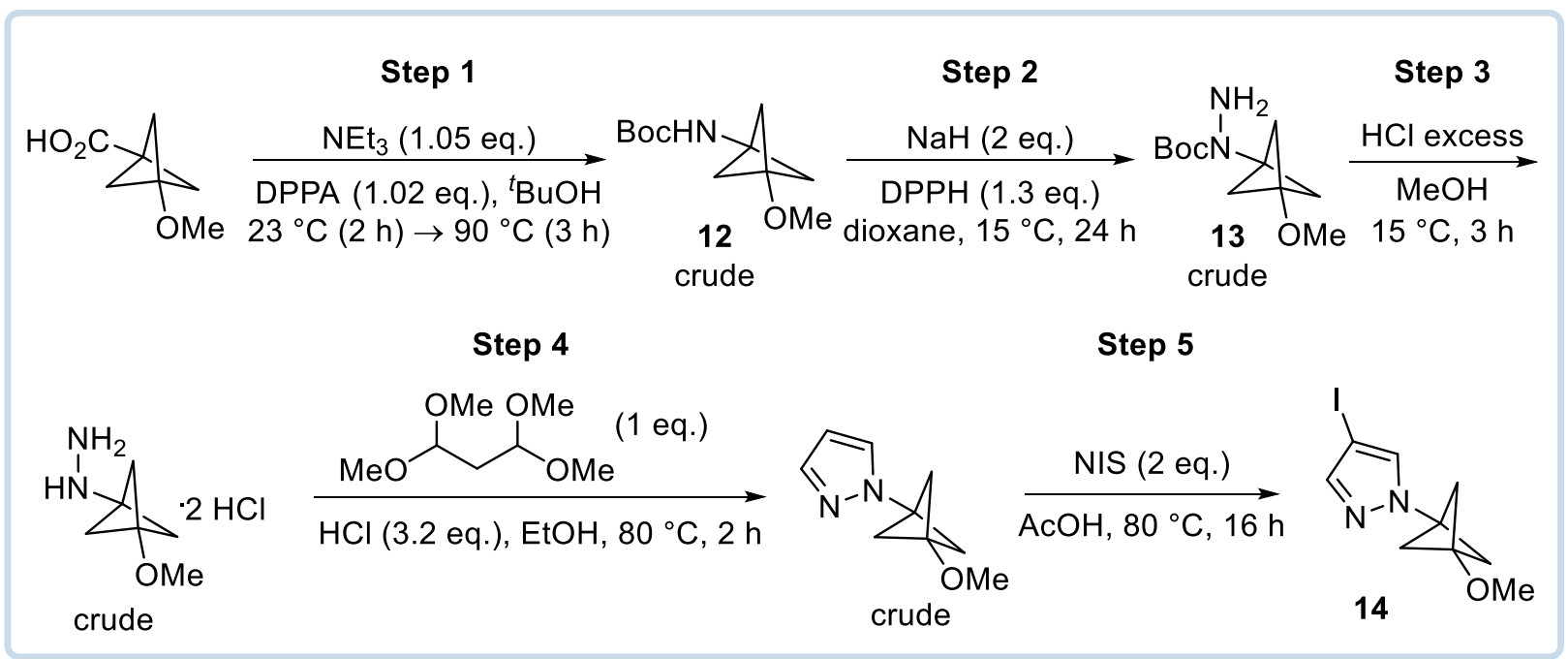

Step 1: tert-butyl (3-methoxybicyclo[1.1.1]pentan-1-yl)carbamate (12). Same procedure as the one used for the synthesis of 9 (vide supra) was followed using 3methoxybicyclo[1.1.1]pentane-1-carboxylic acid (1.00 g, 7.03 mmol, 1.0 eq.). Compound 12 (1.47 g, $6.89 \mathrm{mmol}$, 98\% yield) was obtained as a pale yellow crude solid that was used in the next step after work-up/concentration without further purification. ${ }^{1} \mathrm{H} \mathbf{N M R}\left(600 \mathrm{MHz}, \mathrm{CDCl}_{3}\right): \delta 3.30(\mathrm{~s}, 3 \mathrm{H})$, $2.13(\mathrm{~s}, 6 \mathrm{H}), 1.44(\mathrm{~s}, 9 \mathrm{H}) .{ }^{13} \mathrm{C}\left\{{ }^{1} \mathrm{H}\right\}$ NMR (151 MHz, $\left.\mathrm{CDCl}_{3}\right): \delta$ 130.2, 67.3, 54.9, 53.0, 52.8, 41.8, 28.5 .

Step 2: tert-butyl 1-(3-methoxybicyclo[1.1.1]pentan-1-yl)hydrazine-1-carboxylate (13). Same procedure as the one used for the synthesis of $\mathbf{1 0}$ (step 1 of scale-up synthesis of $\mathbf{1 1}$, vide supra) was followed using 12 (1.05 g, 4.93 mmol, 1.0 eq.). Compound 13 (835 mg, 3.66 mmol, $74 \%$ yield) was obtained as a pale yellow crude solid that was used in the next step after workup/concentration without further purification. Signal broadening and additional splitting was observed due to the presence of amide rotamers. ${ }^{1} \mathrm{H}$ NMR $\left(600 \mathbf{M H z}, \mathbf{C D C l}_{3}\right): \delta 3.30(\mathrm{~s}, 1.57 \mathrm{H})$, $3.29(\mathrm{~s}, 1.40 \mathrm{H}), 2.15(\mathrm{~s}, 3.58 \mathrm{H}), 2.12(\mathrm{~s}, 2.32 \mathrm{H}), 1.47(\mathrm{~s}, 5.45 \mathrm{H}), 1.44(\mathrm{~s}, 3.87 \mathrm{H})$. 
Step 3: (3-methoxybicyclo[1.1.1]pentan-1-yl)hydrazine, $\mathrm{HCl}$ salt. Same procedure as the one used in step 2 of scale-up synthesis of 11 (vide supra) was followed using 13 (804 mg, 3.52 mmol, 1.0 eq.). After concentrating the reaction mixture under vacuum, the title compound was obtained as a yellow crude solid (517 mg crude) and was used in the next step without further purification.

Step 4: 1-(3-methoxybicyclo[1.1.1]pentan-1-yl)-1H-pyrazole. Same procedure as the one used in step 3 of scale-up synthesis of 11 (vide supra) was followed using (3methoxybicyclo[1.1.1]pentan-1-yl)hydrazine, $\mathrm{HCl}$ salt (310 mg, crude). The title product (crude, $298 \mathrm{mg}, 1.814 \mathrm{mmol}, 75 \%$ yield) was obtained as a pale yellow and used in the following step without further purification. ${ }^{1} \mathbf{H}$ NMR $\left(600 \mathbf{M H z}, \mathbf{C D C l}_{3}\right)$ : $\delta 7.57-7.54(\mathrm{~m}, 1 \mathrm{H}), 7.43-7.34(\mathrm{~m}$, $1 \mathrm{H}), 6.34-6.19(\mathrm{~m}, 1 \mathrm{H}), 3.39(\mathrm{~s}, 3 \mathrm{H}), 2.45(\mathrm{~s}, 6 \mathrm{H})$.

Step 5: 4-iodo-1-(3-methoxybicyclo[1.1.1]pentan-1-yl)-1H-pyrazole (14). Same procedure as the one used in step 4 of scale-up synthesis of 11 (vide supra) was followed using 1-(3methoxybicyclo[1.1.1]pentan-1-yl)-1H-pyrazole (241 mg, 1.468 mmol, 1.0 eq.). Compound 14 compound (332 mg, $1.145 \mathrm{mmol}, 78 \%$ yield) was obtained as yellow oil after purification by silica gel chromatography with 0-20\% EtOAc in hexanes as eluent. ${ }^{1} \mathbf{H} \mathbf{N M R}\left(600 \mathbf{~ M H z}, \mathbf{C D C l}_{3}\right): \delta 7.54$ (s, 1H), 7.45 (s, 1H), 3.37 (s, 3H), $2.42(\mathrm{~s}, 6 \mathrm{H}) .{ }^{13} \mathrm{C}\left\{{ }^{1} \mathrm{H}\right\}$ NMR (151 MHz, $\left.\mathbf{C D C l}_{3}\right): \delta$ 145.4, 133.0, 66.7, 56.5, 55.2, 53.6, 48.2. HRMS [M+H]+: calculated 290.9994, found 290.9995. 
VII. Preparation of 16

VII.A. Preparation of 16 from 15

Ligand-Screening Procedure

Table S4. HTS of ligands in the synthesis of 16 from 15

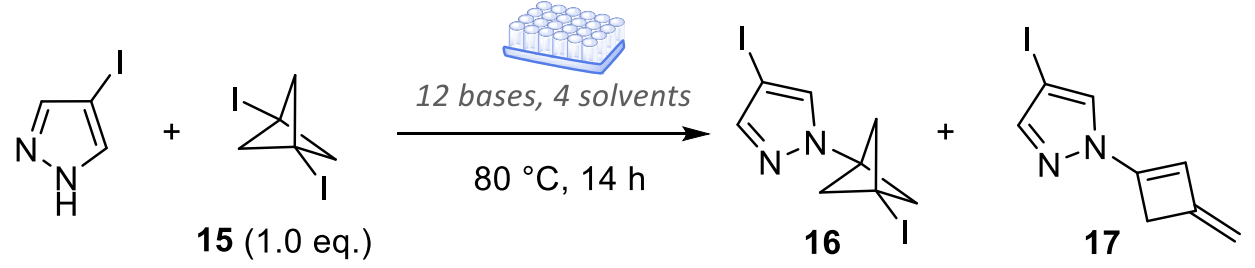

\begin{tabular}{c|cccccccccccccc} 
& $\mathrm{LiCO} 3$ & $\mathrm{~K} 2 \mathrm{CO} 3$ & $\mathrm{NaCO} 3$ & $\mathrm{CsCO} 3$ & $\mathrm{NaHCO} 3$ & $\mathrm{KOAC}$ & $\mathrm{K} 3 \mathrm{PO} 4$ & $\mathrm{KOH}$ & $\mathrm{NaOH}$ & $\mathrm{LiOH}$ & $\mathrm{LiHMDS}$ & $\mathrm{NaOtBu}$ \\
\hline Dioxane & 0.18 & 0.19 & 0.26 & 0.39 & 0.26 & 0.13 & 0.14 & 0.20 & 0.30 & 0.39 & 0.94 & 0.33 \\
EtOH & 1.93 & 1.12 & 1.71 & 1.00 & 1.77 & 1.24 & 0.31 & 0.93 & 1.23 & 1.51 & 0.37 & 0.33 \\
MeCN & 2.01 & 6.05 & 4.40 & 2.49 & 4.34 & 5.73 & 3.68 & 2.35 & 2.70 & 1.75 & 0.31 & 0.23 \\
DCE & 0.03 & 0.17 & 0.94 & 0.33 & 1.07 & 0.69 & 0.49 & 0.59 & 1.16 & 0.00 & 0.93 & 1.35 \\
\hline
\end{tabular}

In the glovebox, four 2-dram vials with stir bars were charged with 4-iodo-1H-pyrazole (29.1g, 150 $\mu \mathrm{mol}), 1,3$-diiodobicyclo[1.1.1]pentane (15, $48 \mathrm{~g}, 150 \mu \mathrm{mol}, 1.0 \mathrm{eq}$.$) and 750 \mu \mathrm{l}$ of one of the four solvents listed. These solutions were stirred to dissolve the reagents, then $50 \mu$ of the four stock solutions was added to the corresponding vials containing $30 \mu \mathrm{mol}$ of the corresponding base using an Eppendorf pipetter as arrayed above. The reactions were then sealed and heated at $80^{\circ} \mathrm{C}$ for $14 \mathrm{~h}$. After cooling to ambient temperature, the reactions were diluted with $500 \mu \mathrm{l}$ of a $0.002 \mathrm{M}$ biphenyl in 3:1 MeCN/DMSO quench solution (this provided $0.25 \mu \mathrm{mol}$ biphenyl in each well). A silicon-rubber storage mat was added, and the contents were shaken to homogenize. 15 $\mu \mathrm{L}$ of each of the diluted reaction mixtures were then added to $250 \mu \mathrm{l}$ of $\mathrm{MeCN}$ in separate wells of a 96-well analytical plate, which was sealed and analyzed on an Agilent UPLC system. Reported values correspond to the ratio of absorbances of $16+17 /$ biphenyl (IS).

Further screening of bases was carried out in the same manner using one stock solution in MeCN to investigate additional inorganic bases. Pertinent data is shown below. 


\begin{tabular}{|c|c|c|c|}
\hline Base & Equiv. & Conversion & $16: 17$ \\
\hline $\mathrm{K}_{2} \mathrm{CO}_{3}$ & 3 & $>95 \%$ & $<1: 20$ \\
\hline $\mathrm{KOAC}$ & 3 & $>95 \%$ & $<1: 20$ \\
\hline TBAOAc & 3 & $>95 \%$ & $<1: 20$ \\
\hline $\mathrm{Cs}_{2} \mathrm{CO}_{3}$ & 3 & $95 \%$ & $1: 1$ \\
\hline $\mathrm{Cs}_{2} \mathrm{CO}_{3}$ & 1.5 & $95 \%$ & $1: 2$ \\
\hline none & - & $88 \%$ & trace \\
\hline
\end{tabular}

\section{Scale-up synthesis of 16 from 15}

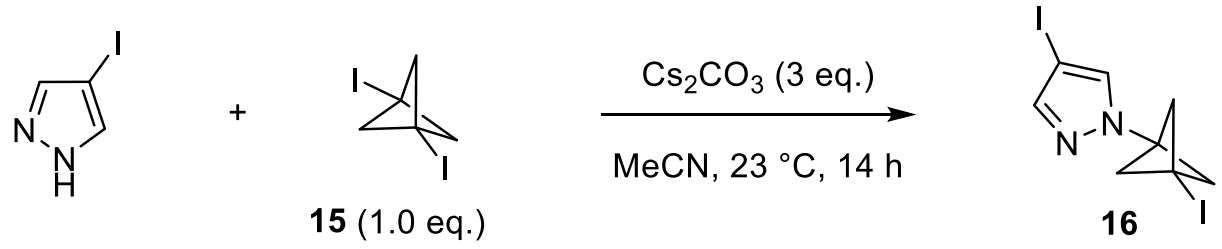

A $30 \mathrm{~mL}$ round-bottomed vial with a stir-bar was charged with 4-iodo- $1 \mathrm{H}$-pyrazole $(0.61 \mathrm{~g}, 3.13$ mmol), 15 (1.0 g, 3.13 mmol, 1.0 eq.) and cesium carbonate (3.06 g, 9.38 mmol, 3.0 eq.). MeCN $(16 \mathrm{ml})$ was then added and the reaction was capped with a Teflon septum cap and stirred at room temperature for $14 \mathrm{~h}$. The reaction mixture was then diluted with $\mathrm{MeCN}(10 \mathrm{~mL})$ and filtered through a pad of Celite. The resulting solution was concentrated under vacuum. Purification of the resulting crude by silica gel chromatography with 0-40\% EtOAc in hexanes as eluent afforded 4-iodo-1-(3-iodobicyclo[1.1.1]pentan-1-yl)-1H-pyrazole (16, $340 \mathrm{mg}, 0.881 \mathrm{mmol}, 28 \%$ yield) as a white solid. ${ }^{1} \mathrm{H}$ NMR (600 MHz, $\left.\mathbf{C D C l}_{3}\right): \delta 7.52(\mathrm{~s}, 1 \mathrm{H}), 7.40(\mathrm{~s}, 1 \mathrm{H}), 2.72(\mathrm{~s}, 6 \mathrm{H}) .{ }^{13} \mathrm{C}\left\{{ }^{1} \mathrm{H}\right\}$ NMR (151 MHz, CDCI3): 145.3, 132.1, 61.7, 56.8, 56.4, -2.1. HRMS [M+H]+: calculated 386.8855, found 386.8860 .

Note: We were unable to cleanly isolate diene byproduct $\mathbf{1 7}$ from the reaction mixture. Its identity was assumed based on LC/MS analysis (observed LCMS $[\mathrm{M}+\mathrm{H}]^{+}:$259) and analogy to know reaction patterns of BCP's (see page S36). 


\section{Mechanistic proposal for the formation of 16 and 17}

Based on proposed mechanisms for related monosubstitution reactions of $15,{ }^{11}$ we hypothesized that the formation of $\mathbf{1 6}$ proceeds through in situ formation of [1.1.1]propellane followed by addition of the resulting $\mathrm{N}$-iodopyrazole I across the central bond of [1.1.1]propellane (Scheme S1).

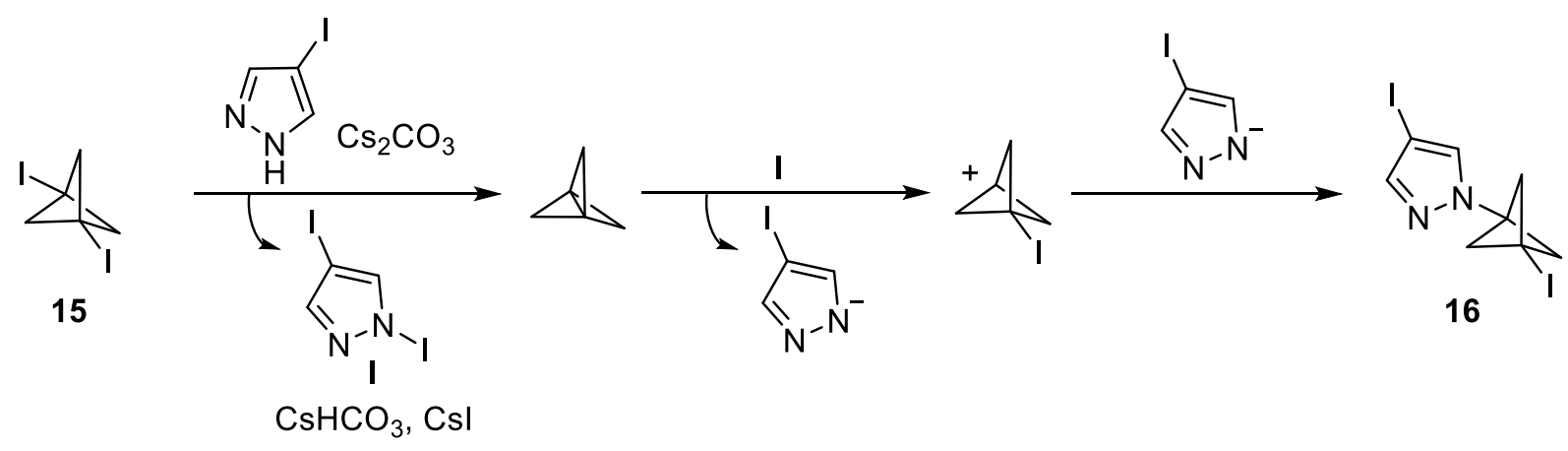

Scheme S1. Proposed mechanism for the formation of 16.

Reaction monitoring experiments suggested that $\mathbf{1 7}$ is not generated via thermal or basepromoted decomposition of 16. Instead, we hypothesized that 17 is generated from 15 via iodide abstraction followed by C3-carbocation rearrangement and subsequent $\beta$-proton abstraction (Scheme S2). ${ }^{11 c, 12}$

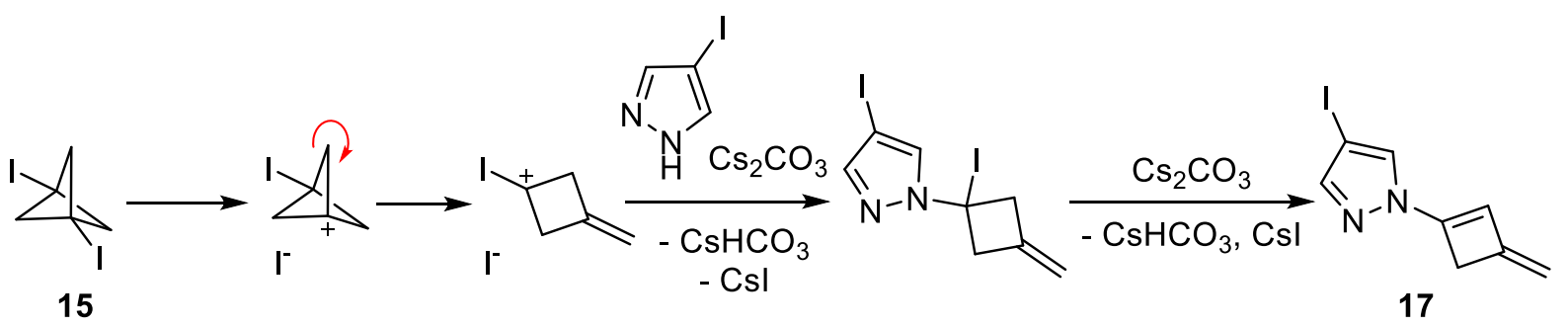

Scheme S2. Proposed mechanism for the formation of 17. 


\section{VII.B. Preparation of 16 from [1.1.1]propellane}

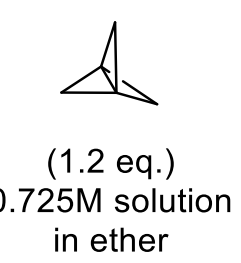

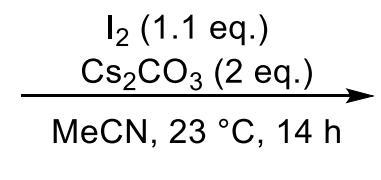

$\mathrm{I}_{2}$ (1.1 eq.)

$\mathrm{MeCN}, 23^{\circ} \mathrm{C}, 14 \mathrm{~h}$

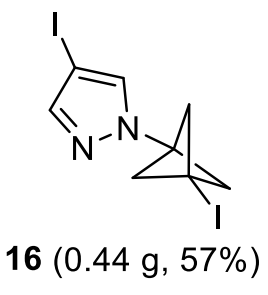

A $30 \mathrm{~mL}$ round-bottomed vial with a stir-bar was charged with iodine (533 $\mathrm{mg}, 2.10 \mathrm{mmol}, 1.1$ eq.), 4-iodo-1H-pyrazole (388 mg, $2.00 \mathrm{mmol}$ ), cesium carbonate (1.30 g, $4.00 \mathrm{mmol} .2 .0$ eq.) and $\mathrm{MeCN}(10 \mathrm{ml})$, then sealed with a Teflon septum cap and stirred at room temperature for 30 min. The vial was then charged with $3.31 \mathrm{ml}$ of a solution of [1.1.1]propellane in ether $(0.725 \mathrm{M}$, $2.4 \mathrm{mmol}, 1.2$ eq., prepared and titrated as reported above $)^{7 \mathrm{~b}}$, and the reaction was stirred at room temperature for $14 \mathrm{~h}$. The reaction mixture was then diluted with $\mathrm{MeCN}(10 \mathrm{~mL})$ and filtered through a pad of Celite. The resulting solution was concentrated under vacuum. Purification of the resulting crude by silica gel chromatography with 0-40\% EtOAc in hexanes as eluent afforded 16 (440 mg, $1.14 \mathrm{mmol}, 57 \%$ yield) as a white solid. Spectroscopic data is in accordance with the material prepared from 15 (vide supra). 


\section{Unsuccessful synthetic approaches}

\section{VIII.A. Decarboxylative $\mathbf{C} 1-\mathrm{N}$ coupling attempts}

Synthesis of BCP iodonium carboxylate reagents was carried out following a literature report. ${ }^{5}$ General method for decarboxylative C-N coupling described in section II.A. was followed with the deviations depicted in Tables S5-S7. Different conditions employed in the absence or presence of light, photocatalyst, base and/or ligand were inspired by conditions reported by the MacMillan group. ${ }^{13}$

Table S5. Attempted synthesis of methyl 3-(4-bromo-1H-pyrazol-1-yl)bicyclo[1.1.1]pentane-1carboxylate via decarboxylative $\mathrm{C} 1-\mathrm{N}$ coupling.<smiles>Cc1cc([N+](=O)[O-])cc([N+](=O)[O-])c1B(OC(=O)C1CCC2CCC1C2)OC(=O)C1CCC2CCC1C2</smiles><smiles>Brc1cn[nH]c1</smiles><smiles>CN(C)C(N)=[18O]</smiles>

(0.10 mmol, 1 eq.) (0 or $30 \mathrm{~mol} \%$ )

CuTC (60 mol\%), BPhen (90 mol\%)

$[\mathrm{Ir}](5 \mathrm{~mol} \%)$

dioxane $(0.05 \mathrm{M}), 23^{\circ} \mathrm{C}, 16 \mathrm{~h}$

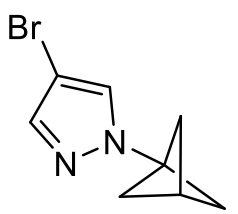

not detected

\begin{tabular}{|c|c|c|c|c|c|}
\hline Entry & Pyrazole (mmol) & {$[\mathrm{Ir}]$} & BTMG (mol\%) & LED & $\begin{array}{c}\text { product } \\
\text { LC/MS }\end{array}$ \\
\hline 1 & 0.20 & $\mathrm{X}$ & $\mathrm{X}$ & $\mathrm{X}$ & no \\
\hline 2 & 0.34 & $\mathrm{Ir}-1$ & 30 & $\sqrt{ }^{a}$ & no \\
\hline 3 & 0.10 & $\mathrm{Ir}-2$ & $\mathrm{X}$ & $\sqrt{ }^{a}$ & no \\
\hline $4^{b}$ & 0.10 & $\mathrm{X}$ & $\mathrm{X}$ & $\mathrm{X}$ & no \\
\hline
\end{tabular}

Ir-1: Ir(F-Meppy) 2 (dtbbpy)PF $;$ Ir-2: $\operatorname{Ir}(\mathrm{ppy})_{3}{ }^{a}$ An integrated Merck photoreactor $(450 \mathrm{~nm}, 100 \%$ LED, stir: 2000 rpm, fan: $6800 \mathrm{rpm}$ ) was used. ${ }^{b}$ lodonium carboxylate $(2.3 \mathrm{eq}$.$) .$ 
Table S6. Attempted synthesis of C3-fluoro BCPP via decarboxylative C1-N coupling.<smiles>Cc1cc(C)c(I(OC(=O)C2CCC(F)(F)C2)OC(=O)C2CCC(F)(F)C2)c(C)c1</smiles><smiles>[R]c1cn[nH]c1</smiles><smiles>CNC(=[Nb])N(C)C</smiles>

(0.10 mmol, 1 eq.)

BTMG (2 eq.)

[Cu] $(60 \mathrm{~mol} \%)$, BPhen (90 mol\%)

[Ir] $(5 \mathrm{~mol} \%)$

dioxane $(0.05 \mathrm{M}), 23{ }^{\circ} \mathrm{C}, 16 \mathrm{~h}$

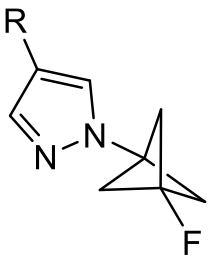

$$
\mathrm{R}=\mathrm{Br}, \mathrm{I}(11), \mathrm{H}, \mathrm{NO}_{2}
$$

traces or not detected

\begin{tabular}{|c|c|c|c|c|c|c|c|c|}
\hline Entry & $\mathbf{R}$ & $x$ (eq.) & {$[\mathrm{Ir}]$} & BTMG & [Cu] & BPhen & LED & $\begin{array}{l}\text { Product } \\
\text { LC/MS }\end{array}$ \\
\hline 1 & $\mathrm{Br}$ & 1.0 & Ir-2 & $x$ & $\mathrm{Cu}(\mathrm{acac})_{2}$ & $X$ & $\sqrt{ }^{a}$ & no \\
\hline 2 & $\mathrm{Br}$ & 1.0 & Ir-2 & $\checkmark$ & $\mathrm{Cu}(\mathrm{acac})_{2}$ & & $\sqrt{ }^{a}$ & traces \\
\hline 3 & $\mathrm{Br}$ & 1.0 & Ir-2 & $x$ & $\mathrm{Cu}(\mathrm{acac})_{2}$ & & $\sqrt{ }^{a}$ & no \\
\hline 4 & $\mathrm{Br}$ & 1.0 & Ir-2 & $\checkmark$ & $\mathrm{Cu}(\mathrm{acac})_{2}$ & & $\sqrt{ }^{a}$ & no \\
\hline 5 & $\mathrm{Br}$ & 2.3 & $x$ & $x$ & CuTc & $\checkmark$ & $x$ & traces \\
\hline 6 & $\mathrm{NO}_{2}$ & 2.0 & Ir-1 & $x$ & $\mathrm{Cu}(\mathrm{acac})_{2}$ & $x$ & $\checkmark$ & no \\
\hline 7 & $\mathrm{H}$ & 2.0 & Ir-1 & $X$ & $\mathrm{Cu}(\mathrm{acac})_{2}$ & $X$ & $\checkmark$ & $3 \%{ }^{b, c, d, e}$ \\
\hline 8 & I & 2.0 & Ir-1 & $x$ & $\mathrm{Cu}(\mathrm{acac})_{2}$ & $x$ & $\checkmark$ & traces \\
\hline 9 & 1 & 2.3 & $x$ & $x$ & CuTc & $\checkmark$ & $x$ & traces \\
\hline
\end{tabular}

Ir-1: Ir(F-Meppy $)_{2}(\mathrm{dtbbpy}) \mathrm{PF}_{6}$; Ir-2: $\operatorname{Ir}(\mathrm{ppy})_{3}$. ${ }^{a} 34 \mathrm{~W}$ Kessil blue LED lamps (3 cm away, with cooling fan to keep the reaction at room temperature). ${ }^{b} \mathrm{An}$ integrated Merck photoreactor (450 nm, 100\% LED, stir: 2000 rpm, fan: 6800 rpm) was used. c9\% conversion of $1 \mathrm{H}$-pyrazole. dUncorrected LC/MS yield and conversion calculated using biphenyl as internal standard. ${ }^{e} \mathrm{No}$ significant increase in product formation was observed after stirring the reaction mixture at $23^{\circ} \mathrm{C}$ for $16 \mathrm{~h}$ and, then, at $40{ }^{\circ} \mathrm{C}$ for $24 \mathrm{~h}$. 
Table S7. Attempted synthesis of 4-bromo-1-(3-methoxybicyclo[1.1.1]pentan-1-yl)-1H-pyrazole via decarboxylative $\mathrm{C} 1-\mathrm{N}$ coupling.

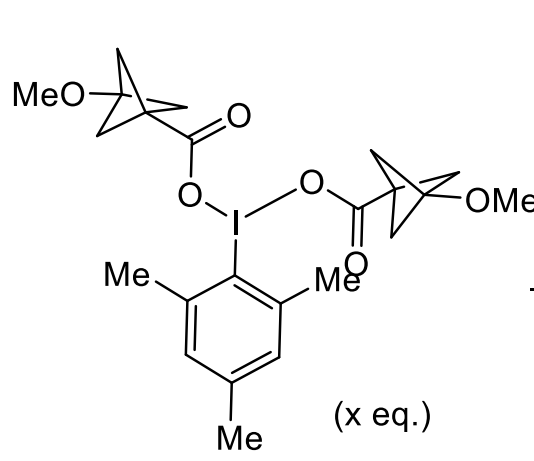<smiles>Brc1cn[nH]c1</smiles>

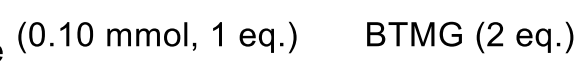

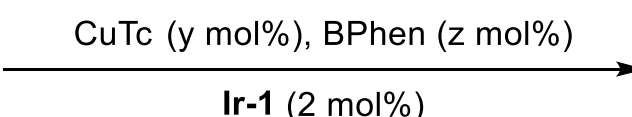
dioxane $(0.05 \mathrm{M}), 23^{\circ} \mathrm{C}, 16 \mathrm{~h}$<smiles>CN(C)C(=[Nb])N(C)O</smiles>

BTMG (2 eq.)

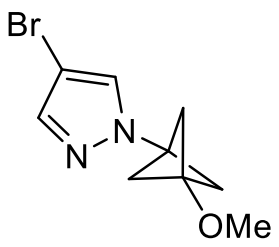

not detected

\begin{tabular}{|c|c|c|c|c|c|c|c|}
\hline Entry & $\mathbf{x}$ (eq.) & [Ir] & BTMG & $\mathbf{y}$ (mol\%) & $\mathbf{z}$ (mol\%) & LED & 18 LC/MS \\
\hline 1 & 1.0 & $\mathrm{Ir}-1$ & $\checkmark$ & 20 & 30 & $\sqrt{ }^{a}$ & no \\
\hline 2 & 2.3 & $\mathrm{X}$ & $\mathrm{X}$ & 60 & 90 & $\mathrm{X}$ & no \\
\hline
\end{tabular}

Ir-1: Ir(F-Meppy)2(dtbbpy)PF $6 .{ }^{a}$ An integrated Merck photoreactor (450 nm, 100\% LED, stir: 2000 rpm, fan: 6800 rpm) was used.

\section{VIII.B. Chan-Lam C1-N coupling attempts}

Potassium bicyclo[1.1.1]pentan-1-yltrifluoroborate was synthesized according to a literature report. ${ }^{1}$ Photodecarboxylative borylation to access C3-fluoro boryl reagents failed under reported conditions. $^{1}$

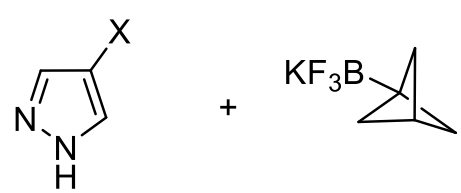

(2.2 eq.)

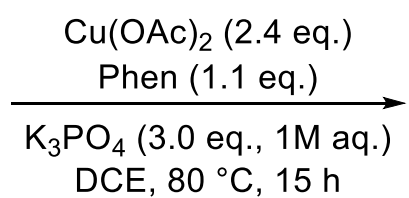

DCE, $80{ }^{\circ} \mathrm{C}, 15 \mathrm{~h}$

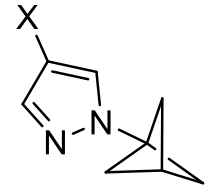

$\mathrm{X}=\mathrm{Br}, \mathrm{I}(\mathbf{6})$

not detected

General method for Chan-Lam coupling described in section II.B. was followed using 4-iodo-1Hpyrazole (30 mg, $0.15 \mathrm{mmol}, 1.0$ eq.) or 4-bromo-1H-pyrazole (23 mg, $0.15 \mathrm{mmol}, 1.0$ eq.) and potassium bicyclo[1.1.1]pentan-1-yltrifluoroborate $(54 \mathrm{mg}, 0.31 \mathrm{mmol}, 2.0$ eq.). No product formation was observed by LC/MS analysis of both reactions. 


\section{VIII.C. C3-Functionalization attempts}

\section{Attempted fluorodecarboxylation on pyrazole or hydrazine $\mathrm{BCP}-\mathrm{CO}_{2} \mathrm{H}$ Synthesis of BCP carboxylic acids}
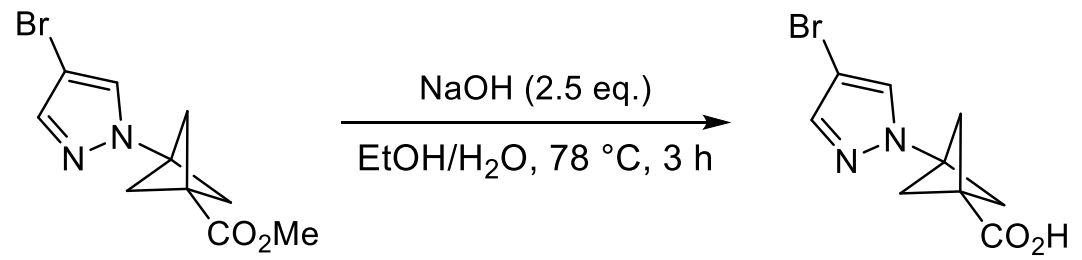

A $100 \mathrm{~mL}$ round-bottomed flask with a stir bar was charged with methyl 3-(4-bromo-1H-pyrazol1-yl)bicyclo[1.1.1]pentane-1-carboxylate (825 mg, $3.04 \mathrm{mmol}, 1.0$ eq.) and $\mathrm{EtOH}(30 \mathrm{~mL})$. After the addition of an aqueous solution of $\mathrm{NaOH}(2.5 \mathrm{M}, 3.04 \mathrm{~mL}, 7.61 \mathrm{mmol}, 2.5 \mathrm{eq}$.$) , the flask was$ connected to a reflux condenser. The reaction mixture was stirred at $78{ }^{\circ} \mathrm{C}$ for $3 \mathrm{~h}$ and then allowed to cool to ambient temperature. The volatiles were then removed under vacuum and the resulting yellow pale solid was dissolved in water $(50 \mathrm{~mL})$. The mixture was acidified with $\mathrm{HCl}(1$ $\mathrm{N})$ to $\mathrm{pH}=7$ and formation of a white solid was observed. Water (100 mL) was added and the organic layer was extracted with $\mathrm{DCM}(100 \mathrm{~mL} \times 3)$, dried over $\mathrm{Na}_{2} \mathrm{SO}_{4}$, filtered, and concentrated under vacuum. 3-(4-Bromo-1H-pyrazol-1-yl)bicyclo[1.1.1]pentane-1-carboxylic acid (594 mg, $2.311 \mathrm{mmol}, 76 \%$ yield) was obtained as a white solid. ${ }^{1} \mathrm{H}$ NMR (600 MHz, DMSO- $\left.d_{6}\right): \delta 8.12$ (s, 1H), 7.60 (s, 1H), 2.43 (s, 6H). ${ }^{13} \mathrm{C}\left\{{ }^{1} \mathrm{H}\right\}$ NMR (151 MHz, CDCl3): 170.2, 139.9, 129.0, 92.5, 53.7, 50.6, 33.6.
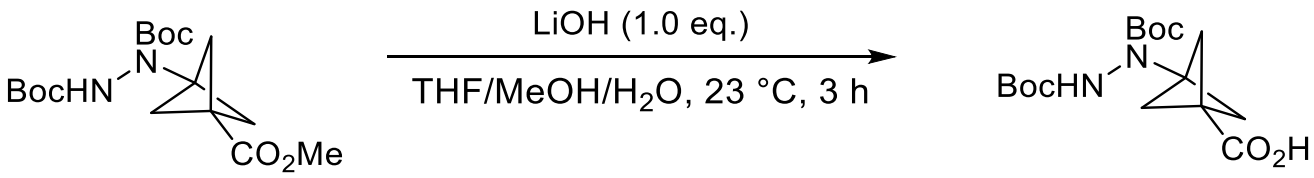

Di-tert-butyl 1-(3-(methoxycarbonyl)bicyclo[1.1.1]pentan-1-yl)hydrazine-1,2-dicarboxylate was synthesized following a literature procedure. ${ }^{14}$ A $50 \mathrm{~mL}$ round-bottomed flask with a stir bar was charged with di-tert-butyl 1-(3-(methoxycarbonyl)bicyclo[1.1.1]pentan-1-yl)hydrazine-1,2- 
dicarboxylate (400 mg, $1.12 \mathrm{mmol}, 1.0$ eq.), LiOH (47 mg, $1.12 \mathrm{mmol}, 1.0$ eq.), $\mathrm{MeOH}(3 \mathrm{~mL})$, THF (3 mL) and $\mathrm{H}_{2} \mathrm{O}(3 \mathrm{~mL})$. The reaction mixture was stirred at $23^{\circ} \mathrm{C}$ for $16 \mathrm{~h}$ and then the resulting mixture was acidified with $\mathrm{HCl}(1 \mathrm{~N})$ to $\mathrm{pH}=7$. The organic layer was extracted with ethyl acetate $(20 \mathrm{~mL} \times 2)$ and the combined organic layers were washed with water $(10 \mathrm{~mL})$ and brine $(10 \mathrm{~mL})$, dried over $\mathrm{Na}_{2} \mathrm{SO}_{4}$, filtered and concentrated under reduced pressure to give 3-(1,2bis(tert-butoxycarbonyl)hydrazineyl)bicyclo[1.1.1]pentane-1-carboxylic acid (354 mg, 1.03 mmol, $92 \%$ yield) as a white solid. Signal broadening and additional splitting was observed due to the presence of amide rotamers. ${ }^{1} \mathrm{H}$ NMR (600 MHz, DMSO- $\left.\boldsymbol{d}_{6}\right): \delta 12.44(\mathrm{~s}, 1 \mathrm{H}), 9.05-8.58(\mathrm{~m}, 1 \mathrm{H})$, $2.14(\mathrm{~s}, 2 \mathrm{H}), 2.11(\mathrm{~s}, 4 \mathrm{H}), 1.43-1.38(\mathrm{~m}, 18 \mathrm{H}) .{ }^{13} \mathrm{C}\left\{{ }^{1} \mathrm{H}\right\}$ NMR (151 MHz, DMSO- $\left.d_{6}\right):$ 170.8, 155.2, 153.9, 79.4, 79.3, 66.4, 28.0, 27.9, 27.8. 


\section{Fluorodecarboxylation attempts}

Table S8. Selected fluorodecarboxylation attempts of 3-(4-Bromo-1H-pyrazol-1yl)bicyclo[1.1.1]pentane-1-carboxylic acid.
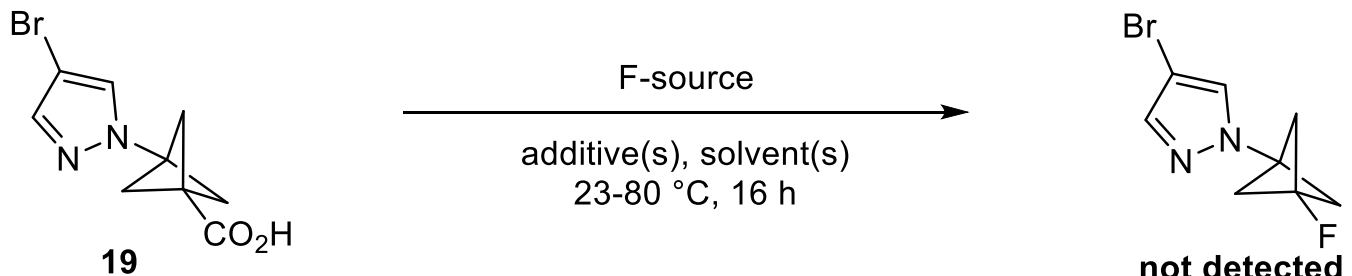

\begin{tabular}{|c|c|c|c|c|c|}
\hline Entry & F-source & Additive(s) & Solvent(s) ${ }^{a}$ & $M(\mathrm{~mol} / \mathrm{L})$ & $\mathrm{T}\left({ }^{\circ} \mathrm{C}\right)$ \\
\hline 1 & Selectfluor (2.5 eq.) & $\mathrm{AgNO}_{3}(7.5 \mathrm{~mol} \%)$ & $\mathrm{H}_{2} \mathrm{O}$ & 0.2 & 65 \\
\hline 2 & Selectfluor (1.8 eq.) & $\mathrm{AgNO}_{3}(20 \mathrm{~mol} \%)$ & $\mathrm{H}_{2} \mathrm{O}$ & 0.2 & 80 \\
\hline 3 & Selectfluor (2.0 eq.) & $\mathrm{AgNO}_{3}(30 \mathrm{~mol} \%)$ & Acetone/ $\mathrm{H}_{2} \mathrm{O} 1: 1$ & 0.1 & 80 \\
\hline 4 & Selectfluor (2.0 eq.) & $\begin{array}{l}\mathrm{AgNO}_{3}(30 \mathrm{~mol} \%) \\
+\mathrm{Na}_{2} \mathrm{~S}_{2} \mathrm{O}_{8}(0.5 \text { eq. })\end{array}$ & Acetone/ $\mathrm{H}_{2} \mathrm{O} 1: 1$ & 0.1 & 80 \\
\hline 5 & Selectfluor (4.0 eq.) & $\mathrm{AgNO}_{3}(30 \mathrm{~mol} \%)$ & Acetone/ $\mathrm{H}_{2} \mathrm{O} 1: 1$ & 0.1 & 70 \\
\hline 6 & Selectfluor (4.0 eq.) & $\mathrm{AgNO}_{3}(30 \mathrm{~mol} \%)$ & 3-Pentanone/ $\mathrm{H}_{2} \mathrm{O}$ 1:1 & 0.1 & 100 \\
\hline 7 & $\mathrm{XeF}_{2}$ (4.0 eq.) & $\mathrm{X}$ & DCE & 0.1 & 23 \\
\hline $8^{b}$ & Selectfluor (3.0 eq.) & $\begin{array}{c}\text { Ir-3 }(1 \mathrm{~mol} \%)^{c} \\
+\mathrm{Na}_{2} \mathrm{HPO}_{4}(2.0 \text { eq. })\end{array}$ & $\mathrm{MeCN} / \mathrm{H}_{2} \mathrm{O} 1: 1$ & 0.1 & 23 \\
\hline
\end{tabular}

a Solvents were degassed by sparging with $\mathrm{N}_{2} .{ }^{b} \mathrm{An}$ integrated Merck photoreactor ( $450 \mathrm{~nm}, 100 \% \mathrm{LED}$, stir: 2000 rpm, fan: 6800 rpm) was used. ${ }^{9}$ Ir-3: $\left.\left(\operatorname{Ir}\left[\mathrm{dF}\left(\mathrm{CF}_{3}\right)\right)_{p p y}\right]_{2}(\mathrm{dtbpy})\right) \mathrm{PF}_{6}$.

General procedure. To a scintillation vial with a stir bar was added 3-(4-Bromo-1H-pyrazol-1yl)bicyclo[1.1.1]pentane-1-carboxylic acid (20 mg, $0.078 \mathrm{mmol}, 1.0$ eq.), F-source and additive(s). The vial was capped with a Teflon septum and submitted to three vacuum $/ \mathrm{N}_{2}$ refill cycles. Degassed solvent(s) was then added via syringe under a positive pressure of $N_{2}$. The resulting mixture was stirred at the corresponding temperature for $16 \mathrm{~h}$. An aliquot of the reaction crude was analyzed by LC/MS. For all entries in Table S8, unreacted starting material was detected and 
either none or traces of desired fluorinated product were detected. Note 1: conditions shown in Table S8 were inspired by a literature report. ${ }^{15}$ Note 2: conditions employed in entry 1 proved to be effective for the decarboxylative fluorination of bicyclo[1.1.1]pentane-1,3dicarboxylic acid. ${ }^{15 a}$

Table S9. Selected fluorodecarboxylation attempts of 3-(1,2-bis(tertbutoxycarbonyl)hydrazineyl)bicyclo[1.1.1]pentane-1-carboxylic acid.
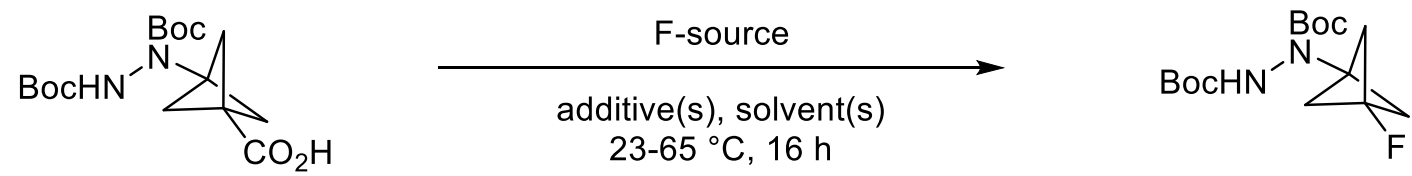

\begin{tabular}{|c|c|c|c|c|c|}
\hline Entry & F-source & Additive(s) & Solvent(s) ${ }^{a}$ & M (mol/L) & $\mathrm{T}\left({ }^{\circ} \mathrm{C}\right)$ \\
\hline 1 & Selectfluor (2.5 eq.) & $\mathrm{AgNO}_{3}(1.0$ eq. $)$ & $\mathrm{H}_{2} \mathrm{O}$ & 0.2 & 65 \\
\hline $2^{b}$ & Selectfluor (3.0 eq.) & $\begin{array}{c}\text { Ir-3 }(1 \mathrm{~mol} \%)^{c} \\
+\mathrm{Na}_{2} \mathrm{HPO}_{4}(2.0 \text { eq. })\end{array}$ & $\mathrm{MeCN} / \mathrm{H}_{2} \mathrm{O} 1: 1$ & 0.1 & 23 \\
\hline $3^{b}$ & Selectfluor (6.0 eq.) & $\begin{array}{c}\text { Ir-3 }(1 \mathrm{~mol} \%)^{c} \\
+\mathrm{Na}_{2} \mathrm{HPO}_{4}(4.0 \text { eq. })\end{array}$ & $\mathrm{MeCN} / \mathrm{H}_{2} \mathrm{O} 1: 1$ & 0.1 & 23 \\
\hline
\end{tabular}

aSolvents were degassed by sparging with $\mathrm{N}_{2} .{ }^{b} \mathrm{An}$ integrated Merck photoreactor (450 nm, $100 \%$ LED, stir: 2000 rpm, fan: $6800 \mathrm{rpm})$ was used. ${ }^{9} \mathrm{rr}-3:\left(\operatorname{Ir}\left[\mathrm{dF}\left(\mathrm{CF}_{3}\right) \mathrm{ppy}\right]_{2}(\mathrm{dtbpy})\right) \mathrm{PF}_{6}$.

General procedure. To a scintillation vial with a stir bar was added 3-(1,2-bis(tertbutoxycarbonyl)hydrazineyl)bicyclo[1.1.1]pentane-1-carboxylic acid (50 mg, 0.15 mmol, 1.0 eq.), F-source and additive(s). The vial was capped with a Teflon septum and submitted to three vacuum $/ \mathrm{N}_{2}$ refill cycles. Degassed solvent(s) was then added via syringe under a positive pressure of $\mathrm{N}_{2}$. The resulting mixture was stirred at the corresponding temperature for $16 \mathrm{~h}$. An aliquot of the reaction crude was analyzed by LC/MS. For all entries in Table S9, unreacted starting material was detected and either none or traces of desired fluorinated product were detected. 


\section{Attempted fluorodehydrogenation on 6}

Table S10. Selected fluorodehydrogenation attempts of 6 .

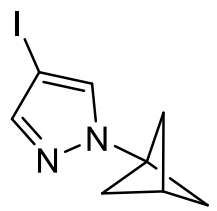

6

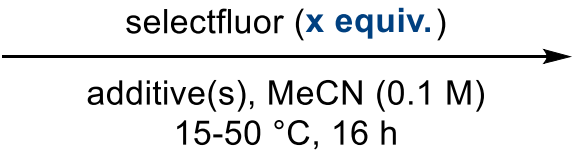

$15-50{ }^{\circ} \mathrm{C}, 16 \mathrm{~h}$

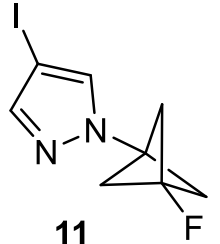

(not detected)

\begin{tabular}{|c|c|c|c|c|}
\hline Entry & x equiv. & Additive & Solvent(s) & $\mathbf{T}\left({ }^{\circ} \mathbf{C}\right)$ \\
\hline 1 & 3 & $\mathrm{BEt}_{3}(40 \mathrm{~mol} \%)$ & MeCN & 50 \\
\hline 2 & 3 & $\mathrm{~V}_{2} \mathrm{O}_{3}(20 \mathrm{~mol} \%)$ & MeCN & 15 \\
\hline 3 & 2.5 & $\mathrm{NDHPI}(2.5 \mathrm{~mol} \%)$ & MeCN & 50 \\
\hline
\end{tabular}

NDHPI = N-hydroxyphthalimide.

General procedure. To a scintillation vial with a stir bar was added $6(40 \mathrm{mg}, 0.15 \mathrm{mmol}, 1.0$ eq.), F-source and additive. The vial was capped with a Teflon septum and submitted to three vacuum $/ \mathrm{N}_{2}$ refill cycles. Degassed $\mathrm{MeCN}(1.5 \mathrm{~mL})$ was then added via syringe under a positive pressure of $\mathrm{N}_{2}$. The resulting mixture was stirred at the corresponding temperature for $16 \mathrm{~h}$. An aliquot of the reaction crude was analyzed by LC/MS. For all entries in Table S10, remained starting material was detected and either none or traces of 11 were detected. Note 1: conditions shown in Table S10 were inspired by a literature report. ${ }^{16}$ 


\section{VIII.D. Attempted synthesis of BCP pyrazole intermediates \\ Attempted synthesis of BCP-boryl intermediate}

Table S11. Attempted synthesis of BCP-boryl intermediate via Chan-Lam coupling.

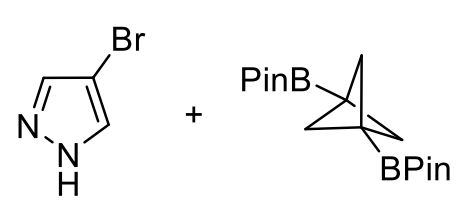

(2 eq.)

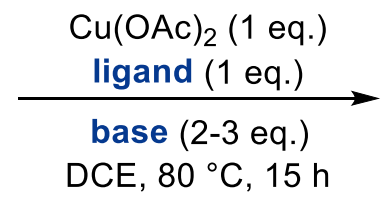

DCE, $80^{\circ} \mathrm{C}, 15 \mathrm{~h}$

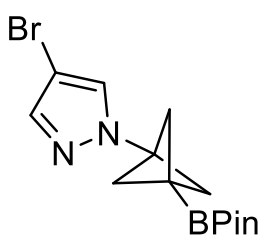

BCPP-BPin

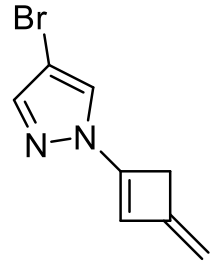

diene

\begin{tabular}{|c|c|c|c|c|}
\hline Entry & ligand & base & BCPP-BPin & diene \\
\hline 1 & \\
\hline 2 &
\end{tabular}

General method for Chan-Lam coupling described in section II.B. was followed for entry 1. Entry 2 was carried out as follows. ${ }^{17}$ To a $5 \mathrm{~mL}$ scintillation vial containing a stir bar, $\mathrm{Cu}(\mathrm{OAc})_{2}(45 \mathrm{mg}$, $0.25 \mathrm{mmol}, 1.0$ eq.), 2,2'-bipyridine (39 mg, $0.25 \mathrm{mmol}, 1.0$ eq.), $\mathrm{Na}_{2} \mathrm{CO}_{3}$ (53 mg, $0.50 \mathrm{mmol}, 2.0$ eq.), 1,3-bis(4,4,5,5-tetramethyl-1,3,2-dioxaborolan-2-yl)bicyclo[1.1.1]pentane (160 mg, 0.50 mmol, 2.0 eq.) and 4-bromo-1 $\mathrm{H}$-pyrazole ( $37 \mathrm{mg}, 0.25 \mathrm{mmol}, 1.0$ eq.) were added. The vial was capped with a Teflon septum and submitted to three vacuum $/ \mathrm{N}_{2}$ refill cycles. Anhydrous 1,2dichloroethane $(2.5 \mathrm{~mL})$ was added via syringe under a positive pressure of $\mathrm{N}_{2}$. The resulting mixture was stirred at $80^{\circ} \mathrm{C}$ for $15 \mathrm{~h}$. The reaction mixture was analyzed by LC/MS. No desired BCPP-BPin product was detected and diene product was detected instead as the major product. The crude mixture was directly purified by silica gel chromatography with $0-70 \%$ EtOAc in hexanes as eluent affording 4-bromo-1-(3-methylenecyclobut-1-en-1-yl)-1H-pyrazole (diene) as 
a white solid. ${ }^{1} \mathrm{H}$ NMR (600 MHz, $\left.\mathbf{C D C l}_{3}\right)$ : $\delta 7.67(\mathrm{~s}, 1 \mathrm{H}), 7.64(\mathrm{~s}, 1 \mathrm{H}), 6.00(\mathrm{~s}, 1 \mathrm{H}), 4.85(\mathrm{~s}, 1 \mathrm{H})$, $4.67(\mathrm{~s}, 1 \mathrm{H}), 3.36(\mathrm{~s}, 2 \mathrm{H})$.

\section{Attempted synthesis of BCP-tosylate intermediate}

Table S12. Attempted synthesis of BCP-OTs intermediate
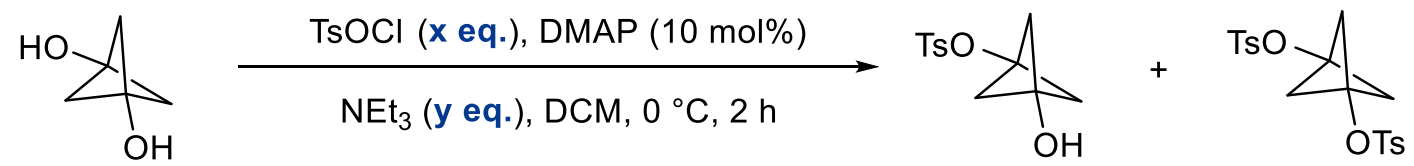

\begin{tabular}{|c|c|c|c|c|}
\hline \multicolumn{1}{|c|}{} & \multicolumn{2}{c|}{ bistosylate } & monotosylate \\
\hline Entry & $\mathbf{x}$ & $\mathbf{y}$ & bistosylate & monostosylaye $^{a}$ \\
\hline 1 & 1 & 1.1 & traces & $73 \%$ \\
\hline 2 & 2 & 2 & traces & \\
\hline
\end{tabular}

alsolated yield.

\section{Synthesis of bicyclo[1.1.1]pentane-1,3-diyl bis(4-(trifluoromethyl)benzenesulfonate (entry}

2 as reference). To a $5 \mathrm{~mL}$ scintillation vial with a stir bar was added bicyclo[1.1.1]pentane-1,3diol (15 mg, 0.15 mmol, 1.0 eq.), 4-dimethylaminopyridine (DMAP, 1.83 mg, 0.02 mmol, $10 \mathrm{~mol} \%$ ) and 4-(trifluoromethyl)benzenesulfonyl chloride (73 mg, $0.30 \mathrm{mmol}, 2.0 \mathrm{eq}$.). The vial was capped with a Teflon septum and submitted to three vacuum $/ \mathrm{N}_{2}$ refill cycles. Then, anhydrous DCM (750 $\mu \mathrm{L})$ and anhydrous triethylamine $\left(42 \mu \mathrm{L}, 0.300 \mathrm{mmol}, 2.0\right.$ eq.) were added at $0{ }^{\circ} \mathrm{C}$ and the reaction mixture was stirred at this temperature for $2 \mathrm{~h}$. Note: For both entry 1 and 2, LC/MS analysis after 40 min showed formation of bistosylate product and only traces of monotosylate product. Purification of the crude reaction mixture by silica gel chromatography with $0-50 \%$ EtOAc in hexanes as eluent afforded bicyclo[1.1.1]pentane-1,3-diyl bis(4-methylbenzenesulfonate) (bistosylate, $57 \mathrm{mg}, 0.110 \mathrm{mmol}, 73 \%$ yield) as a white crystalline solid. ${ }^{1} \mathbf{H}$ NMR (600 MHz, $\left.\mathrm{CDCl}_{3}\right): \delta 8.02(\mathrm{~d}, J=8.3 \mathrm{~Hz}, 4 \mathrm{H}), 7.84(\mathrm{~d}, J=8.3 \mathrm{~Hz}, 4 \mathrm{H}), 2.45(\mathrm{~s}, 6 \mathrm{H}), 1.53(\mathrm{~s}, 6 \mathrm{H})$. 


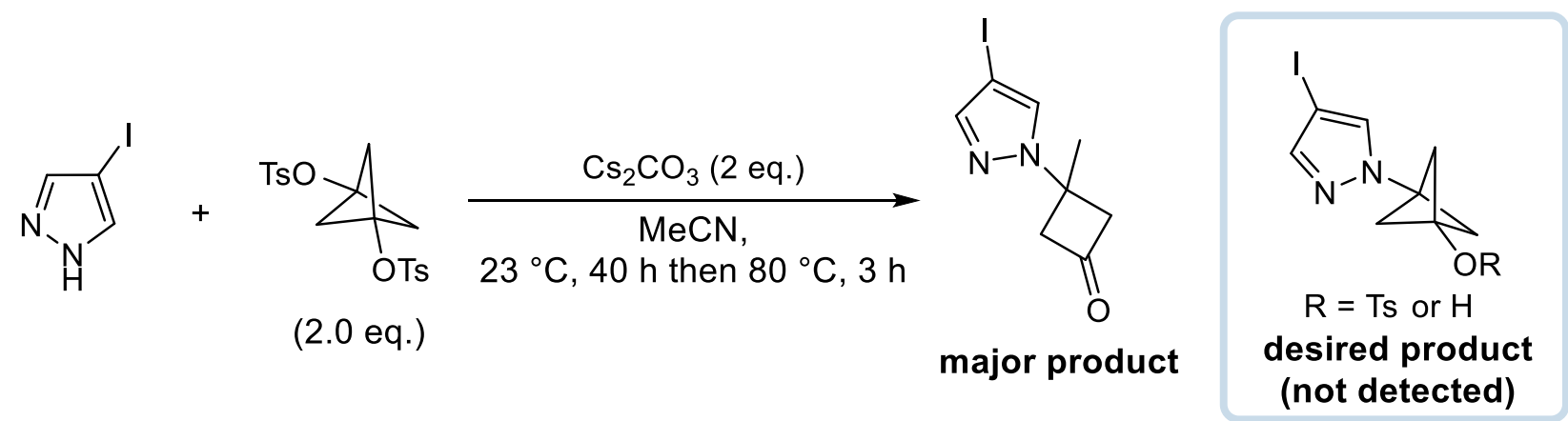

Monosubstitution attempt of bicyclo[1.1.1]pentane-1,3-diyl bis(4(trifluoromethyl)benzenesulfonate. To a $5 \mathrm{~mL}$ scintillation vial with a stir bar was added 4-iodo1H-pyrazole (20 mg, $0.11 \mathrm{mmol}, \quad 1.0$ eq.), 2 bicyclo[1.1.1]pentane-1,3-diyl bis(4(trifluoromethyl)benzenesulfonate (54 mg, $0.11 \mathrm{mmol}, 1.0 \mathrm{eq}$.) and $\mathrm{Cs}_{2} \mathrm{CO}_{3}(68 \mathrm{mg}, 0.21 \mathrm{mmol}$. 2.0 eq.). The vial was capped with a Teflon septum and submitted to three vacuum $/ \mathrm{N}_{2}$ refill cycles. Then, anhydrous MeCN (1.1 mL) was added under a $\mathrm{N}_{2}$ atmosphere and the reaction mixture was stirred at $23^{\circ} \mathrm{C}$ for $40 \mathrm{~h}$. LC/MS analysis showed low conversion to 3-(4-iodo-1H-pyrazol-1yl)-3-methylcyclobutan-1-one $\quad(10: 1 \quad$ 4-iodopyrazole/3-(4-iodo-1H-pyrazol-1-yl)-3methylcyclobutan-1-one) and no formation of desired product. The reaction was then stirred at 80 ${ }^{\circ} \mathrm{C}$ for $3 \mathrm{~h}$ and LCMS analysis showed increased amount of 3-(4-iodo-1H-pyrazol-1-yl)-3methylcyclobutan-1-one (1:1 4-iodopyrazole/3-(4-iodo-1H-pyrazol-1-yl)-3-methylcyclobutan-1one) but no formation of desired product. Purification of the crude reaction mixture by silica gel chromatography with 0-50\% EtOAc in hexanes as eluent afforded 3-(4-iodo-1H-pyrazol-1-yl)-3methylcyclobutan-1-one (10 mg, $0.04 \mathrm{mmol}, 35 \%$ yield) as a white crystalline solid. ${ }^{1} \mathbf{H}$ NMR (600 $\left.\mathbf{M H z}, \mathrm{CDCl}_{3}\right): \delta 7.63(\mathrm{~s}, 1 \mathrm{H}), 7.58(\mathrm{~s}, 1 \mathrm{H}), 3.99-3.77(\mathrm{~m}, 2 \mathrm{H}), 3.44-3.10(\mathrm{~m}, 2 \mathrm{H}), 1.89(\mathrm{~s}, 3 \mathrm{H})$. 
IX. NMR spectra
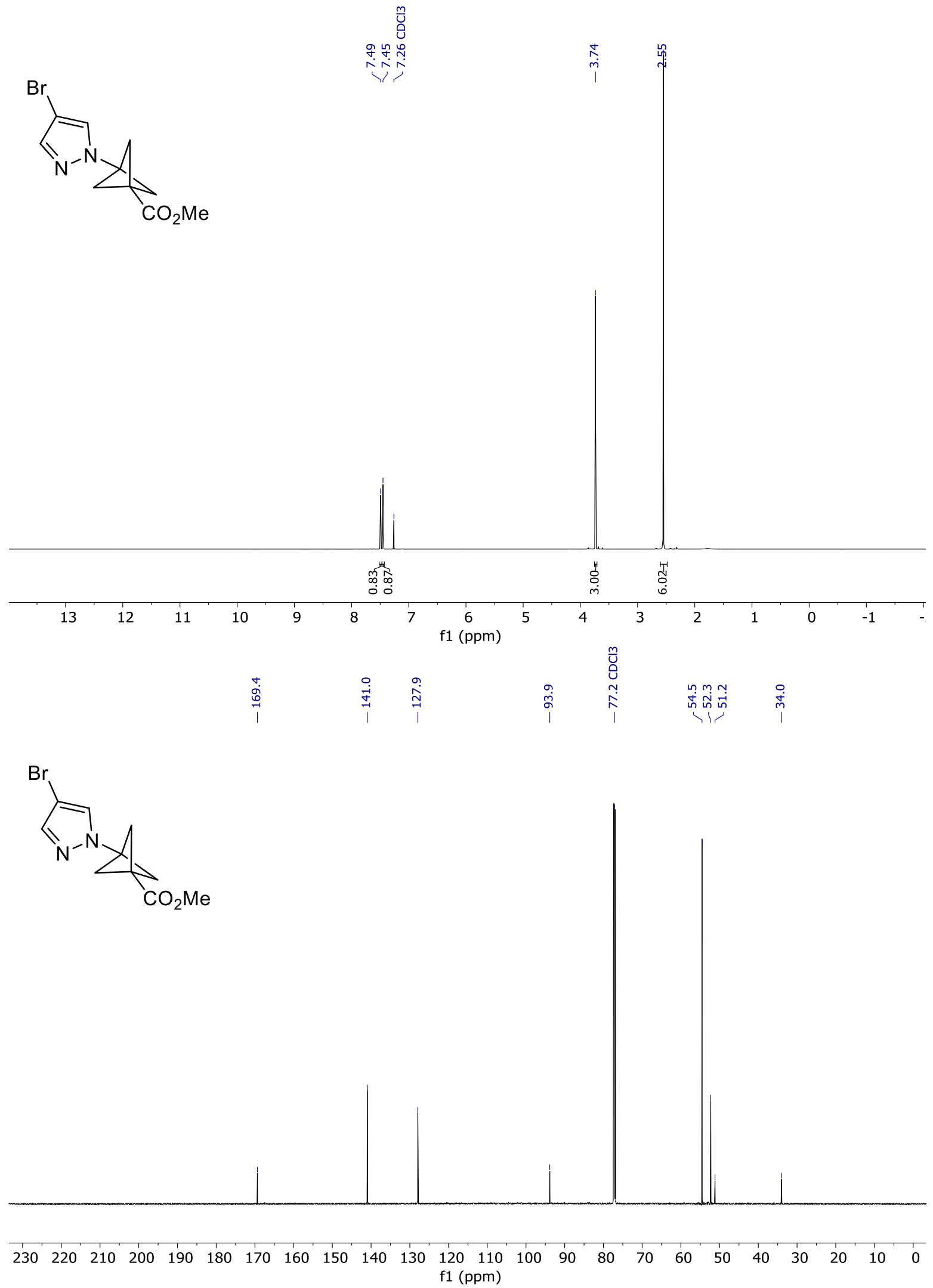

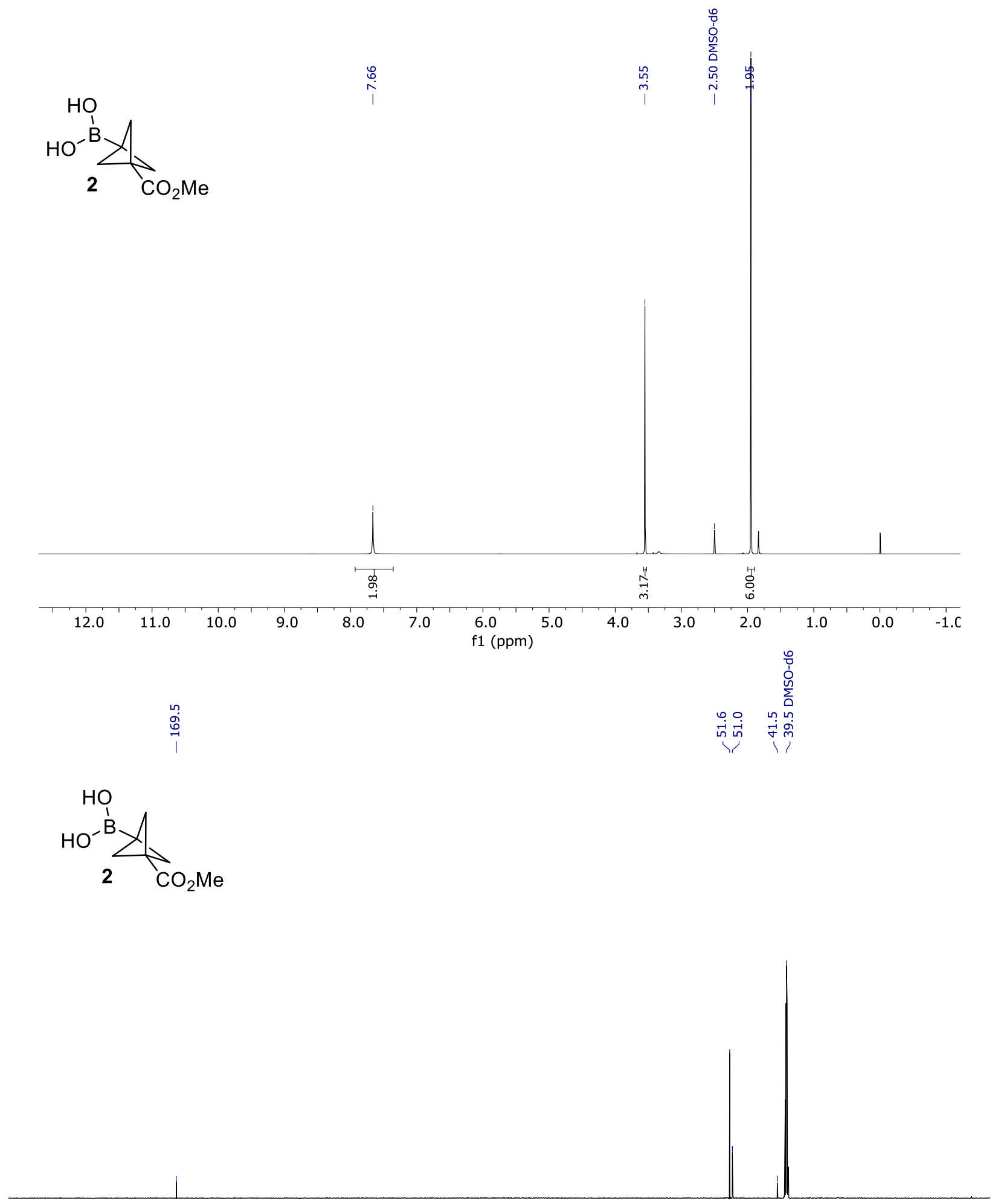

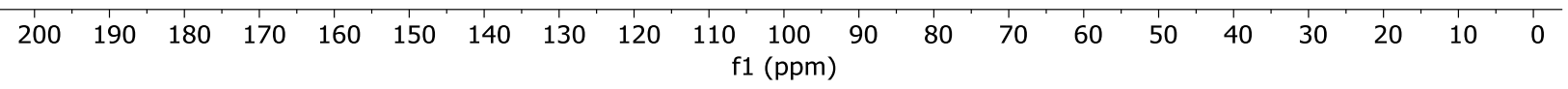



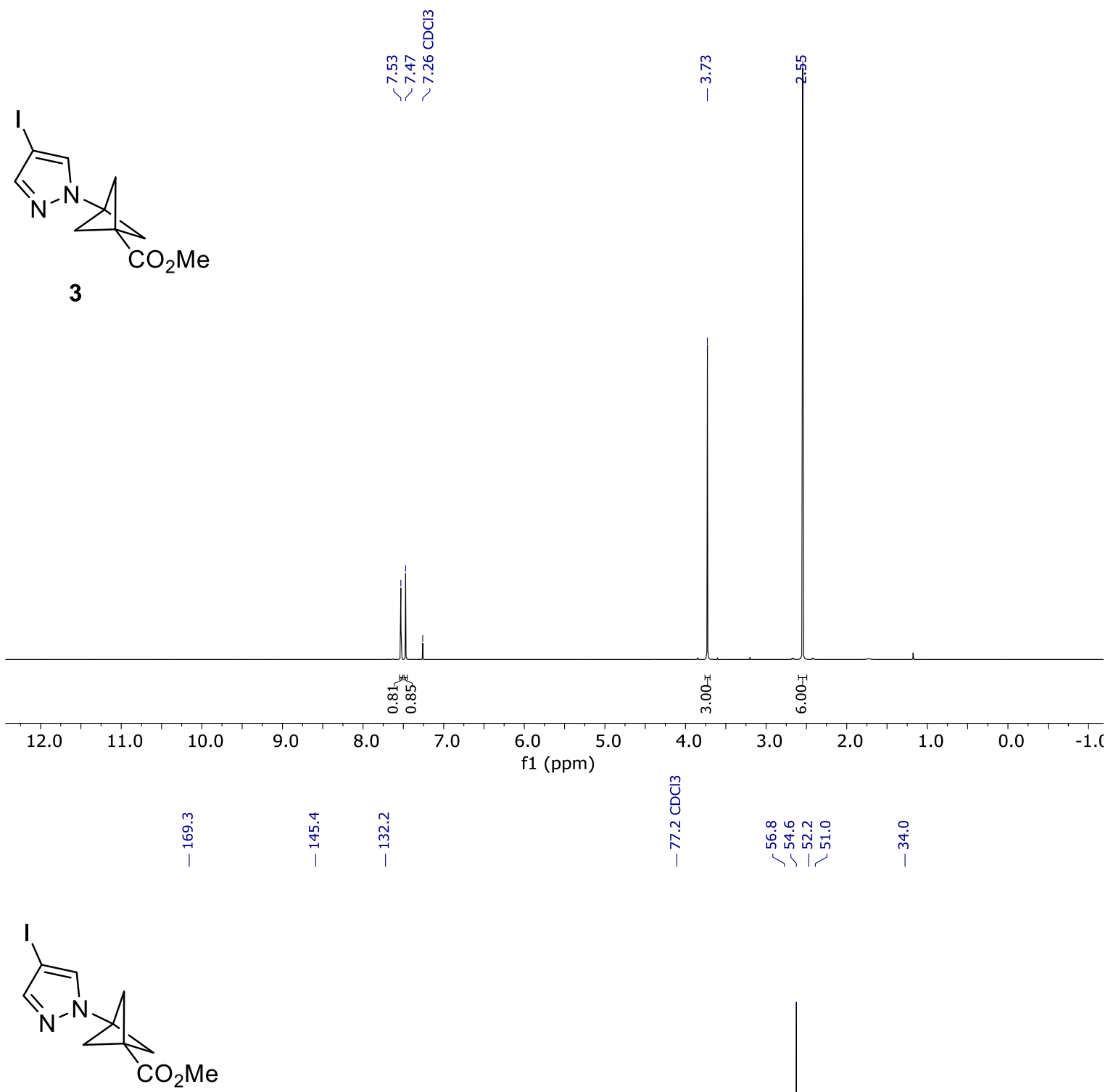

3

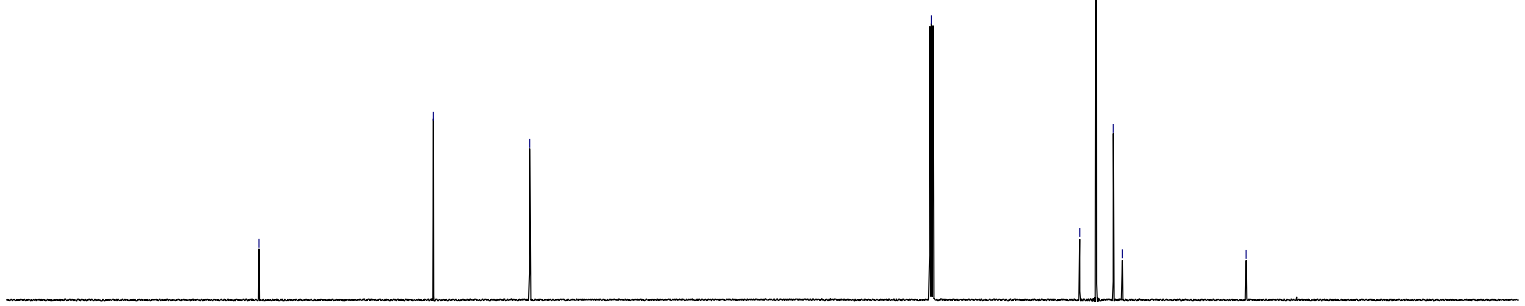

20

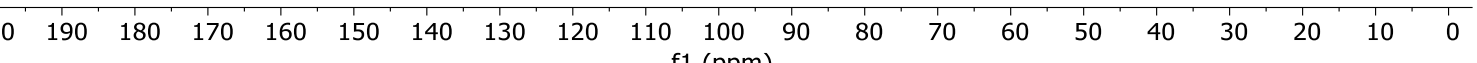




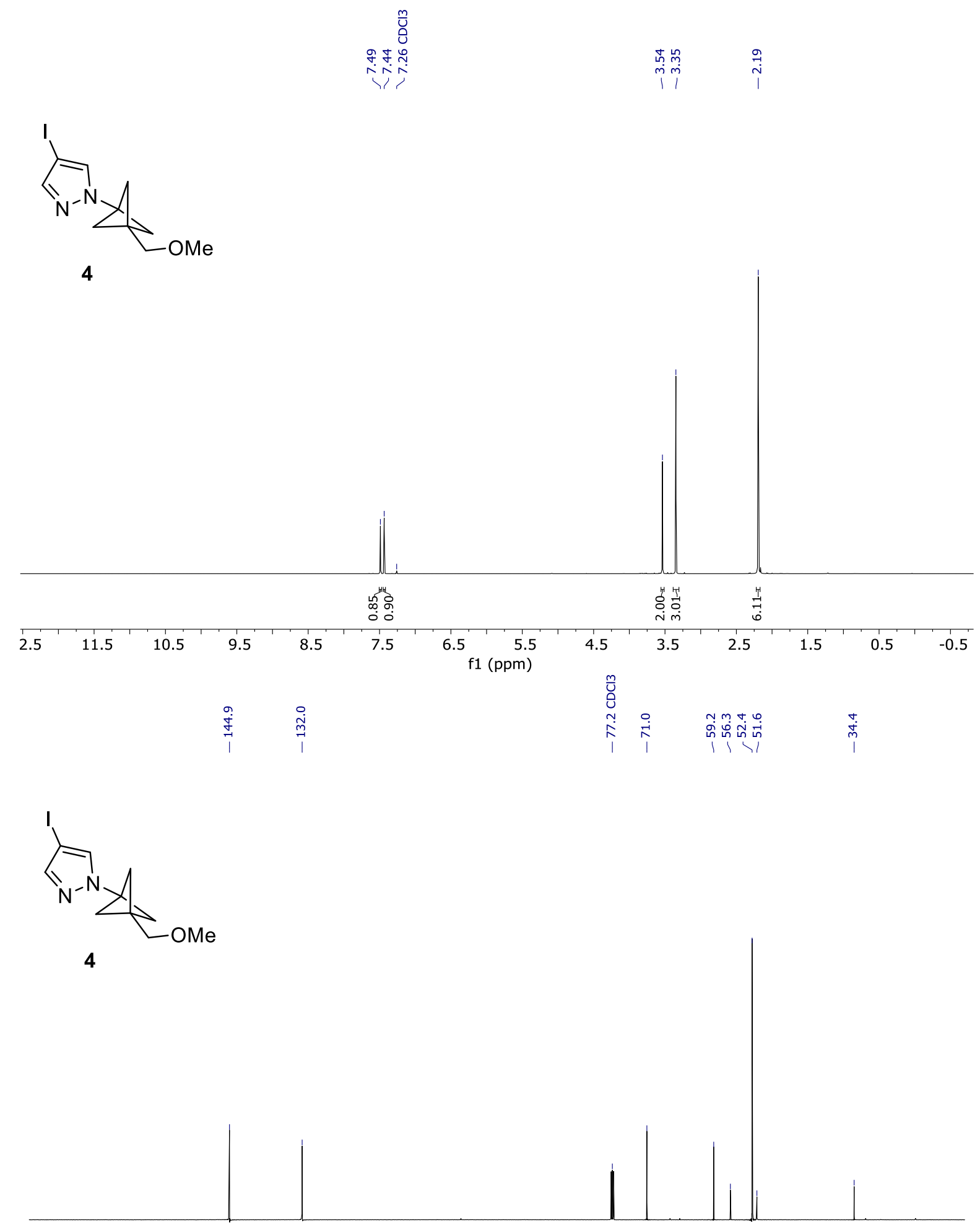

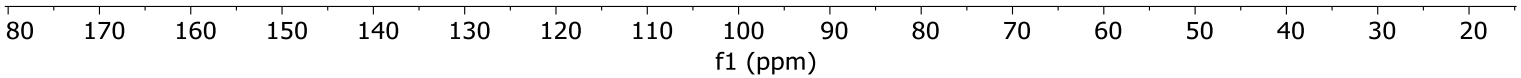



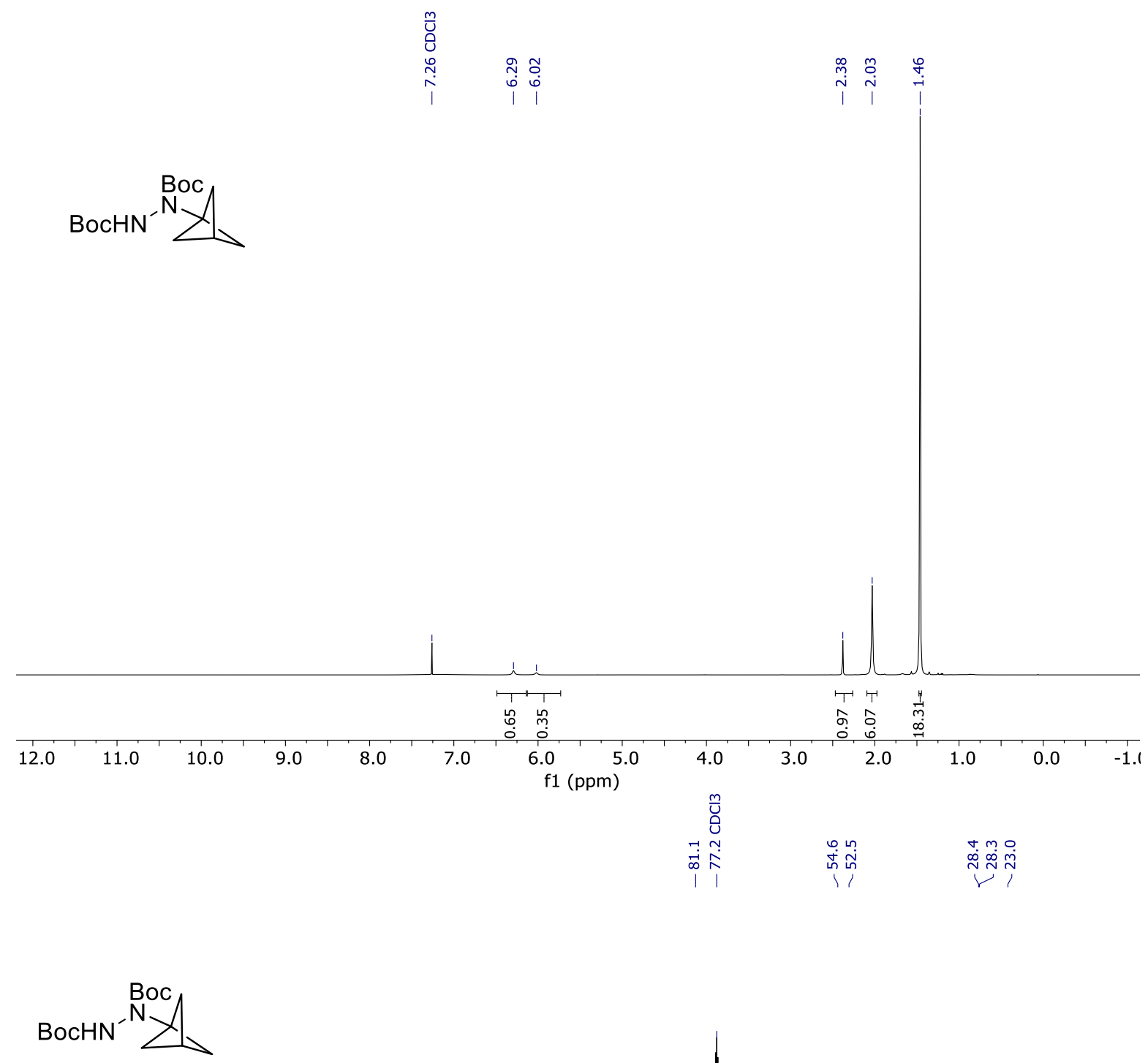

$\begin{array}{llllllllllllllllllllll}200 & 190 & 180 & 170 & 160 & 150 & 140 & 130 & 120 & 110 & 100 & 90 & 80 & 70 & 60 & 50 & 40 & 30 & 20 & 10 & 0\end{array}$ 

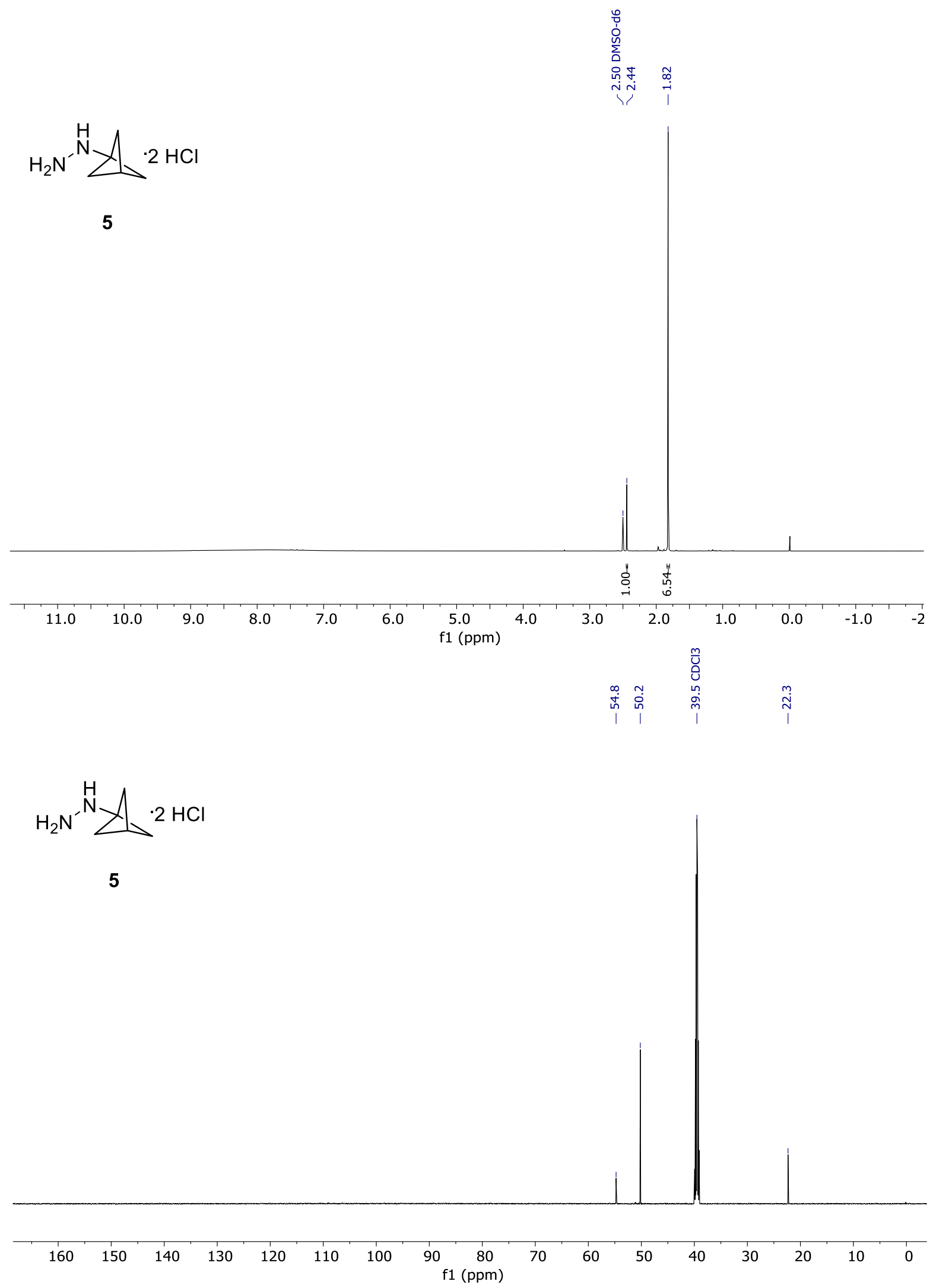

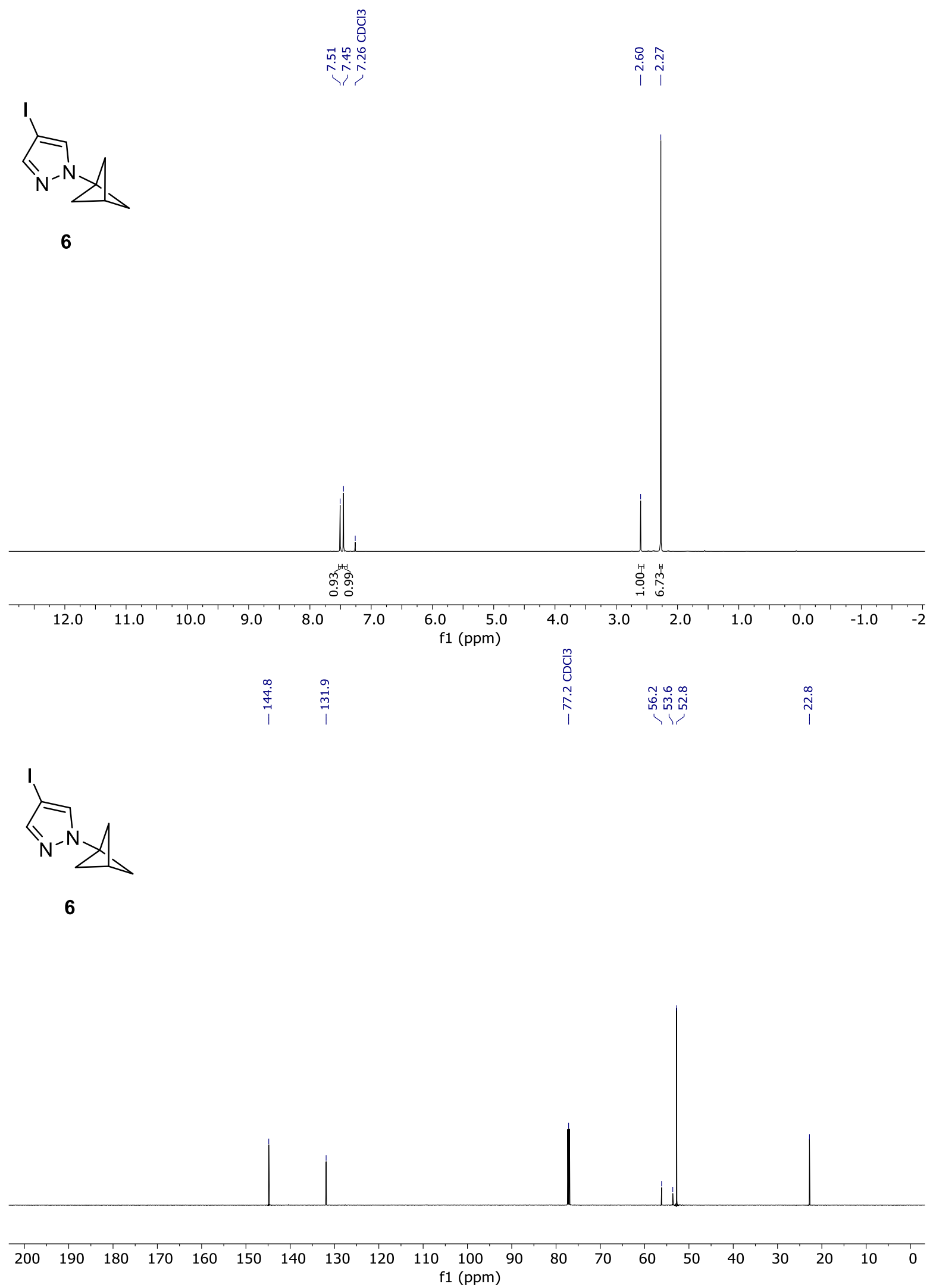


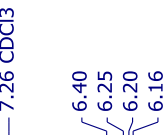

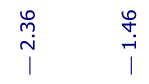

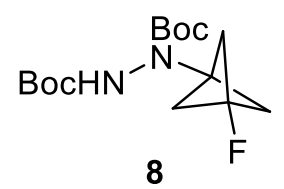

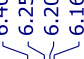

$$
\text { i }
$$

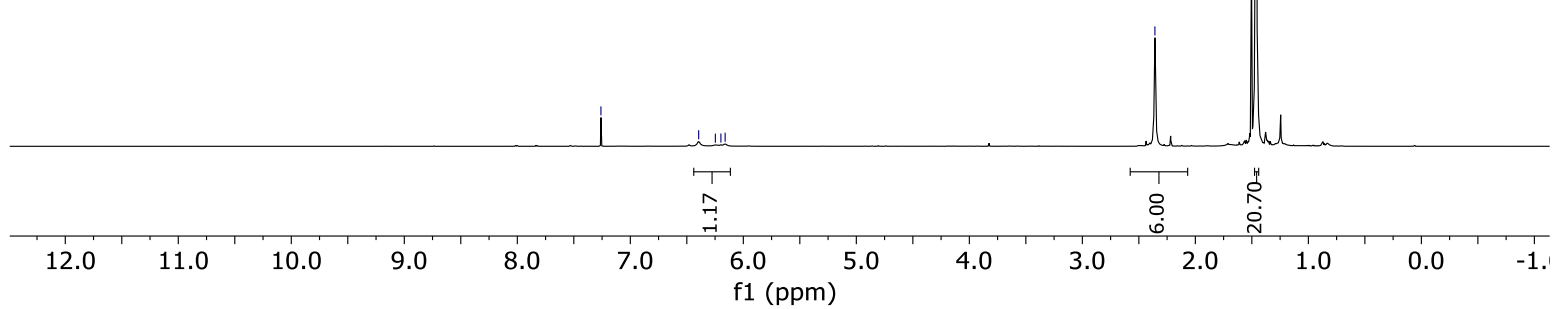



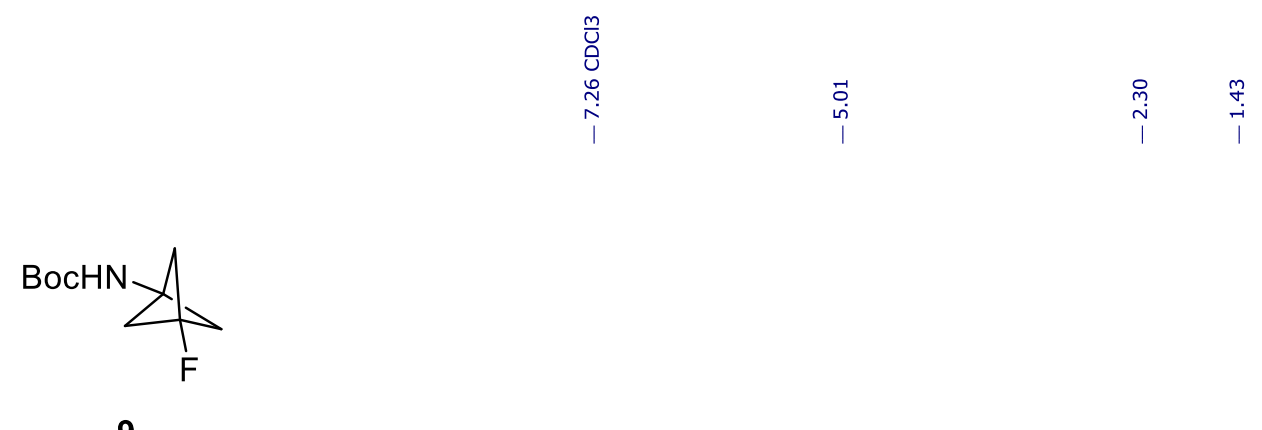

9

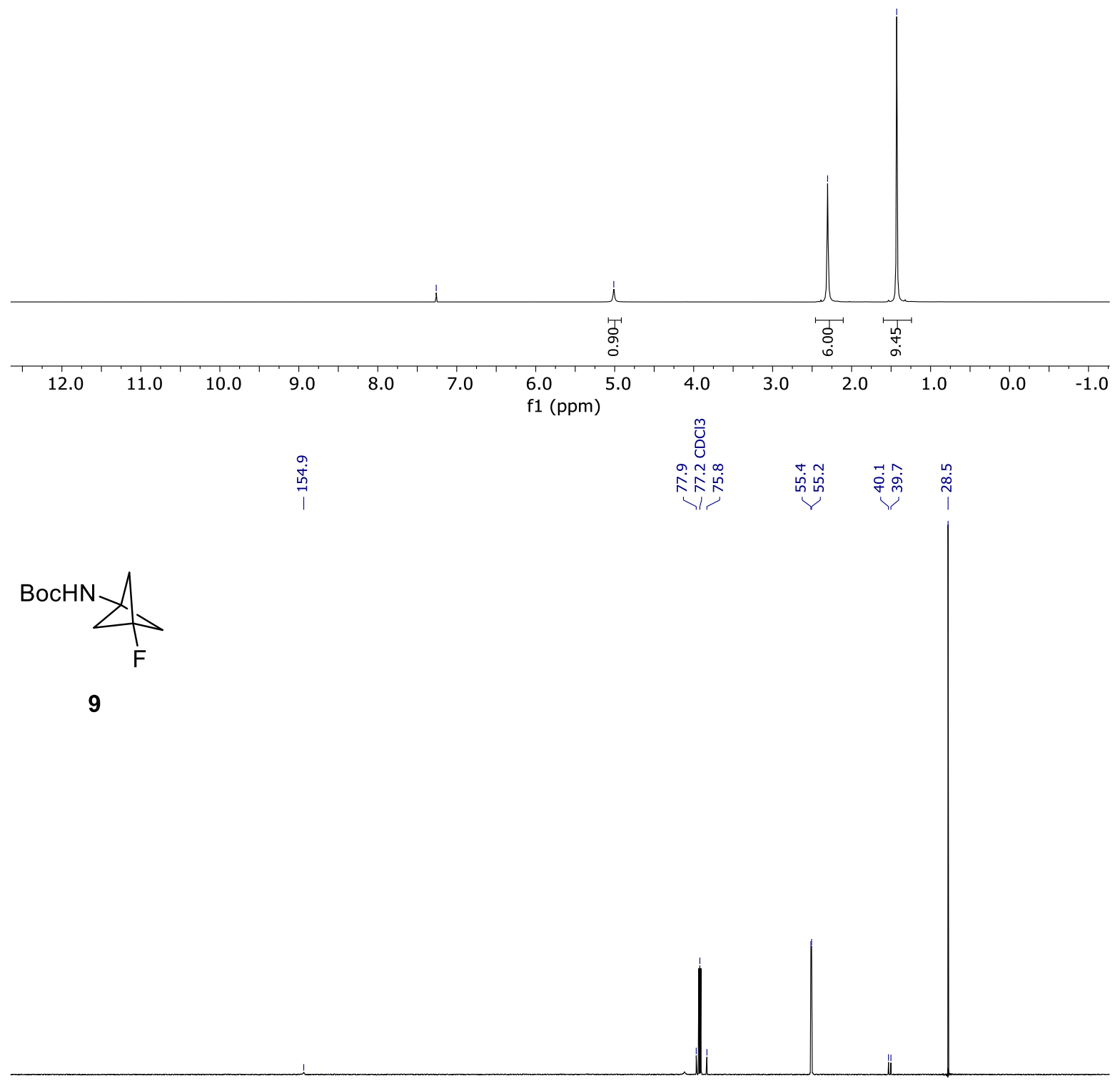

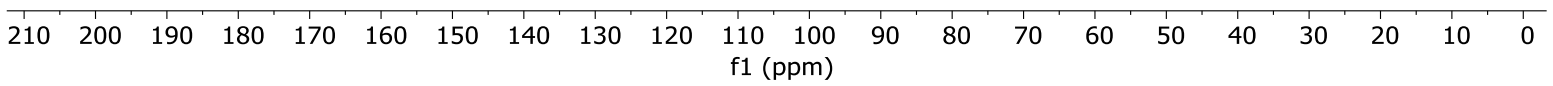




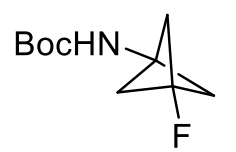

9

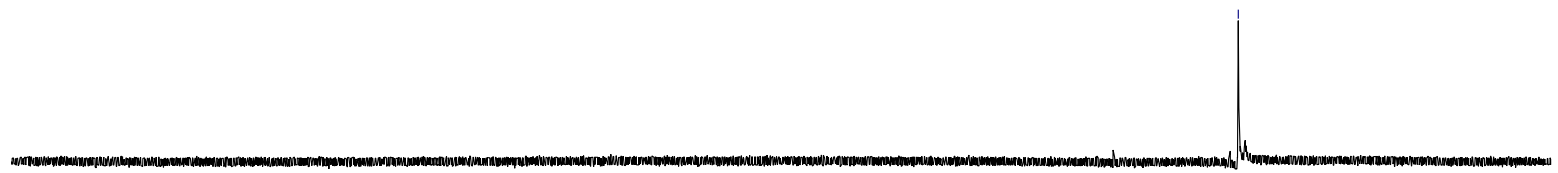

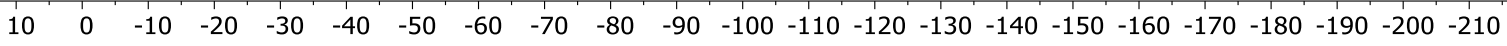
f1 (ppm) 

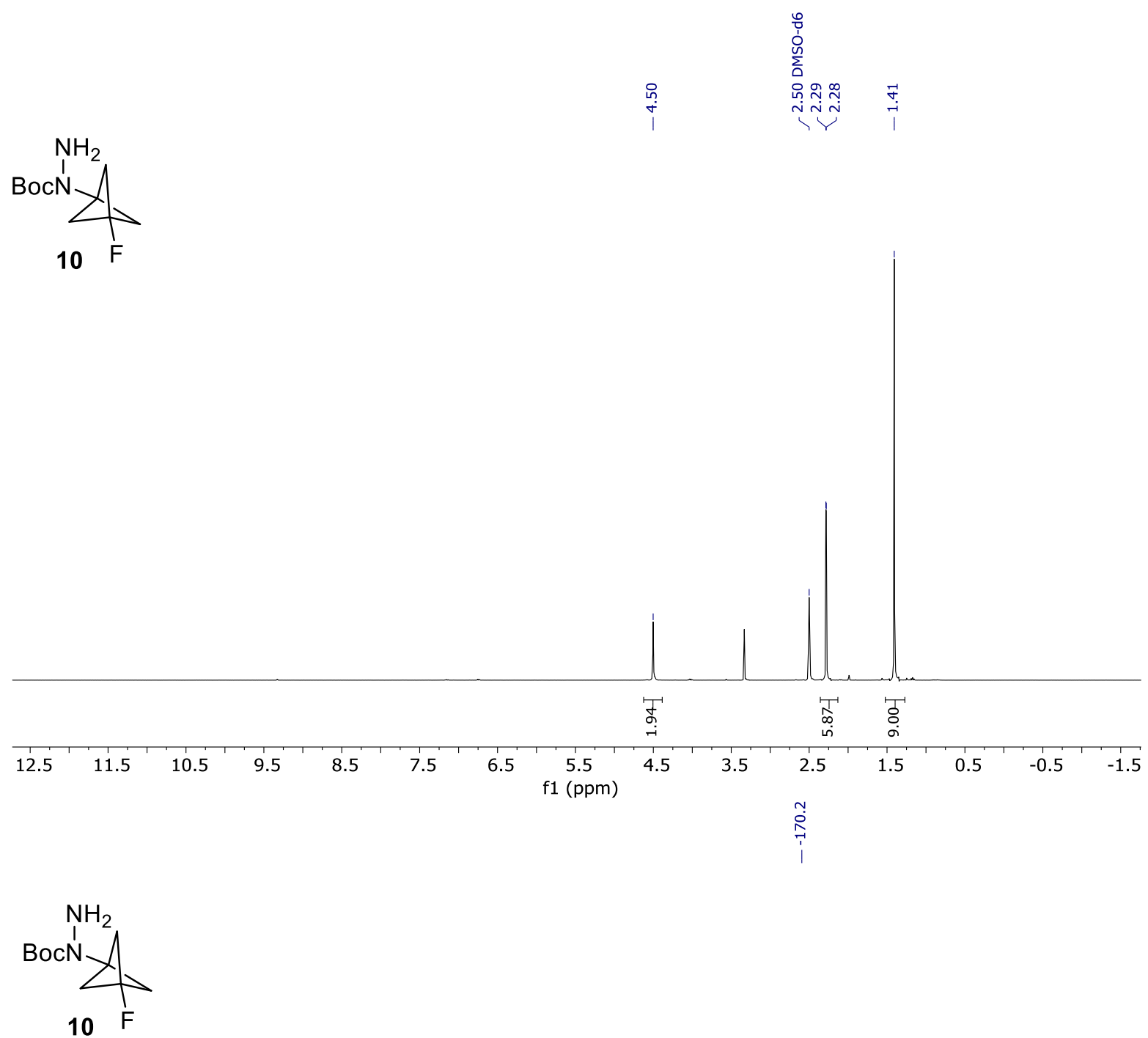

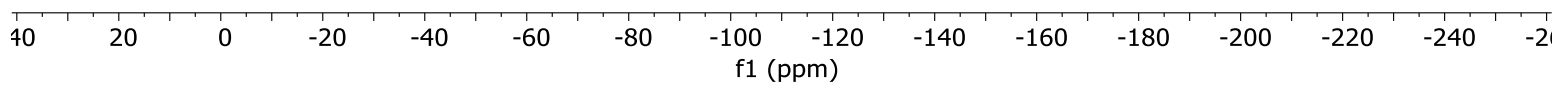



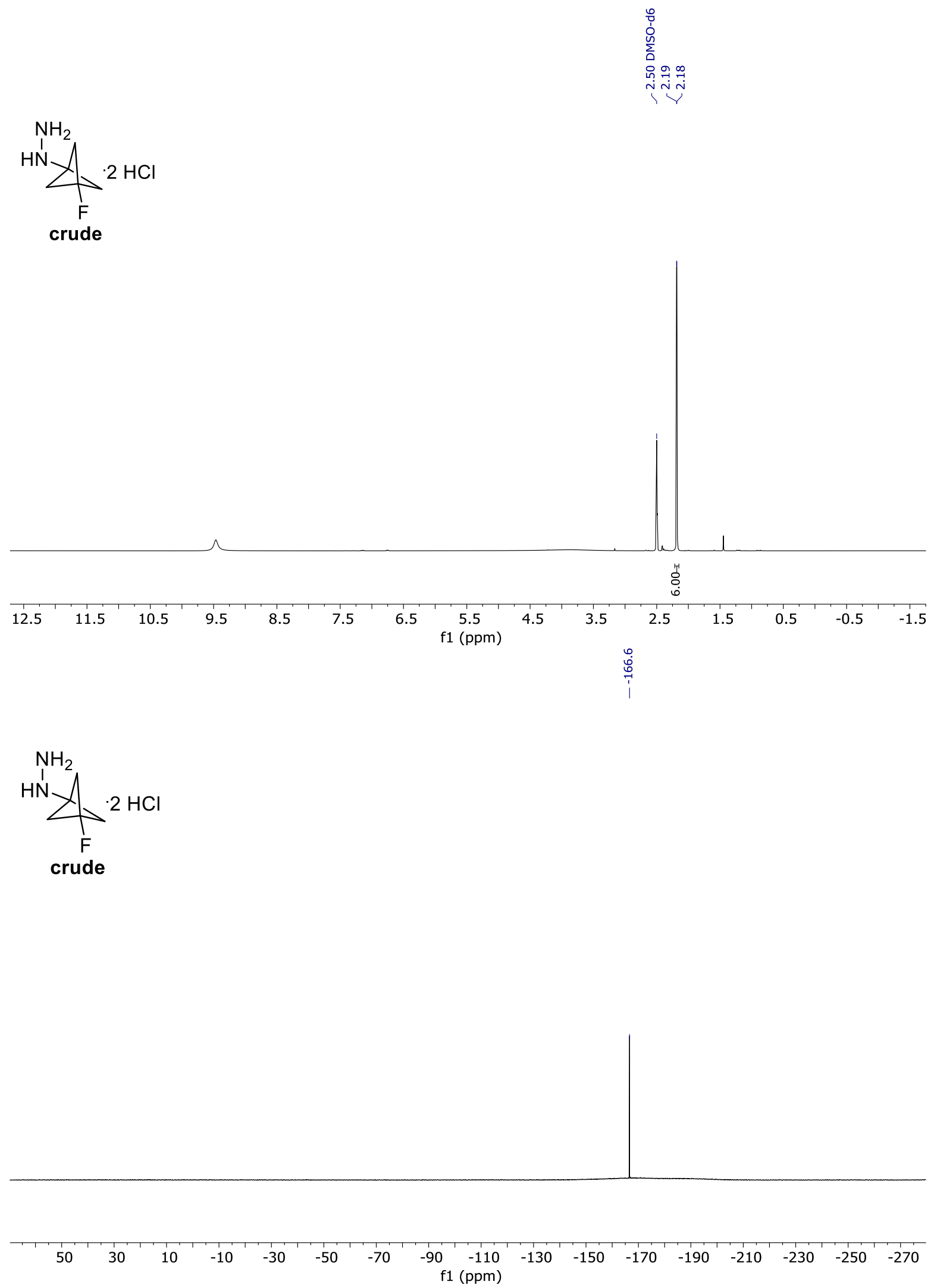

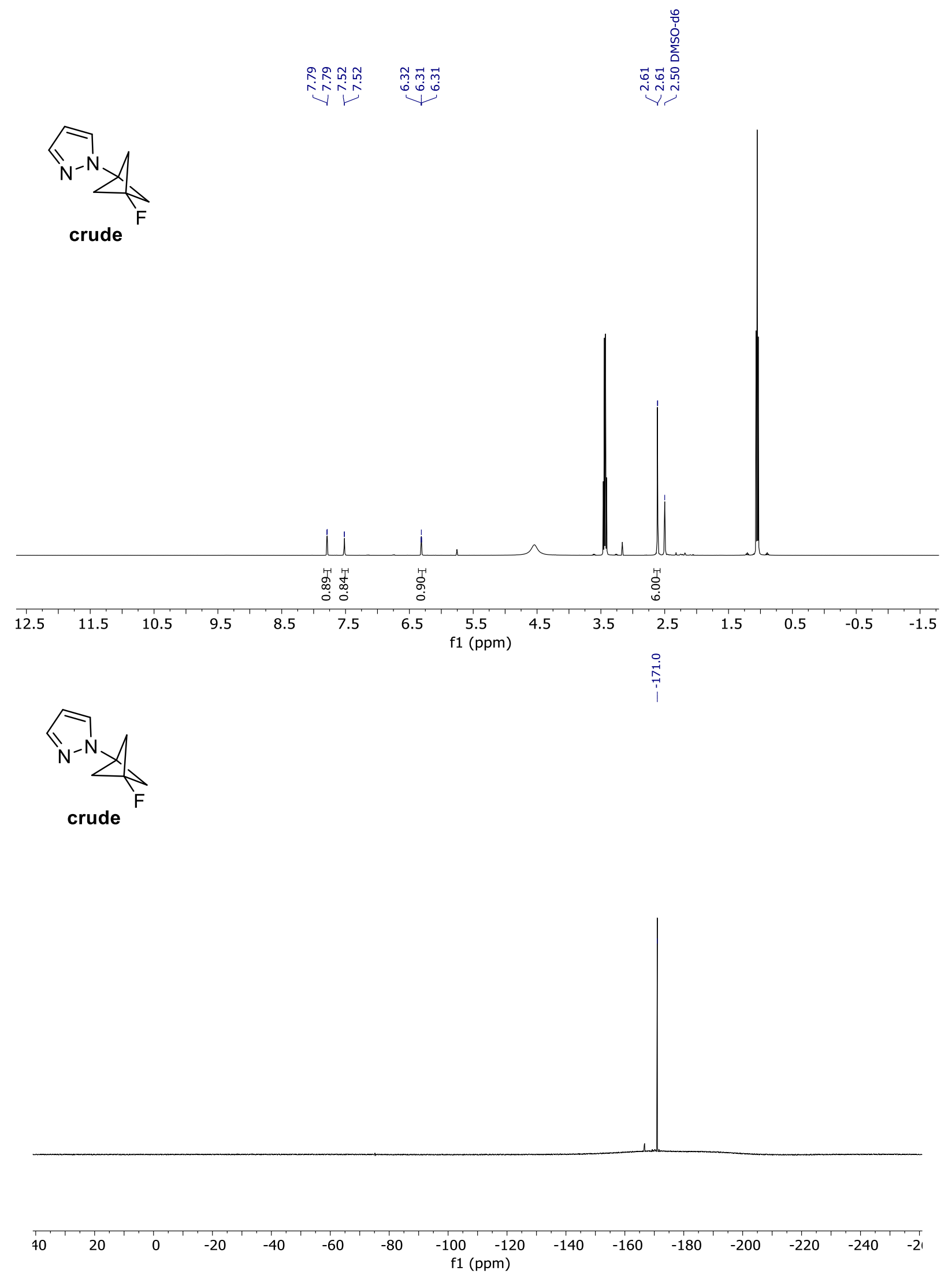

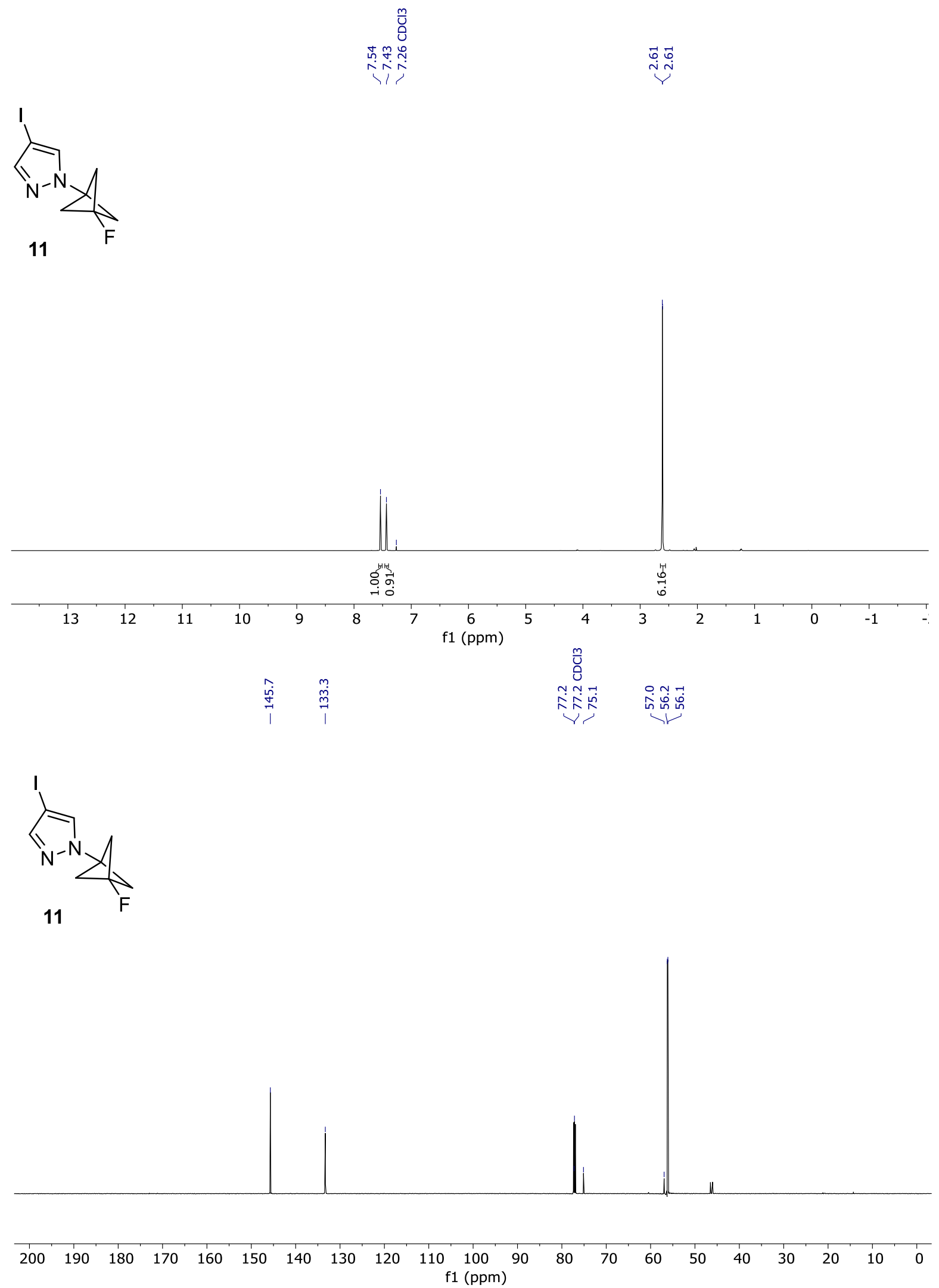

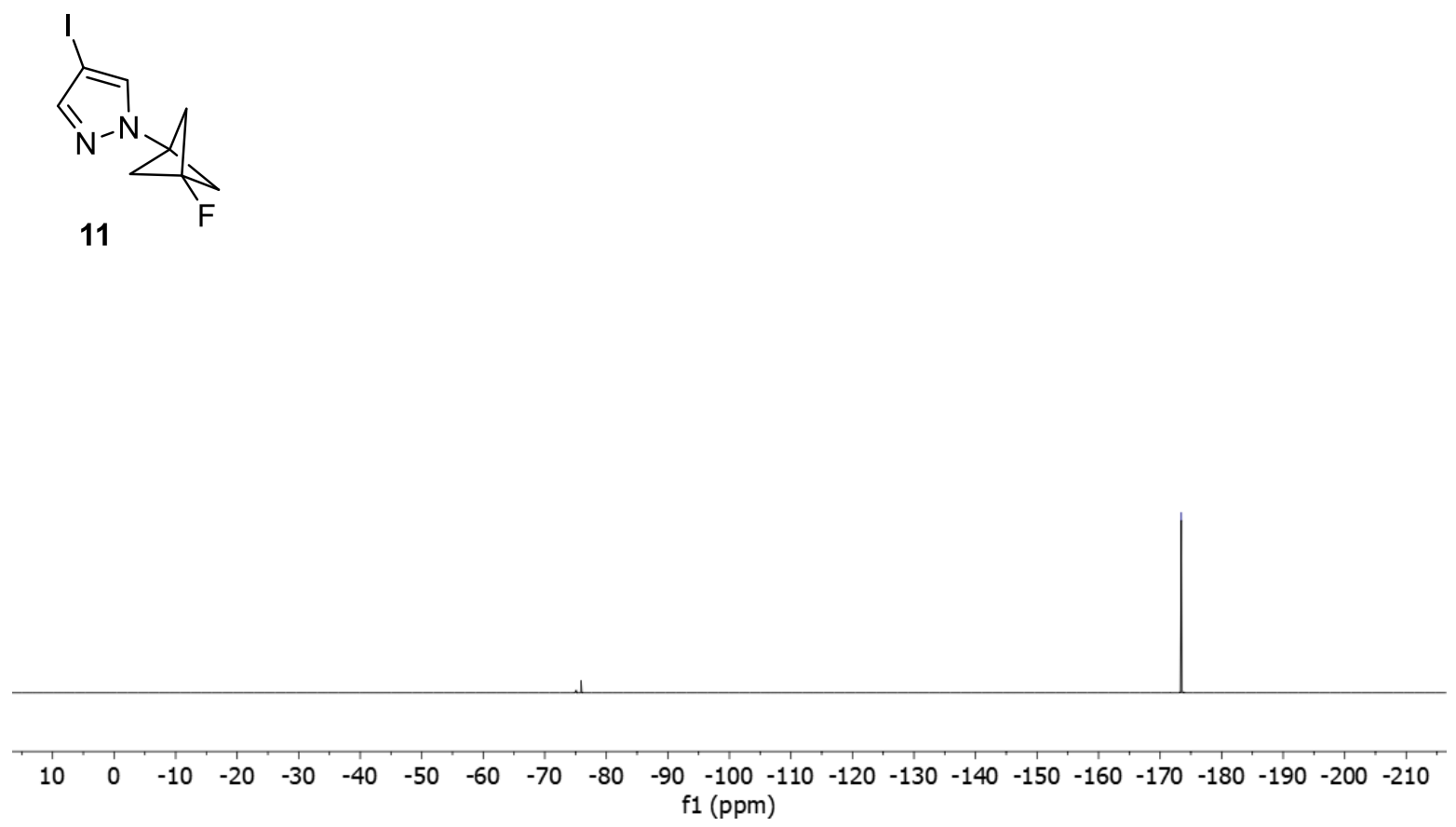

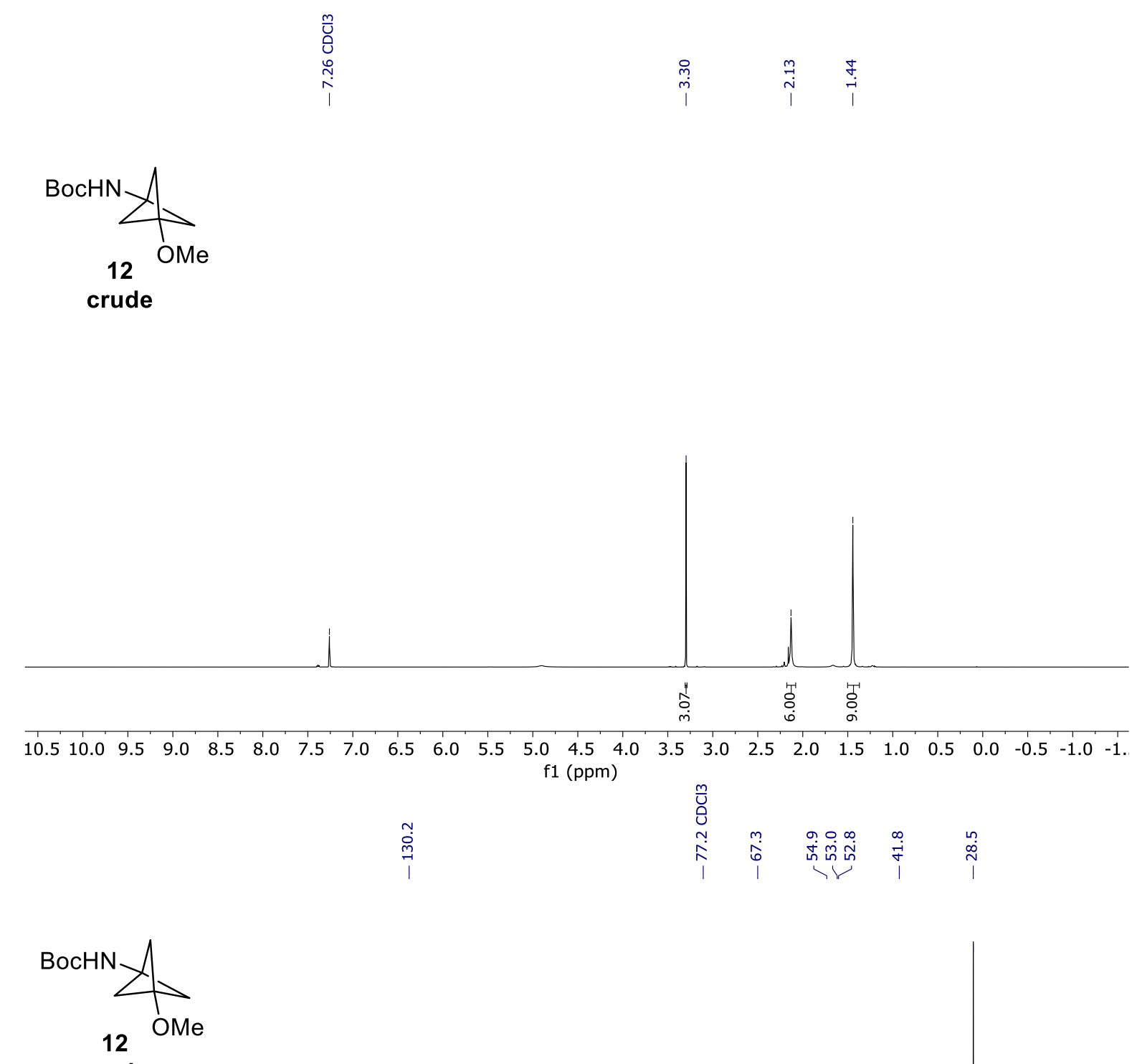

crude

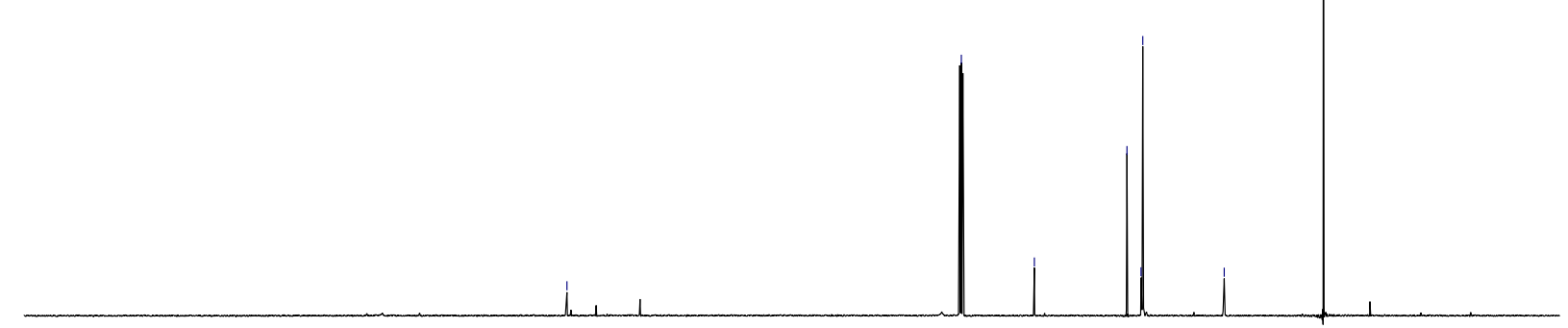

\begin{tabular}{lllllllllllllllllllll}
\hline 200 & 190 & 180 & 170 & 160 & 150 & 140 & 130 & 120 & 110 & 100 & 90 & 80 & 70 & 60 & 50 & 40 & 30 & 20 & 10 & 0
\end{tabular} f1 (ppm) 

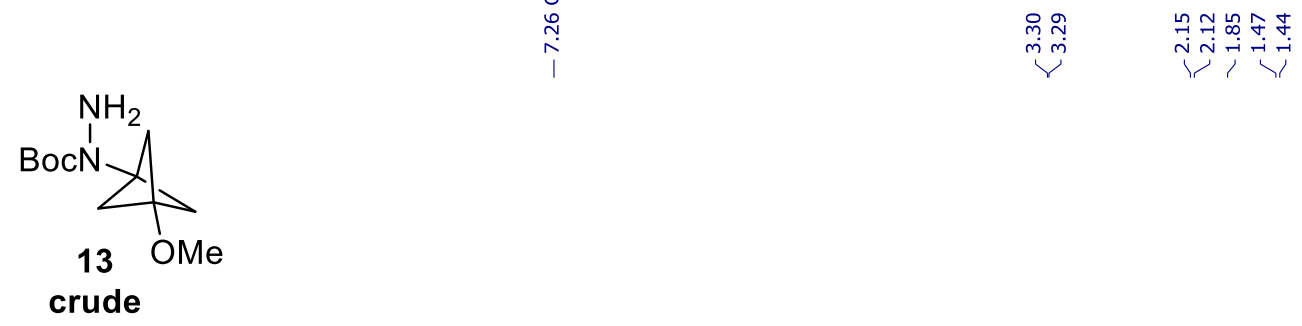

crude
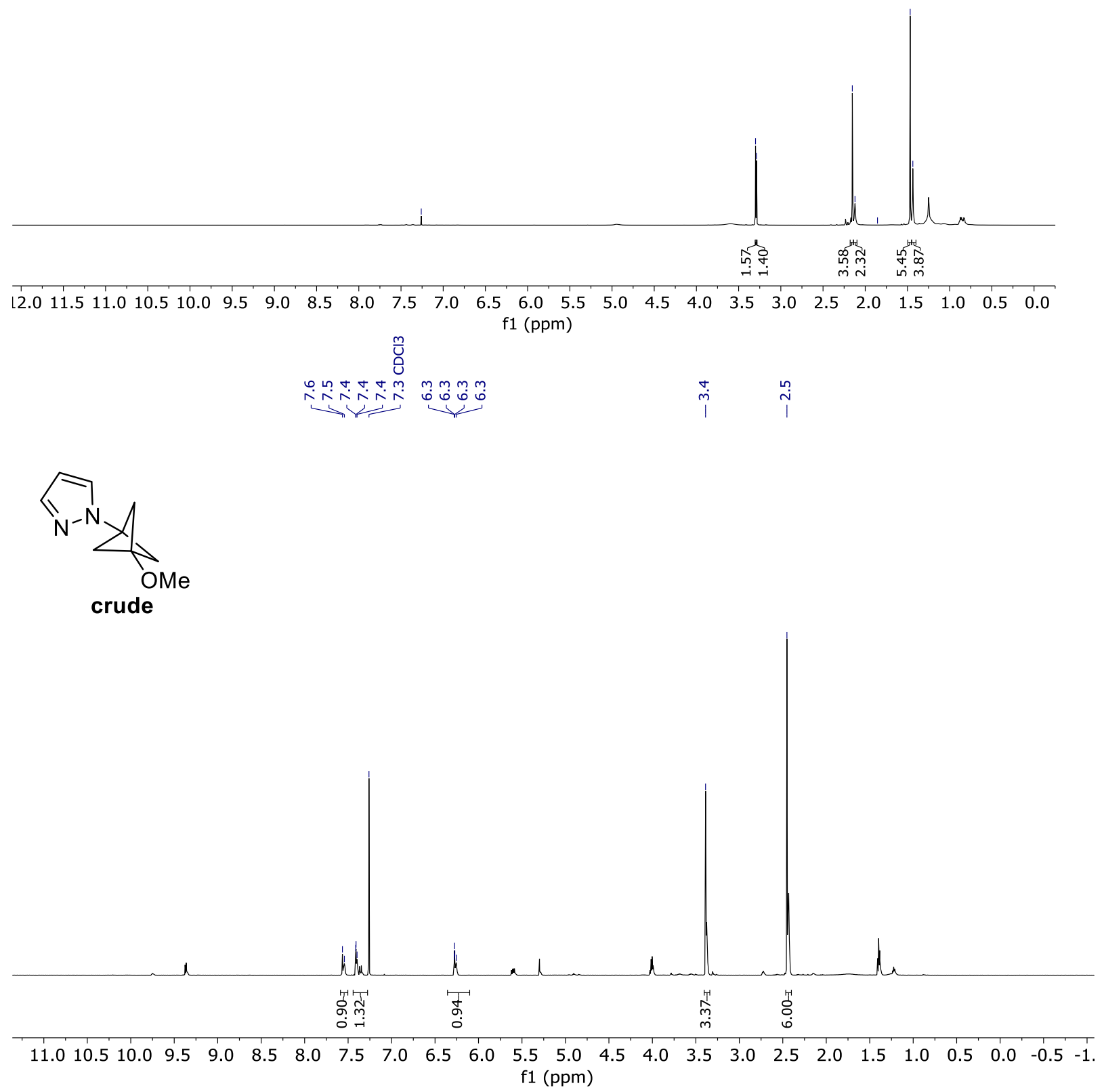

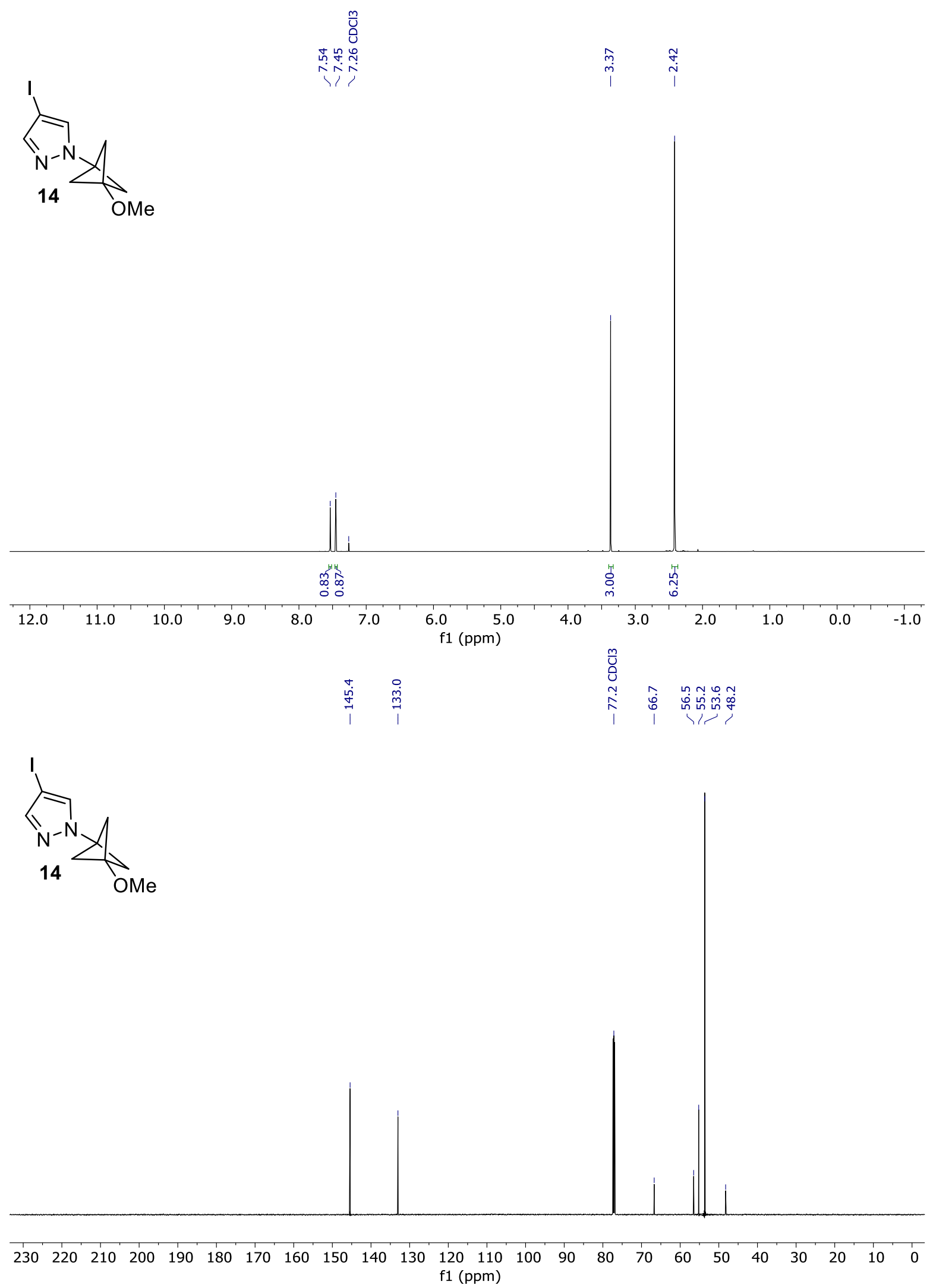

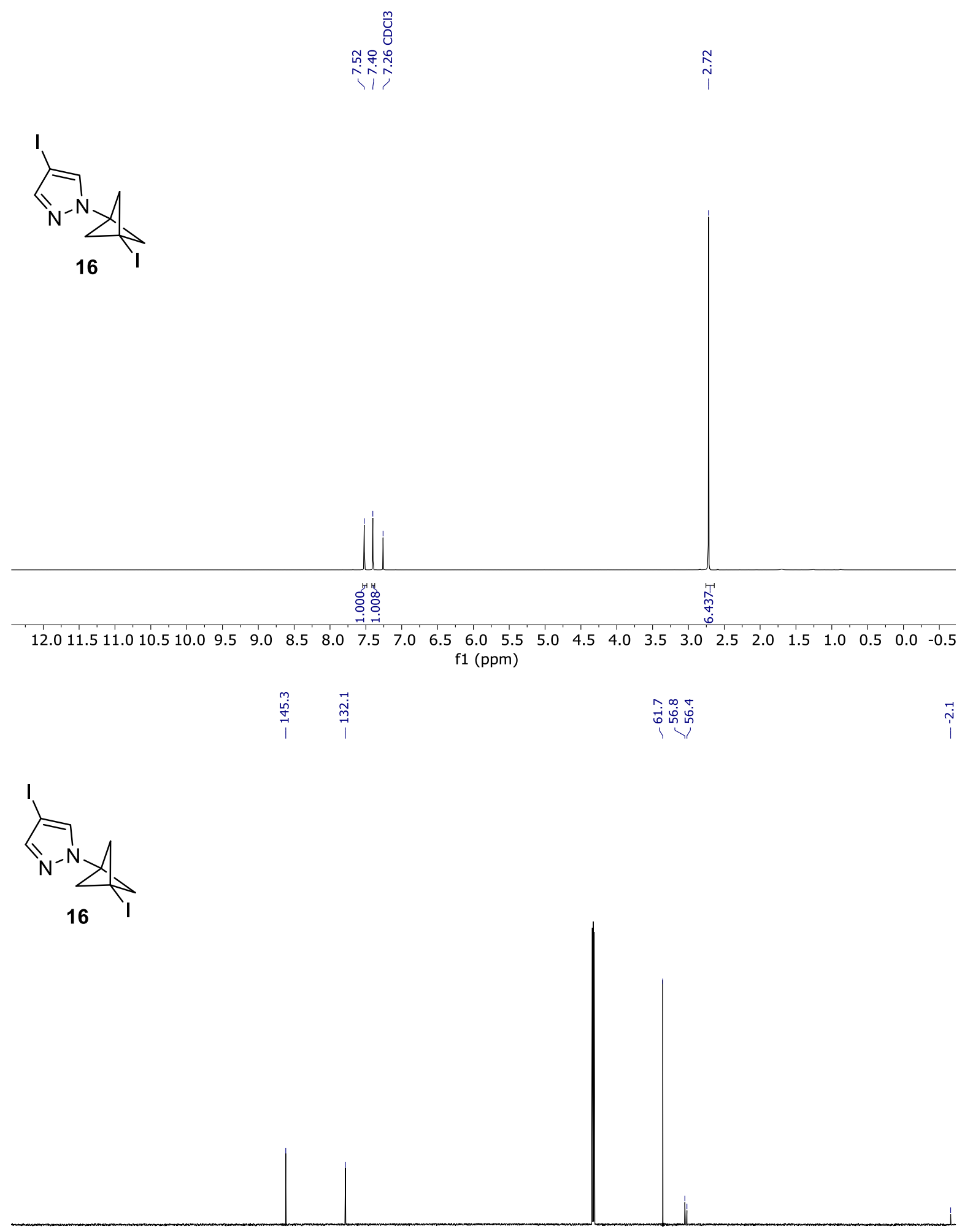

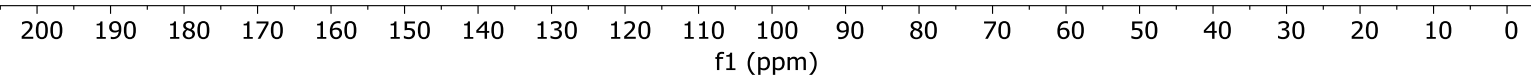



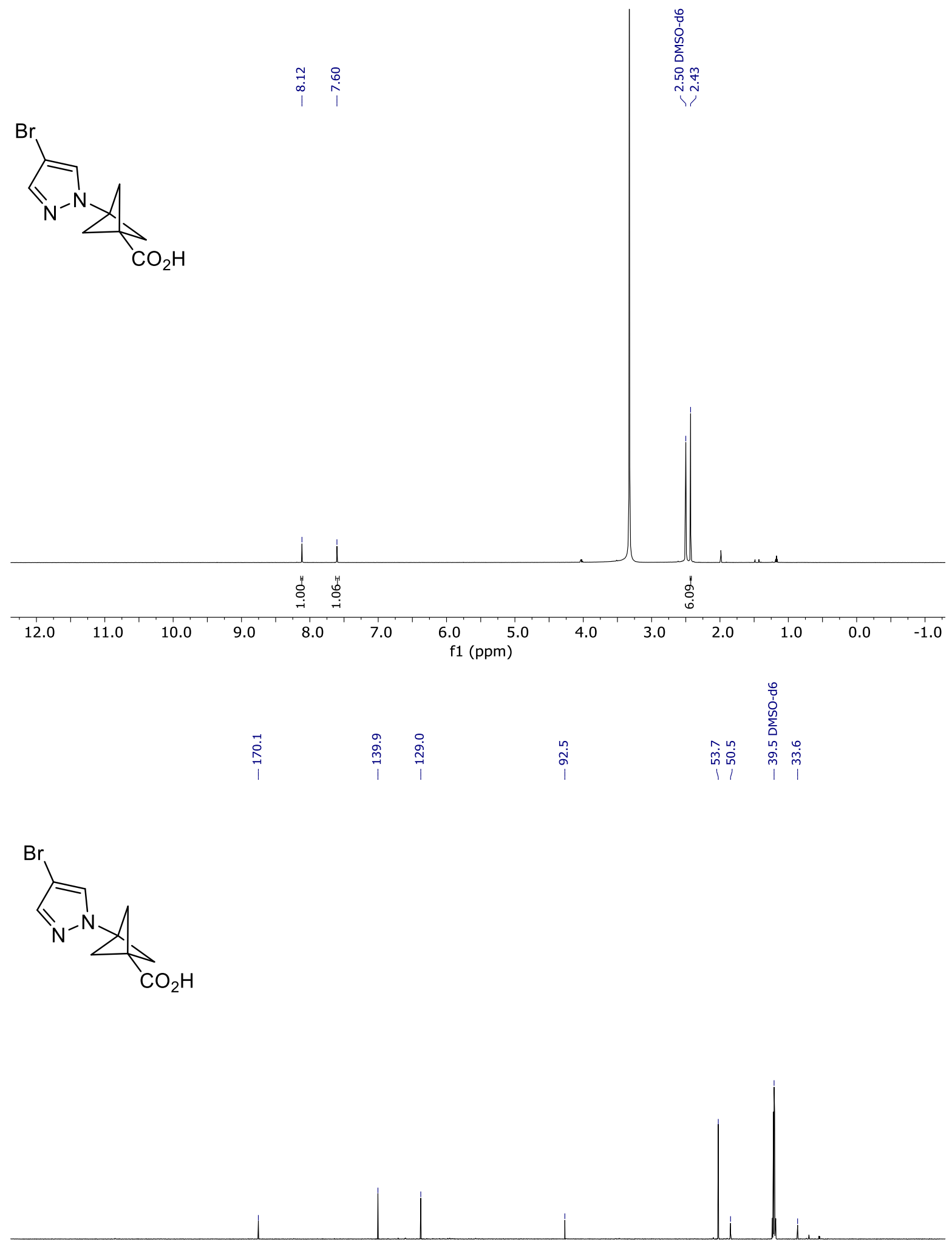

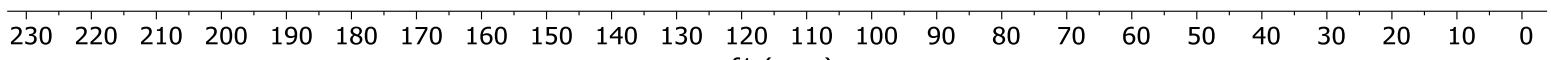
f1 (ppm) 

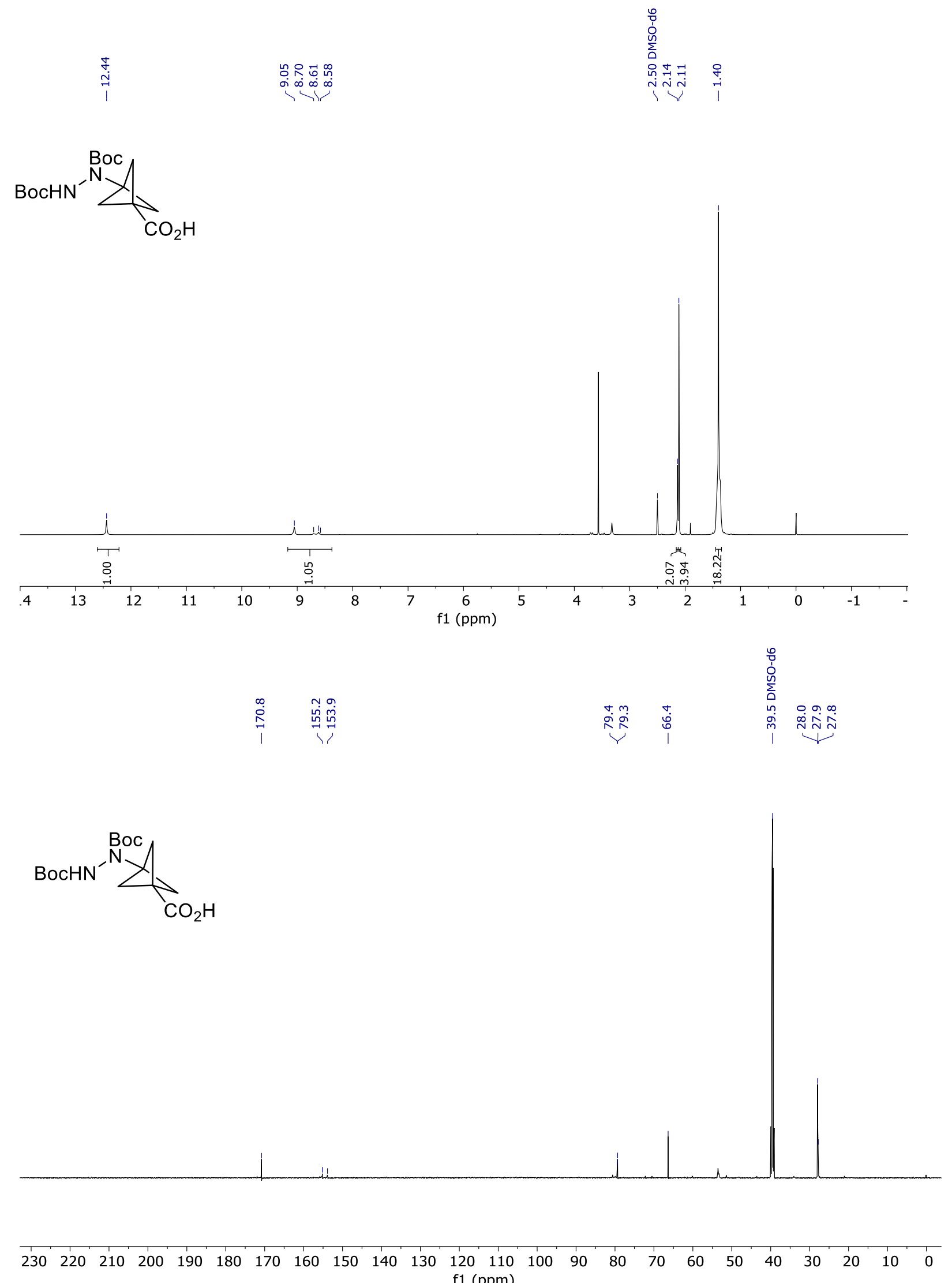

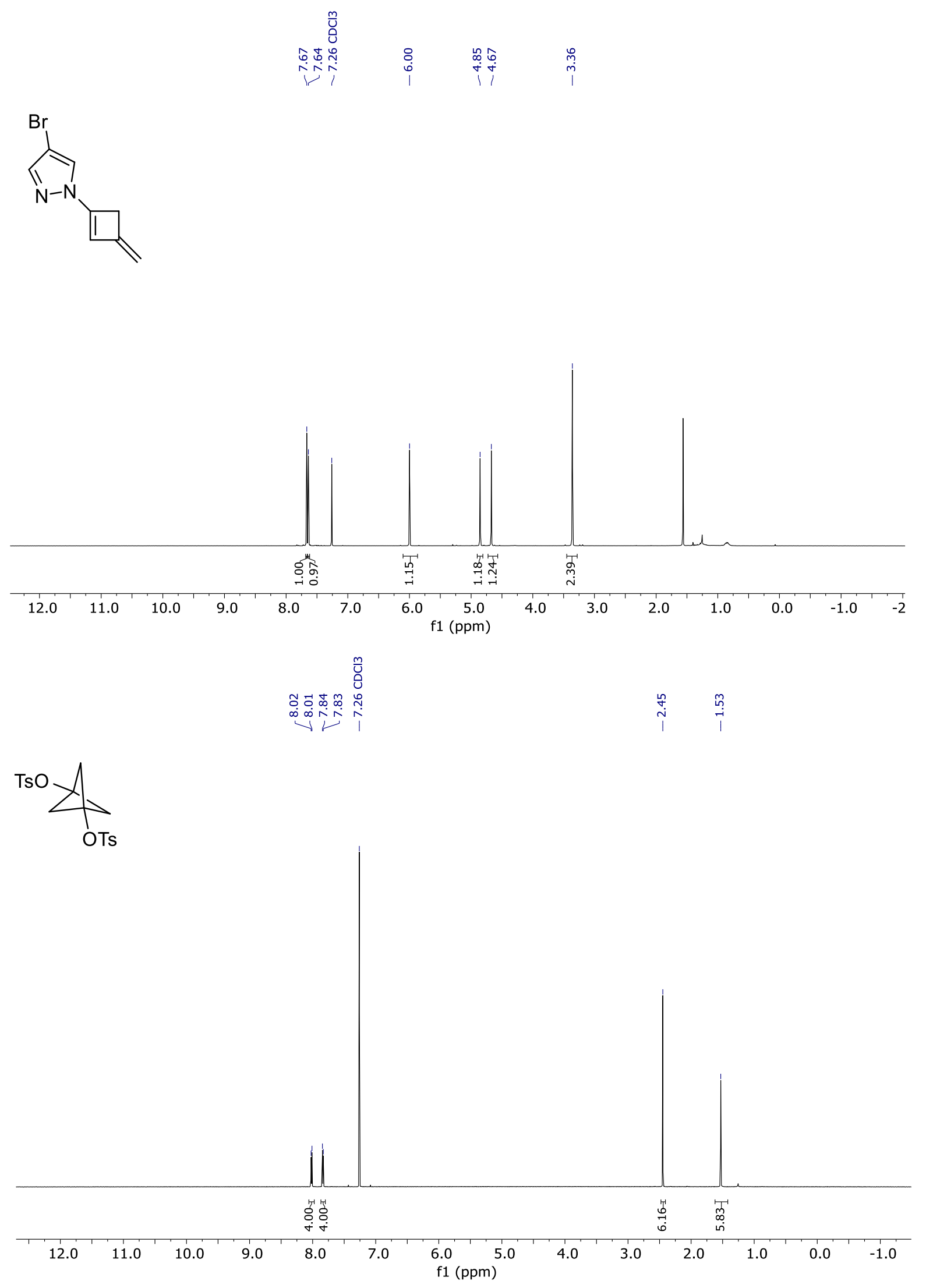


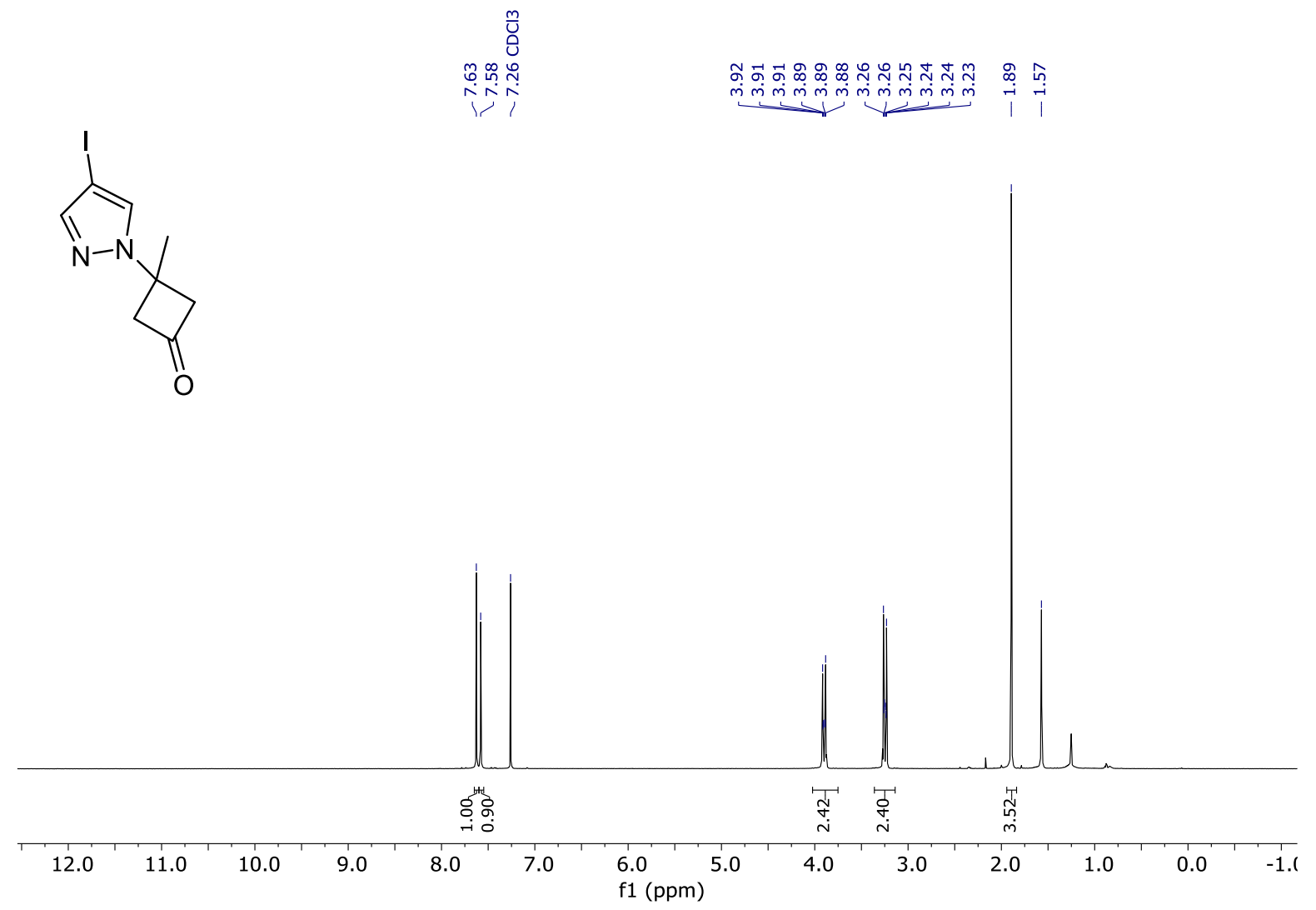




\section{References}

1. VanHeyst, M. D.; Qi, J.; Roecker, A. J.; Hughes, J. M. E.; Cheng, L.; Zhao. Z.; Yin, J. Continuous Flow-Enabled Synthesis of Bench-Stable Bicyclo[1.1.1]pentane Trifluoroborate Salts and Their Utilization in Metallaphotoredox Cross-Couplings. Org. Lett. 2020, 22, 1648-1654.

2. Goh, Y. L.; Adsool, V. A. Radical Fluorination Powered Expedient Synthesis of 3Fluorobicyclo[1.1.1]pentan-1-amine. Org. Biomol. Chem. 2015, 13, 11597-11601.

3. MestReNova Version 12.0.1-20560 @ 2018 Mestrelab Research S.L.

4. Le, C.; Wismer, M. K.; Shi, Z.-C.; Zhang, R.; Conway, D. V.; Li, G.; Vachal, P.; Davies, I. W.; MacMillan, D. W. C. A General Small-Scale Reactor To Enable Standardization and Acceleration of Photocatalytic Reactions. ACS Cent. Sci. 2017, 3, 647-653.

5. Yufan, L.; Zhang, X.; MacMillan, D. W. C. Decarboxylative $\mathrm{sp}^{3}$ C-N Coupling via Dual Copper and Photoredox Catalysis. Nature 2018, 559, 83-88.

6. Bunker, K. D.; Sach, N. W.; Huang, Q.; Richardson, P. F. Scalable Synthesis of 1Bicyclo[1.1.1]pentylamine via a Hydrohydrazination Reaction. Org. Lett. 2011, 13, 4746-4748.

7. (a) Lopchuk, J. M.; Fjelbye, K.; Kawamata, Y.; Malins, L. R.; Pan, C.-M.; Gianatassio, R.; Wang, J.; Prieto, L.; Bradow, J.; Brandt, T. A.; Collins, M. R.; Elleraas, J.; Ewanicki, J.; Farrell, W.; Fadeyi, O. O.; Gallego, G. M.; Mousseau, J. J.; Oliver, R.; Sach, N. W.; Smith, J. K.; Spangler, J. E.; Zhu, H.; Zhu, J.; Baran, P. S. Strain-Release Heteroatom Functionalization: Development, Scope, and Stereospecificity. J. Am. Chem. Soc. 2017, 139, 3209-3226. (b) Hughes, J. M. E.; Scarlata, D. A.; Chen, A. C.-Y.; Burch, J. D.; Gleason, J. L. Aminoalkylation of [1.1.1]Propellane Enables Direct Access to High Value 3-Alkylbicyclo[1.1.1]pentan-1-amines. Org. Lett. 2019, 21, 6800-6804.

8. Yatham, V. R.; Bellotti, P.; König, B. Decarboxylative hydrazination of unactivated carboxylic acids by cerium photocatalysis. Chem. Commun. 2019, 55, 3489-3492.

9. (a) Lang, S. B.; Cartwright, K. C.; Welter, R. S.; Locascio, T. M.; Tunge, J. A. Photocatalytic Aminodecarboxylation of Carboxylic Acids. Eur. J. Org. Chem. 2016, 3331-3334. (b) Hu, A.; Guo, J.-J.; Pan, H.; Zuo, Z. Selective Functionalization of Methane, Ethane, and Higher Alkanes by Cerium Photocatalysis. Science 2018, 361, 668-672.

10. Goh, Y. L.; Adsool, V. A. Radical Fluorination Powered Expedient Synthesis of 3Fluorobicyclo[1.1.1]pentan-1-amine. Org. Biomol. Chem. 2015, 13, 11597-11601.

11. (a) Adcock, J. L.; Gakh, A. A. Synthesis of Novel Cage Quaternary Salts via Nucleophilic Substitution of 1,3-Diiodobicyclo[1.1.1]pentane. Further Evidence for a Stable 3-lodo-1bicyclo[1.1.1]pentyl Cation. Tett. Lett. 1992, 33, 4875-4878. (b) Adcock, J. L.; Gakh, A. A. Nucleophilic Substitution in 1-Substituted 3-lodobicyclo[1.1.1]pentanes. A New Synthetic Route to Functionalized Bicyclo[1.1.1]pentane Derivatives. J. Org. Chem. 1992, 57, 6206-6210. (c) Wiberg, K. B.; McMurdie, N. Formation and Reactions of Bicyclo[1.1.1 ]pentyl-I Cations. J. Am. Chem. Soc. 1994, 116, 11990-11998. 
12. Wiberg, K. B.; McMurdie, N. Formation of [1.1.1]propellane by nucleophilic attack on 1,3diiodobicyclo[1.1.1]pentane. Unrearranged carbocation intermediates in the reaction of [1.1.1]propellane with electrophiles. J. Am. Chem. Soc. 1991, 113, 8995-8996.

13. http://chemlabs.princeton.edu/macmillan/wp-content/uploads/sites/6/Decarboxylative-C-Ncoupling-recent-progress-09-20182.pdf

14. Kanazawa, J.; Maeda, K.; Uchiyama, M. Radical multicomponent carboamination of [1.1.1]propellane. J. Am. Chem. Soc. 2017, 139, 17791-17794.

15. (a) Goh, Y. L.; Adsool, V. A. Radical Fluorination Powered Expedient Synthesis of 3Fluorobicyclo[1.1.1]pentan-1-amine. Org. Biomol. Chem. 2015, 13, 11597-11601. (b) Ventre, S.; Petronijevic, F. R.; MacMillan, D. W. C. Decarboxylative Fluorination of Aliphatic Carboxylic Acids via Photoredox Catalysis. J. Am. Chem. Soc. 2015, 137, 5654-5657. (c) Patrick, T. B.; Johri, K. K.; White, D. H. Fluorodecarboxylation with Xenon Difluoride. J. Org. Chem. 1983, 48, 4158-4159.

16. (a) Xia, J.-B.; Ma, Y.; Chen, C. Vanadium-Catalyzed $\mathrm{C}\left(\mathrm{sp}^{3}\right)-\mathrm{H}$ Fluorination Reactions. Org. Chem. Front. 2014, 1, 468-472; (b) Amaoka, Y.; Nagatomo, M.; Inoue, M. Metal-Free Fluorination of $\mathrm{C}\left(\mathrm{sp}^{3}\right)-\mathrm{H}$ Bonds Using a Catalytic N-Oxyl Radical. Org. Lett. 2013, 15, 2160-2163; (c) Pitts, C. R.; Ling, B.; Woltornist, R.; Liu, R.; Lectka, T. Triethylborane-Initiated Radical Chain Fluorination: A Synthetic Method Derived from Mechanistic Insight. J. Org. Chem. 2014, 79, 8895-8899.

17. Conditions inspired by: (a) Harris, M. R.; Li, Q.; Lian, Y.; Xiao, J.; Londregan, A. T. Construction of 1-Heteroaryl-3-azabicyclo[3.1.0]hexanes by $\mathrm{sp}^{3}-\mathrm{sp}^{2}$ Suzuki-Miyaura and Chan-Lam Coupling Reactions of Tertiary Trifluoroborates. Org. Lett. 2017, 19, 2450-2453. (b) Bénard, S.; Neuville, L.; Zhu, J. Copper-Mediated N-Cyclopropylation of Azoles, Amides, and Sulfonamides by Cyclopropylboronic Acid. J. Org. Chem. 2008, 73, 6441-6444. 